\author{
Banco de México \\ Documentos de Investigación
}

Banco de México

Working Papers

$\mathrm{N}^{\circ} 2015-14$

\title{
Uso de agregados monetarios como indicadores de la evolución futura de los precios al consumidor: Crecimiento monetario y meta de inflación
}

\section{Manuel Ramos-Francia}

Banco de México

\author{
Antonio E. Noriega
}

Banco de México

\section{Cid Alonso Rodríguez-Pérez}

Banco de México

Julio 2015

La serie de Documentos de Investigación del Banco de México divulga resultados preliminares de trabajos de investigación económica realizados en el Banco de México con la finalidad de propiciar el intercambio y debate de ideas. El contenido de los Documentos de Investigación, así como las conclusiones que de ellos se derivan, son responsabilidad exclusiva de los autores y no reflejan necesariamente las del Banco de México.

The Working Papers series of Banco de México disseminates preliminary results of economic research conducted at Banco de México in order to promote the exchange and debate of ideas. The views and conclusions presented in the Working Papers are exclusively the responsibility of the authors and do not necessarily reflect those of Banco de México. 
Documento de Investigación

2015-14

Working Paper

2015-14

\title{
Uso de agregados monetarios como indicadores de la evolución futura de los precios al consumidor: Crecimiento monetario y meta de inflación*
}

\author{
Manuel Ramos-Francia ${ }^{\dagger} \quad$ Antonio E. Noriega \\ Banco de México Banco de México
}

\section{Cid Alonso Rodríguez-Pérez ${ }^{\S}$ \\ Banco de México}

Resumen: En este trabajo se construyen indicadores de presiones inflacionarias a partir de la relación de largo plazo que existe entre los agregados monetarios y los precios, una vez que ésta se ajusta adecuadamente para tomar en cuenta la escala de transacciones, así como el costo de oportunidad de mantener dinero. Para ello, se realiza un extenso análisis econométrico de la demanda de dinero de largo plazo para México utilizando el agregado monetario M1. A partir de ésta, se calculan dos indicadores, la brecha del dinero y el indicador m*. Dicha brecha consiste en medir la desviación de M1 real de su relación con sus determinantes de largo plazo. El indicador $\mathrm{m}^{*}$ se basa en la estimación del índice de precios que es congruente con la cantidad de M1 en la economía una vez que ésta se ajusta por la tendencia de largo plazo de sus determinantes tomando en cuenta sus coeficientes de largo plazo. Nuestros resultados indican que la política monetaria ha sido congruente con el objetivo de inflación del Banco de México.

Palabras Clave: Demanda por dinero, inflación, brecha del dinero, modelos autoregresivos de rezagos distribuidos, cointegración, general a específico, estabilidad/cambio estructural.

Abstract: We construct inflation pressure indicators based on the long-run relationship that exists between monetary aggregates and prices, once it is adequately adjusted to account for the scale of transactions, as well as the opportunity cost of holding money. To that end, an extensive long-run econometric analysis of money demand is carried out for Mexico using the monetary aggregate M1. Based on it, two indicators are calculated, the money gap and the $\mathrm{m}^{*}$ indicator. Such gap measures deviations of real M1 from its relationship with its long-run determinants. The $\mathrm{m}^{*}$ indicator is based on the estimation of the price index which is congruent with the quantity of M1 in the economy once it is adjusted for the long-run tendency of its determinants considering its long-run coefficients. Our results indicate that monetary policy has been congruent with the inflation target of Banco de México.

Keywords: Money demand, inflation, money gap, autoregressive distributed lag model, cointegration, general-to-specific, stability, structural change.

JEL Classification: C22, C32, E31, E41, E51

\footnotetext{
*Un agradecimiento a Carlos Capistrán quien fue un coautor en las primeras etapas de este documento.

† Banco de México. Correo electrónico: mrfran@banxico.org.mx.

¥Dirección General de Emisión. Correo electrónico: anoriega@banxico.org.mx.

$\S$ Dirección General de Investigación Económica. Correo electrónico: cidrodriguez@banxico.org.mx.
} 


\section{Introducción}

Una de las frases más conocidas en la literatura económica es de Milton Friedman, quien en 1963 argumentaba que: "La inflación es siempre y en todo lugar un fenómeno monetario". A pesar de que la teoría y la evidencia empírica detrás de esa frase han influido de manera importante en el pensamiento económico, Woodford (2008) argumentaría 45 años después que: "En estos días los agregados monetarios juegan un papel menor en las deliberaciones de política monetaria en la mayoría de los bancos centrales". En efecto, en la actualidad la mayoría de los modelos utilizados en un gran número de bancos centrales para análisis de política monetaria no utilizan a los agregados monetarios. Esto se debe fundamentalmente a que dichos modelos se concentran en las desviaciones de la inflación respecto a un estado estacionario dado exógenamente, y a que no modelan explícitamente la tendencia de la inflación. Por ejemplo, tanto los modelos conocidos como "modelos de brecha" (gap models) como los modelos "dinámicos estocásticos de equilibrio general" ( DSGE models) utilizados en bancos centrales, típicamente suponen que la tendencia de la inflación es constante en el estado estacionario o, en el otro extremo, que sigue una caminata aleatoria. Estos modelos intentan explicar las desviaciones de la inflación respecto a dicha tendencia. ${ }^{1}$ Muchos de estos modelos utilizan funciones de pérdida como objetivo del banco central, donde éste se preocupa por minimizar la inflación alrededor de una meta. ${ }^{2}$ En este contexto, los agregados monetarios pierden importancia porque la cantidad de dinero en la economía determina el nivel de precios en el largo plazo, pero no necesariamente influye en las desviaciones respecto a dicho nivel. ${ }^{3}$

Sin embargo, Reynard (2007) argumenta que la principal preocupación de los bancos centrales, y de la población en general, no necesariamente son las relativamente pequeñas desviaciones alrededor de un estado estacionario dado, sino el moverse de un estado de inflación baja a uno de inflación alta o de deflación. En este sentido, siguiendo el argumento

\footnotetext{
${ }^{1}$ Por ejemplo, en un documento de investigación reciente del Banco de Canadá, Cayen, Gosselin y Kozicki (2009, pp.1) argumentan que: "Es muy común expresar los modelos DSGE en un formato que sólo captura fluctuaciones de ciclo de negocios. Versiones log-linearizadas de los modelos describen la evolución de la desviación de las variables macroeconómicas de sus "estados estacionarios". Frecuentemente en estas versiones, las log-linearizaciones se hacen alrededor de los estados estacionarios de las variables en niveles. En caso de ser estimadas, a los datos correspondientes se les quita la tendencia en un primer paso independiente. La evolución de la tendencia usualmente no se toma en cuenta en las simulaciones, suponiendo implícitamente que son conocidas por los agentes o, por lo menos, independientes de la evolución del ciclo.”. 2 Adicionalmente, en muchos de estos modelos el banco central también se preocupa por minimizar las fluctuaciones del producto alrededor de su tendencia de largo plazo. Ver Galí (2008).

${ }^{3}$ Un caso similar ocurre con la producción agregada. Es bien sabido que lo que determina el nivel de la producción agregada de un país son factores como la productividad, el empleo y el capital. Sin embargo, en los modelos utilizados en bancos centrales usualmente sólo se modela la brecha del producto y no el nivel de la producción como tal. En este sentido, los factores determinantes del crecimiento no son tomados en cuenta en el análisis, o tienen un rol menor. En el caso de la producción agregada, un banco central que sólo tenga como objetivo la estabilidad de precios quizá sólo necesite analizar la brecha del producto y no los determinantes de su nivel, por lo que en este caso el modelado podría estar justificado. Sin embargo, debe resaltarse que modelos de este tipo sólo pueden utilizarse para pronosticar dicha brecha y no la tendencia de la producción en el largo plazo.
} 
de Reynard, la parte de la inflación que se analiza en los modelos actuales no necesariamente es la más importante desde el punto de vista del bienestar de la población. Tampoco lo es desde un punto de vista de tratar de explicar un componente importante de la inflación, ya que la tendencia que se elimina puede llegar a explicar la mayor parte de los movimientos de aquella. Como ejemplo, la Gráfica 1 muestra la inflación anual del Índice Nacional de Precios al Consumidor (INPC) del primer trimestre de 1987 al primero de 2014, así como su tendencia (estimada con el filtro Hodrick-Prescott, ampliamente utilizado para este propósito). ${ }^{4}$ En este ejemplo, la parte cíclica, considerada usualmente en los modelos de bancos centrales, equivale a la diferencia entre las dos. Para efectos de pronóstico y, por lo tanto, para las decisiones de política monetaria, es claro que la tendencia es la parte más importante de la evolución de la inflación. Más aún, una regresión de la inflación contra una constante y la tendencia explica alrededor del $81 \%$ de la variación total de la inflación para $1986 \mathrm{~T} 1-2014 \mathrm{~T} 1 .^{5}$ Es decir, la tendencia, que es la parte que usualmente se desecha en los modelos actualmente utilizados por la mayoría de los bancos centrales, explica más de tres cuartas partes de la varianza total de la inflación anual en el caso de México.

La importancia de la tendencia de largo plazo de la inflación explica por qué algunos bancos centrales no han abandonado del todo el seguimiento de los agregados monetarios; incluso, a pesar de que dicho seguimiento deba hacerse independientemente de los modelos utilizados para analizar a la inflación y a otras variables macroeconómicas y financieras. El caso más importante lo constituye el Banco Central Europeo (BCE). El BCE, para promover la estabilidad de precios, ha basado su política monetaria en dos pilares: el análisis económico y el análisis monetario. El BCE (2011, pp. 10) menciona que "[...] es un hecho indiscutible que periodos prolongados de alta inflación están asociados a un crecimiento monetario alto, y que la inflación es ultimadamente un fenómeno monetario. Por lo tanto, la segunda perspectiva, referida como 'análisis monetario', se basa en la relación entre crecimiento monetario e inflación a lo largo de horizontes de mediano a largo plazo, y explota el hecho de que las tendencias monetarias guían a las tendencias inflacionarias. El análisis monetario sirve, en particular, como un medio de doble verificación, a partir de una perspectiva de mediano a largo plazo, en relación a las indicaciones de corto-mediano plazo para la política monetaria derivadas del análisis económico". ${ }^{6}$

\footnotetext{
${ }^{4}$ El filtro Hodrick-Prescott descompone una serie observada en dos componentes, uno de tendencia y otro cíclico. El ajuste de la sensibilidad de la tendencia al ciclo es obtenido modificando un multiplicador $\lambda$. Cuando $\lambda$ es cero, la tendencia resultante es igual a la serie original, mientras que cuando $\lambda$ es infinito el resultado es una línea recta. Para la aplicación del filtro, siguiendo las recomendaciones de Hodrick y Prescott para datos trimestrales, se utilizó un parámetro de suavizamiento $\lambda=1600$ (bajo el supuesto de que cualquier perturbación que tiene efectos durante 8 o más años tiene carácter permanente). Ver Hodrick y Prescott (1997).

${ }^{5}$ Por supuesto, en los últimos años, la importancia relativa de la tendencia y el componente cíclico ha cambiado. Ver Chiquiar, Noriega y Ramos-Francia (2010).

${ }^{6} \mathrm{El}$ BCE mantiene que el análisis macroeconómico convencional no es lo suficientemente avanzado para combinar el análisis de fenómenos económicos reales con tendencias monetarias dentro de un mismo esquema. Dadas estas consideraciones, para mantener el crecimiento de los agregados monetarios congruente con el
} 


\section{Gráfica 1. Inflación anual del INPC y su tendencia de largo plazo ${ }^{1 /}$}

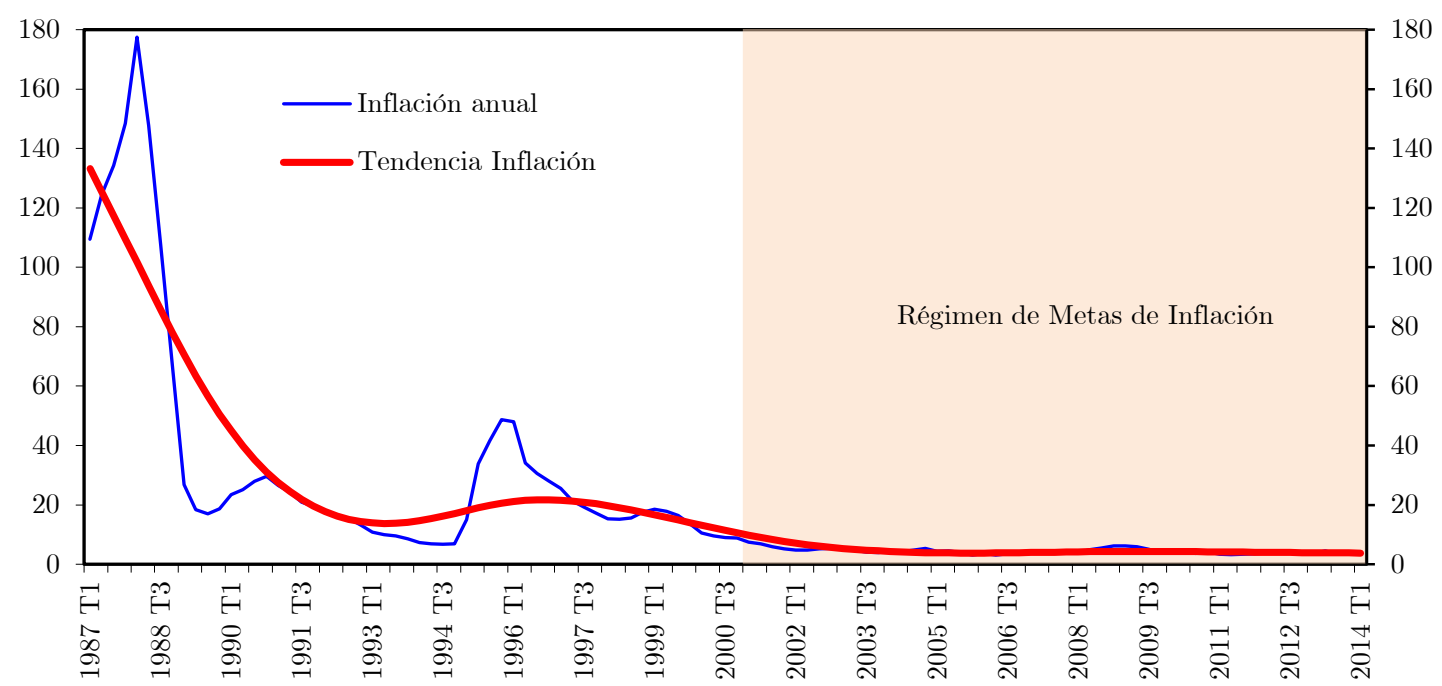

1/ Se utiliza el filtro Hodrick-Prescott con un parámetro de suavizamiento de 1600 para estimar la tendencia.

Precisamente por la importancia que tiene la tendencia de la inflación, en este artículo se examina la relación empírica entre los agregados monetarios y los precios al consumidor en México. En particular, se investiga si la relación de largo plazo entre los agregados monetarios y los precios, ajustada adecuadamente para tomar en cuenta una variable de escala, así como el costo de oportunidad de mantener dinero, se puede utilizar para construir indicadores que sirvan de guía cuantitativa respecto a la evolución futura de los precios y, por lo tanto, de las presiones inflacionarias. Adicionalmente, los resultados obtenidos son utilizados para presentar una valoración empírica sobre la congruencia entre la política monetaria observada, y el objetivo de inflación del Banco de México. Estos resultados se obtienen a partir de la estimación de una función de demanda por dinero.

En un artículo reciente, Noriega et al. (2011, NRR de aquí en adelante) estiman una función de demanda por dinero para el periodo 1986-2010, que reportan como estable y congruente con la teoría económica. Sin embargo, un análisis más completo (que se presenta en la sección 2.3.1 del presente artículo) sugiere que dicha estabilidad debe de ser analizada más ampliamente. NRR tenían como objetivo presentar estimaciones econométricas de la demanda de dinero pero, sobre todo, ejemplificar su uso en ejercicios diversos (estabilidad de los equilibrios inflacionarios duales, nivel de inflación que maximiza el señoreaje, y medidas de exceso de dinero). El objetivo de NRR no era presentar un análisis amplio sobre la estabilidad de la demanda de dinero, ni valorar empíricamente la congruencia de la política monetaria del Banco de México, que sí son, ambos, objetivos del presente trabajo. Adicionalmente, el supuesto de que las variables son integradas de orden 1 a lo largo de todo el periodo de estudio (1986-2010), cuando

objetivo de estabilidad de precios, el BCE decidió anunciar valores anuales de referencia para la tasa de crecimiento de M3. Ver "The Monetary Policy of the ECB", 2a edición, publicada en 2004, disponible en: www.ecb.europa.eu/pub/pdf/other/monetarypolicy2004en.pdf 
existe evidencia de un cambio en la tendencia estocástica de la inflación alrededor de 2001 (véase Chiquiar et al. (2010) y Noriega et al. (2013)), puede provocar cierta fragilidad respecto a los resultados de cointegración obtenidos por NRR. En efecto, de acuerdo a pruebas que presentaremos más adelante, encontramos evidencia de inestabilidad de los parámetros ocurrida precisamente alrededor de 2001. Debido a todo lo anterior, en este artículo revisamos y actualizamos los resultados de NRR, relacionados con la estimación de una demanda por dinero, introduciendo dos cambios principales. El primero se refiere al uso de la muestra 2001-2014, con el objetivo de analizar el desempeño de la política monetaria durante el periodo de metas de inflación. El segundo cambio tiene que ver con la metodología econométrica utilizada. Para este estudio, se decidió utilizar la prueba sobre la existencia de una relación de largo plazo, presentada por Pesaran et al. (2001), que permite diferentes órdenes de integración entre las variables, por parecernos una metodología más flexible. Antes de abordar estos cambios en la sección 3, enseguida presentamos evidencia empírica sobre varios aspectos de la demanda por dinero en México.

\section{Consideraciones sobre la demanda por dinero}

Para construir indicadores de la evolución futura de los precios utilizando agregados monetarios es necesario primero estimar una demanda de dinero de largo plazo que sea estable y que sea, sobra decirlo, congruente con la teoría económica. ${ }^{7}$ Las demandas estimadas usualmente son las de saldos monetarios reales, es decir, suponen homogeneidad de grado uno en precios. Por ello, en esta sección primero se evalúa si este supuesto puede hacerse para los datos mexicanos a través de un análisis de la relación entre los agregados monetarios y los precios, para posteriormente estimar la demanda real de dinero de largo plazo. El análisis que se presenta a continuación se hace utilizando el agregado monetario M1. ${ }^{8}$ La muestra que se utiliza va del primer trimestre de 1986 al primero de $2014 .{ }^{9}$

\footnotetext{
${ }^{7}$ En NRR se describe cómo obtener la demanda de dinero a partir de un modelo de optimización con un agente representativo. Ver, entre otros, Pétursson (2000), Feenstra (1986) y Lucas (1988).

${ }^{8} \mathrm{El}$ agregado monetario M1 está compuesto por los billetes y monedas en poder del público, las cuentas de cheques en bancos residentes, los depósitos en cuenta corriente y los depósitos a la vista de las Sociedades de Ahorro y Préstamo. Los billetes y monedas en poder del público se obtienen al excluir la caja de los bancos de los billetes y monedas en circulación.

${ }^{9}$ Los datos de los agregados monetarios, con base en la metodología actual, están disponibles a partir de diciembre de 1985. Esta presentación de los agregados incluye solamente al ahorro del sector privado. La metodología anterior consideraba también al ahorro del sector público (ahorro del Gobierno Federal, empresas y organismos públicos, gobiernos estatales y municipales, Gobierno del Distrito Federal y fideicomisos de fomento). A pesar de que bajo la definición anterior es posible contar con series históricas a partir de enero de 1960 para los billetes y monedas en poder del público (M0), el agregado monetario M1, y el agregado monetario más amplio (M4), se decidió utilizar la definición actual por considerarse que: (i) el sector público puede responder a consideraciones distintas a las del sector privado al momento de definir su ahorro; y, (ii) para el periodo anterior a 1978 sería necesario considerar variables distintas a los CETES como medida del costo de oportunidad.
} 


\subsection{Correlación entre el crecimiento de M1 y la inflación del INPC}

Uno de los hechos estilizados en los que se basa el análisis de los agregados monetarios en el largo plazo, de acuerdo con McCandless y Weber (1995) es: "En el largo plazo, existe una alta correlación (casi unitaria) entre la tasa de crecimiento de la oferta monetaria y la tasa de inflación. Lo anterior es válido para las diferentes clasificaciones de dinero y para toda la muestra de países analizados.". Esta evidencia se resume en el Cuadro 1. En efecto, las correlaciones son cercanas a 1, lo que usualmente se toma como indicativo, en concordancia con la teoría cuantitativa del dinero, de que en el largo plazo existe una relación uno a uno entre el crecimiento del dinero y el crecimiento de los precios (i.e., que no existe ilusión monetaria, por lo que el dinero es neutral).

Cuadro 1. Correlación entre el crecimiento de los agregados monetarios e inflación*

Periodo de 1960 a 1990

\begin{tabular}{lccc}
\hline \hline & \multicolumn{3}{c}{ Coeficientes de correlación } \\
\cline { 2 - 4 } Muestra: & M0 & M1 & M2 \\
\hline \hline & & & 0.950 \\
110 Países & 0.925 & 0.958 & \\
Submuestra: & & & 0.958 \\
21 Países OCDE & 0.894 & 0.940 & 0.993 \\
14 Países de Latinoamérica & 0.973 & 0.992 & \\
\hline \hline
\end{tabular}

* La inflación se define como la tasa de crecimiento del Índice de Precios al Consumidor

Fuente: McCandless y Weber (1995) con datos del Fondo Monetario Internacional

Sin embargo, el aparente rompimiento de esta relación fue uno de los factores que contribuyó a desplazar al dinero como indicador de presiones inflacionarias. ${ }^{10}$ Esto puede ilustrarse con el caso de México. El Cuadro 2 presenta las correlaciones entre el crecimiento de distintos agregados monetarios y la inflación. Estas correlaciones en general son menores a las estimadas por McCandless y Weber, en particular la del agregado M1, y son inferiores a la unidad. Este resultado es común para otros países cuando se incluyen datos posteriores a los utilizados por McCandless y Weber, en particular, periodos de estabilidad de precios (Estrella y Mishkin, 1997). Más aún, para el caso de México, el Cuadro 2 presenta intervalos de confianza (al 95\%) para las correlaciones y ninguno de estos intervalos contiene ni al 0 ni al 1 , por lo que se puede concluir que las correlaciones son estadísticamente positivas y menores a la unidad (al 5\% de significancia estadística).

Sin embargo, Benati (2009) ha argumentado recientemente que la correlación simple puede estar contaminada con choques que afectan a los agregados monetarios y/o a la inflación en el corto plazo (por ejemplo, choques a la velocidad del dinero). Bajo este argumento, en línea con Lucas $(1980)^{11}$, Benati propone analizar la correlación entre estas

\footnotetext{
${ }^{10}$ Para ver una discusión al respecto véase, por ejemplo, McCallum y Nelson (2011).

${ }^{11}$ Robert Lucas (1980) utilizó técnicas de filtrado de series para extraer los componentes de baja frecuencia de la tasa de crecimiento de M1 y de la inflación al consumidor en Estados Unidos para el periodo 19551975, y encontró una correlación cercana a 1 entre ambas series.
} 
series en el largo plazo (i.e., en la baja frecuencia). En el caso de México, la Gráfica 2 presenta las tasas de crecimiento anual de M1 y del INPC de tres maneras. El panel de la izquierda muestra los datos sin modificar, el panel central muestra los componentes de largo plazo, mientras que el panel de la derecha muestra los componentes cíclicos. ${ }^{12}$ Se observa que los componentes de largo plazo de las series parecen estar muy correlacionados, mientras que la correlación de los componentes cíclicos parece ser menor, contaminando a los datos sin ajustar.

Cuadro 2. Correlación entre el crecimiento anual de los agregados monetarios e inflación* México 1986 T1 a 2014 T1

\begin{tabular}{lcc}
\hline \hline & Puntual & Intervalo 95\% \\
\hline M1 & 0.754 & $0.660-0.825$ \\
M2 & 0.961 & $0.943-0.973$ \\
M3 & 0.949 & $0.926-0.965$ \\
\hline \hline
\end{tabular}

* La inflación se define como la tasa de crecimiento anual del INPC.

Fuente: Elaboración propia con datos del Banco de México.

Gráfica 2. Tasa de crecimiento anual de M1 e inflación anual: tendencias de largo plazo y componente cíclico
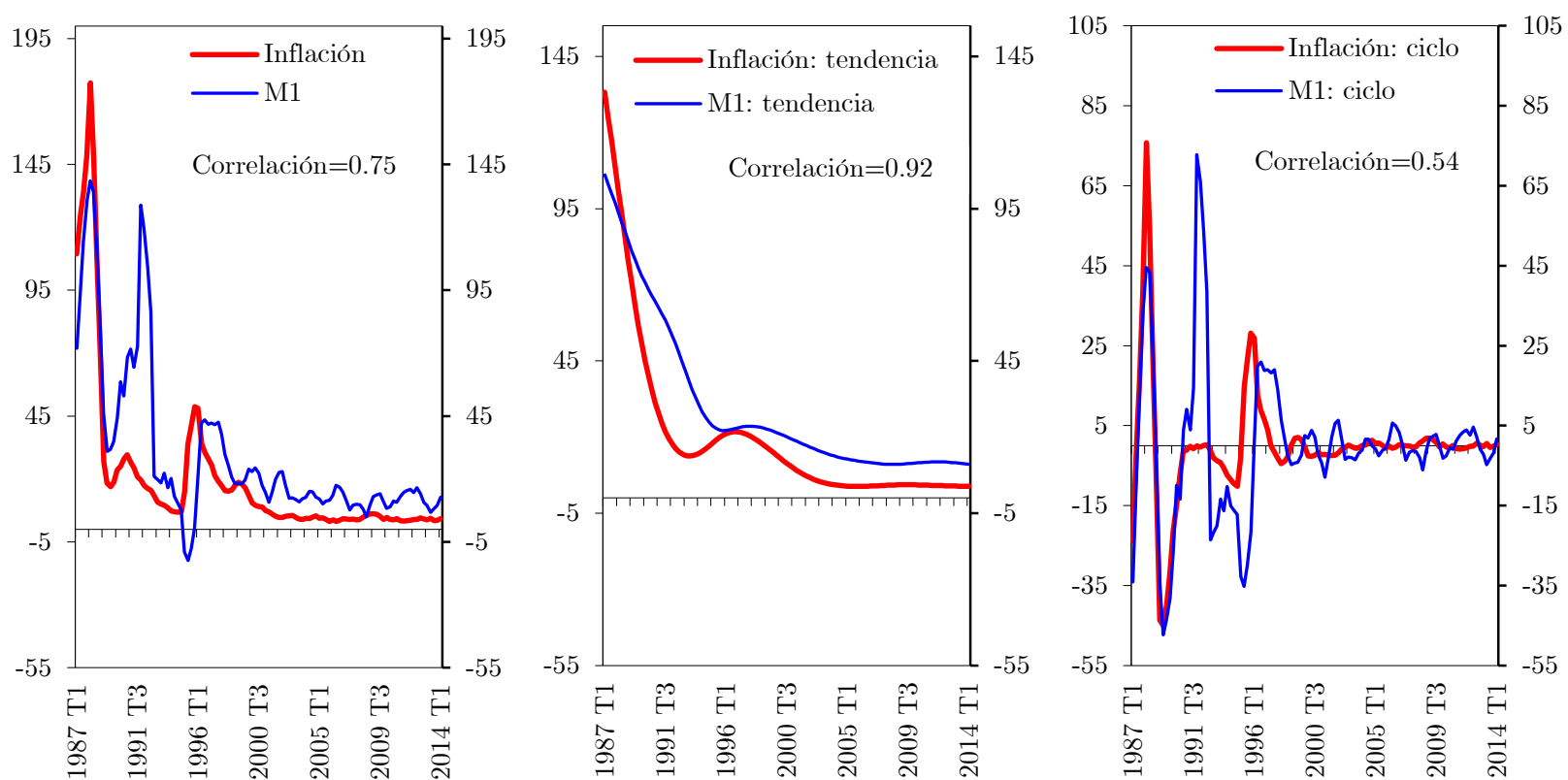

Para estimar formalmente la correlación en la baja frecuencia (largo plazo), es posible utilizar el concepto de coherencia espectral. ${ }^{13}$ La coherencia entre dos series puede interpretarse como la correlación entre dichas series en cada frecuencia. La Gráfica 3

${ }^{12}$ En ambos casos para obtener la tendencia y el ciclo se utilizó el filtro Hodrick-Prescott con $\lambda=1600$.

${ }^{13}$ La coherencia espectral entre dos series es una medida del grado en el que las series son influidas por ciclos en una determinada frecuencia. Es decir, se puede obtener la relación para el largo plazo (frecuencia cero), para frecuencias más relacionadas a los ciclos de negocios, o para el muy corto plazo. Ver Hamilton (1994). 
presenta los resultados para el caso del crecimiento trimestral de M1 y la inflación trimestral en México. ${ }^{14}$ Como puede apreciarse, la correlación en la frecuencia cero es de 0.81 y el intervalo al $95 \%$ de confianza incluye al 1, por lo que no es posible rechazar la hipótesis, al 5\% de significancia, de que la correlación en el largo plazo es unitaria. Benati encuentra algo similar para Estados Unidos, Reino Unido y otros países. ${ }^{15}$

\section{Gráfica 3. Correlación por frecuencias entre el crecimiento trimestral de M1 e inflación trimestral}

(Coherencia espectral; Intervalo de confianza de 95\%)

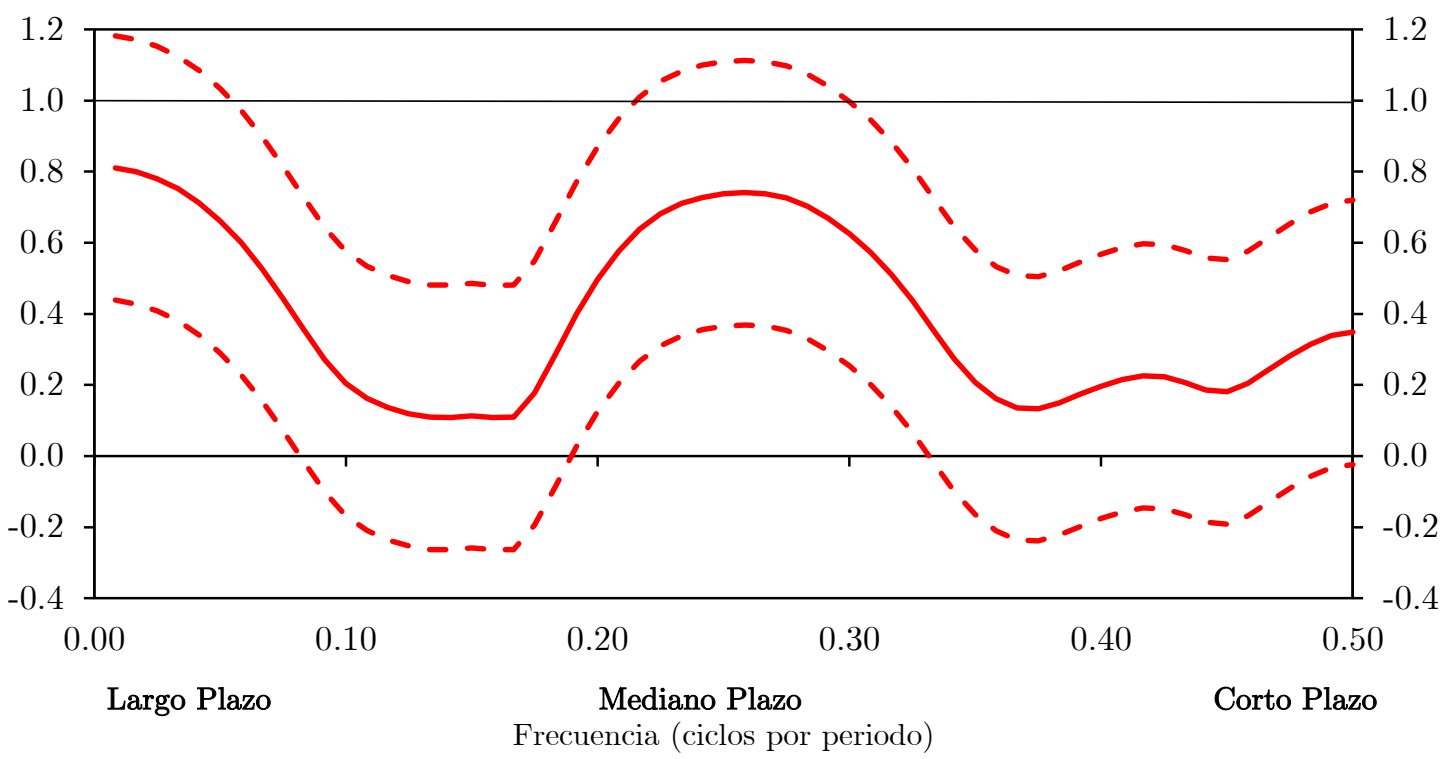

En efecto, la evidencia presentada en esta sección sugiere que la correlación de largo plazo entre el crecimiento de M1 y la inflación, para el caso de México, parece corresponder con la teoría, ya que no es posible rechazar, al 95\% de confianza, que dicha correlación es igual a 1 en el largo plazo. Utilizando esta información, a continuación se presenta un análisis de largo plazo de los agregados monetarios reales. En particular, se presentan estimaciones de la demanda de dinero donde se impone la restricción de que el coeficiente de largo plazo asociado al nivel de precios es igual a 1 (i.e., se impone que la demanda de dinero nominal es homogénea de grado 1 en precios).

\footnotetext{
${ }^{14}$ La coherencia espectral es calculada usando la primera diferencia de la transformación logarítmica de las series, por lo cual puede interpretarse como la tasa de crecimiento trimestral. De hecho, una condición necesaria para llevar a cabo este tipo de análisis espectral es que las series entren en su forma estacionaria, en este caso, en primeras diferencias. Más allá de esto, y como es demostrado por Levy (2002), este resultado de que la coherencia espectral en la más baja frecuencia es estadísticamente 1, como se muestra en la Gráfica 3 , es evidencia de que las series están cointegradas.

${ }^{15}$ Benati (2009) propone un modelo al que incorpora choques sistemáticos a la velocidad del dinero y periodos infrecuentes de aumento en la inflación, con el cual logra generar una correlación en la baja frecuencia igual uno y una correlación total menor a la unidad.
} 


\subsection{Relación entre saldos reales, PIB y tasa de interés}

Para estimar una demanda de saldos reales es necesario utilizar como variables explicativas una variable de escala, que represente el volumen de transacciones en la economía, así como una variable del costo de oportunidad de mantener saldos reales. Para ello se utilizaron el Producto Interno Bruto (PIB) real trimestral y la tasa de interés de los CETES a 28 días. Las variables se utilizaron en logaritmos y las tasas de crecimiento se calcularon como diferencias logarítmicas. La excepción es la tasa de interés, la cual está medida en rendimiento porcentual anual dividida entre cien.

La Gráfica 4 presenta la relación de los saldos reales con la variable de escala, es decir, con el PIB real. El aumento en el nivel de M1 real en 1991 se explica en gran medida por un cambio en la regulación. ${ }^{16}$ Sin embargo, la caída de 1994 y 1995 no corresponde a un cambio regulatorio, sino que forma parte de la respuesta ante la crisis económica. Después de dicha crisis, las series tienen una tendencia similar, por lo que una elasticidad unitaria parece posible. Es preciso tomar en cuenta el motivo transaccional al construir un indicador de futuras presiones inflacionarias basado en agregados monetarios, ya que una cantidad mayor de dinero en la economía en respuesta al incremento en el número de transacciones, consecuencia a su vez de un mayor ingreso (o producción agregada), no tiene porqué inducir mayor inflación en el futuro. ${ }^{17}$ Un aspecto muy importante a resaltar de esta gráfica es el comportamiento de los saldos reales durante las tres crisis contenidas en la muestra. Durante las dos primeras, la de 1987 y la de 1994-1995, se observa una caída importante de los saldos reales. Sin embargo, no se observa una caída similar ante la más reciente crisis global (2008-2009).

\footnotetext{
${ }^{16}$ M1 real aumentó 84\% entre 1990 y 1991. Este cambio de nivel se explica por el incremento de $151.7 \%$ en las cuentas de cheques que ocurrió como consecuencia de un cambio regulatorio. Dicho cambio hizo que los fondos en fideicomisos abiertos de inversión de valores y en cuentas maestras se transfirieran a cuentas de cheques (que pagan intereses), lo cual produjo dicho incremento en el agregado M1.

${ }_{17}$ Para una revisión del motivo transaccional, así como de otros aspectos relacionados con la demanda de dinero, ver Serletis (2007).
} 
Gráfica 4. Saldos reales (M1/P) y PIB real

(datos ajustados por estacionalidad en logaritmos)

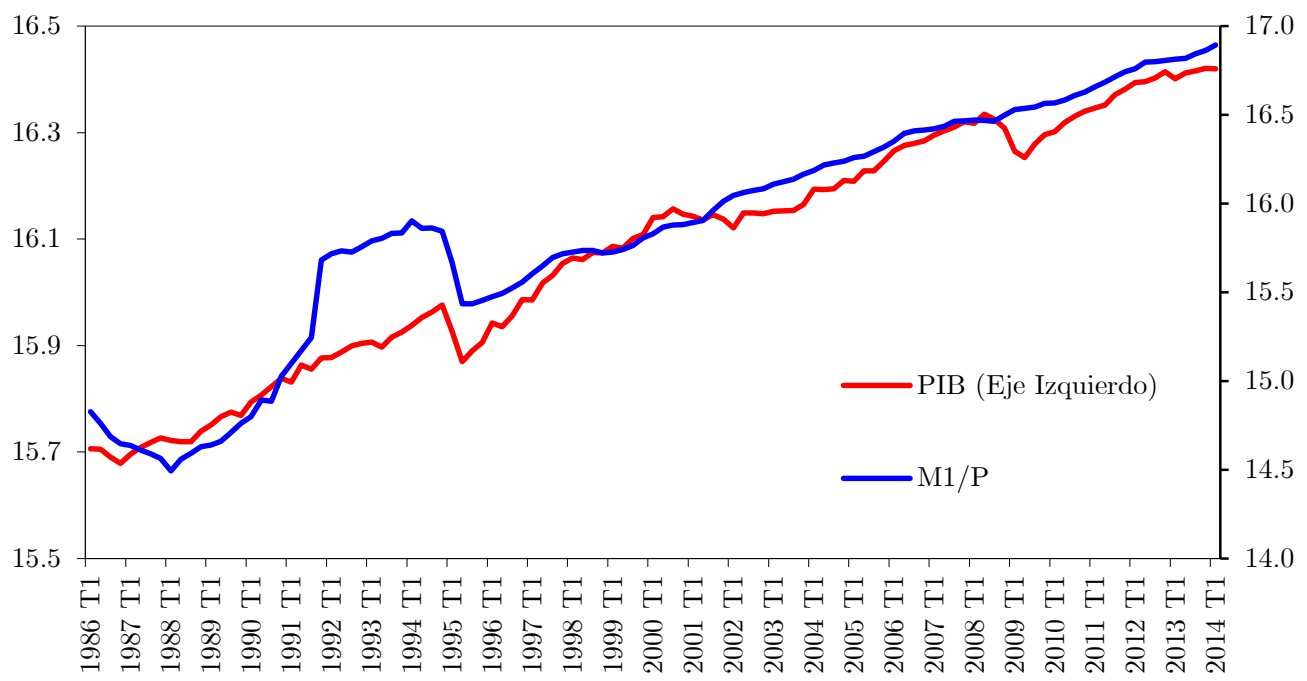

Por su parte, la Gráfica 5 ilustra la relación entre (el inverso de) la velocidad del dinero y la tasa de interés. Se utiliza la velocidad del dinero para controlar por el efecto de la variable de escala. ${ }^{18}$ En primer lugar es posible apreciar que la evidencia está a favor de una semi-elasticidad negativa de la tasa de interés. En segundo, es posible observar un proceso de re-monetización importante asociado a la disminución de la tasa de interés después de la crisis de 1994-1995. Este proceso puede verse como un efecto "Fisheriano", en el sentido de que las tasas de interés han disminuido porque las expectativas de inflación así lo han hecho (Fisher, 1930). Esto es, cuando la inflación disminuye sistemáticamente, el dinero crece más rápido que los precios porque el costo de oportunidad de mantener dinero disminuye también sistemáticamente, lo que induce a la gente a mantener balances monetarios adicionales. Es importante considerar este efecto, ya que no hacerlo debilita la relación entre el crecimiento del dinero y la inflación futura. Como señala Reynard (2006): "incrementos en los saldos monetarios resultado de tasas de interés decrecientes como consecuencia de un efecto de Fisher es un efecto transitorio de nivel que puede tomar varios años y que no está asociado con una mayor inflación futura". Puesto de otra forma, cuando la tasa de interés disminuye debido a una desinflación, la inflación decrece más de lo que el dinero podría explicar si no se toman en cuenta estos movimientos. Por ello, cualquier indicador de futuras presiones inflacionarias construido a partir de agregados monetarios debe controlar por el efecto en el largo plazo de la tasa de interés.

\footnotetext{
${ }^{18}$ En logaritmos, el inverso de la velocidad es igual a $(m-p-y)$, de tal manera que lo que se está graficando es el nivel de M1 una vez que se corrige por los precios y por la variable de escala (imponiendo elasticidades precio e ingreso unitarias).
} 
Gráfica 5. Tasa de interés e inverso de la velocidad

(datos ajustados por estacionalidad en logaritmos)

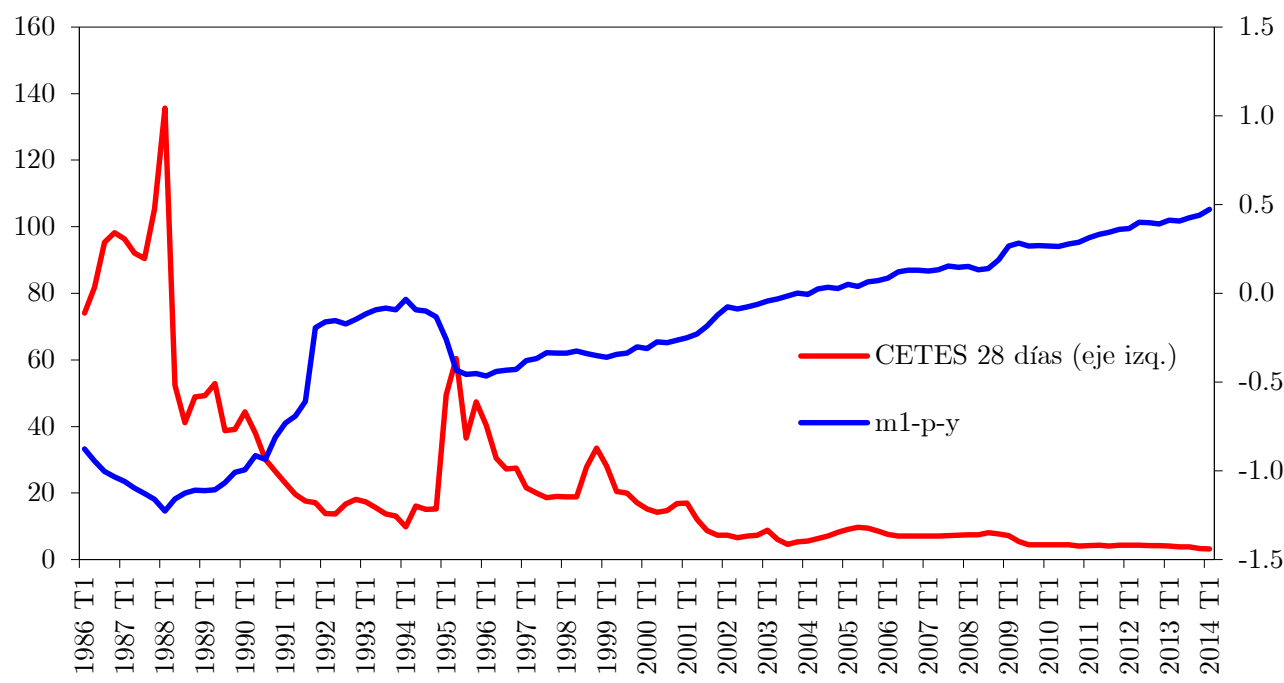

\subsection{La demanda por dinero estimada por $\mathrm{NRR}^{19}$}

En NRR, mediante el uso de un modelo de corrección de error, se estima una demanda por dinero, y bajo un análisis sencillo de estabilidad se llega a la conclusión que la demanda por dinero es estable tanto en el corto como en el largo plazo. Sin embargo, como se muestra más adelante, la evidencia revela que aplicando una batería más amplia de pruebas, la conclusión sobre la estabilidad de la demanda por dinero de largo plazo no es tan clara. Así, primeramente se presentan los resultados del análisis de estabilidad realizado a las estimaciones de NRR, que indican la presencia de cambios significativos en los parámetros de largo plazo alrededor de 2001, que coincide con un cambio trascendental en el sistema nominal de la economía, en el cual la inflación pasó de ser un proceso no estacionario, a uno estacionario, y con la implementación del esquema de política monetaria de metas de inflación. Posteriormente, en la Sección 3, se presentan los resultados de reestimar la demanda por dinero para el período 2001-2014.

\subsubsection{Análisis de estabilidad en NRR: 1986-2010}

En su estudio, empleando datos trimestrales de 1986T1 a 2010T2 y mediante el uso de la metodología de cointegración de Johansen (1988), NRR estiman una relación de cointegración entre M1 en términos reales, una variable de escala de transacciones y una variable de costo de oportunidad, medidas por el PIB real y la tasa de interés de los CETES a 91 días, respectivamente, encontrando evidencia de que no es posible rechazar que los saldos reales responden uno a uno con la variable de escala. A continuación se transcribe la demanda por dinero estimada por NRR,

\footnotetext{
${ }^{19}$ Otras estimaciones de la demanda de dinero para el caso de México pueden encontrarse, por ejemplo, en: Ortiz (1982), Ramos-Francia (1993), Khamis y Leone (2001), y Román-Aguilar y Vela-Dib (1996).
} 


$$
(m 1-p-y)_{t}=-2.08 i_{t}+7.08
$$

En lo referente a la estabilidad de los parámetros de esta relación de cointegración o de largo plazo, los autores presentan evidencia de una prueba de parámetros constantes con base en el estadístico de Nyblom (1989) contextualizada por Hansen y Johansen (1999) en el marco metodológico de los Vectores de Corrección de Error (VECM, por sus siglas en inglés). Así, con base en este estadístico de prueba, calculado mediante la estimación recursiva (hacia adelante) del VECM, se concluye que no se puede rechazar la hipótesis nula de que los parámetros de la demanda por dinero de largo plazo son estables.

En esta subsección, utilizando exactamente los mismos datos que en NRR, vamos más allá y extendemos el análisis de estabilidad de los parámetros de la demanda por dinero presentada en NRR, aplicando una batería de pruebas recursivas (hacia adelante y hacia atrás) sobre el VECM utilizado por los autores en su estimación. ${ }^{20}$

En general, las pruebas recursivas pueden ser aplicadas de dos maneras distintas, dependiendo del método recursivo que se implemente (véase, por ejemplo, Juselius 2006). En el análisis recursivo hacia adelante (forward recursive), esto es, dejando fijo el inicio de la muestra, se toma como punto de partida la estimación del modelo en una submuestra, $1, \ldots, T 1$, donde $T 1<T$, y entonces recursivamente se extiende el punto final de la submuestra, $t 1$, hasta que la muestra completa es cubierta, i.e. $t 1=T 1, T 1+1, \ldots, T$. En el análisis recursivo hacia atrás (backward recursive), en efecto, dejando fijo el final de la muestra, se toma como punto de partida la estimación del modelo en una submuestra, $T 1, \ldots, T$, y recursivamente se adhieren observaciones al punto inicial de la submuestra, esto es, las recursiones se definen para las submuestras $t 1-T, t 1=T 1, T 1-1, T 1-$ $2, \ldots, 1 .{ }^{21}$ La mayoría de la bibliografía sobre la estabilidad de la demanda por dinero se concentra en pruebas recursivas hacia adelante, sin embargo, es también importante considerar las estimaciones recursivas hacia atrás, pues como discute Juselius (2006), en muchos casos la parte más lejana de la muestra puede representar un régimen distinto al de la economía actual, por lo que en tales situaciones podría preferirse darle mayor atención al régimen actual en el análisis de la estabilidad de los parámetros.

Además del tipo de análisis recursivo que se implemente, en el contexto metodológico del VECM, la mayoría de las pruebas de diagnóstico de estabilidad pueden presentarse en dos versiones del modelo (véase Apéndice I): (a) La versión completa del modelo, forma$X$, que no es más que el VECM en su forma conocida; y (b) La versión concentrada del modelo, forma- $R$. Esta versión es como eliminar el efecto de corto plazo de la estimación,

\footnotetext{
${ }^{20}$ En sus estimaciones NRR modelan un VAR con 2 rezagos, incorporando 2 variables dicotómicas: (i) la primera para capturar el cambio regulatorio que tuvo un incremento en las cuentas de cheques (componente de M1); (ii) la segunda, para controlar por el efecto del Pacto de Solidaridad Económica, que como NRR mencionan, se vio reflejado en un importante descenso en la tasa de inflación y en la tasa de interés de los CETES a 91 días en el segundo trimestre de 1988. El VECM es especificado con una constante no restringida dentro del vector cointegrador, e incluyen 3 variables dicotómicas centradas para controlar por la variación estacional.

${ }^{21}$ En general, el valor de $T 1$ se escoge tal que exista un mínimo de grados de libertad en la estimación de la submuestra inicial. En la parte empírica de este documento se considera un valor de $T 1$ de aproximadamente el 30 por ciento de la muestra tanto en el análisis recursivo hacia adelante como en el recursivo hacia atrás.
} 
de tal manera que es como "limpiar" la relación de largo plazo. Dado que estas dos versiones del modelo pueden dar diferentes resultados de las pruebas, siguiendo a Juselius (2006), considérese el siguiente ejemplo para una adecuada interpretación de los resultados. Suponga que se tiene un modelo con parámetros no-constantes en la estructura de corto plazo, y parámetros constantes en la de largo plazo. Entonces, dado que la forma- $R$ se ha "pulido" de los efectos de corto plazo, estas pruebas deberían aceptar la constancia de los parámetros de largo plazo, mientras que es más probable que la forma- $X$ esté influenciada por la inestabilidad de la estructura de corto plazo. Así, cuando las pruebas recursivas basadas en la forma- $R$ luzcan más estables que las de la forma- $X$, esto sugerirá inestabilidad en los coeficientes de corto plazo.

Dado lo anterior, se analizan los resultados de las pruebas recursivas hacia adelante (F) y hacia atrás (B), usando tanto la forma- $X$ como la forma- $R$ donde sea posible. Se presentan tres categorías diferentes de pruebas recursivas: las basadas en eigenvalores, las basadas en el espacio cointegrador, y las basadas en la estimación de parámetros. La descripción de cada caso específico se detalla en el Apéndice I, mientras que con fines de síntesis y claridad en la exposición de los resultados, en el Cuadro 3 se presenta un breve resumen de estos.

Primeramente, nótese que la estructura de corto plazo del VECM parece ser inestable. Todas las pruebas en que se puede separar la forma- $X$ de la forma- $R$, con excepción del estadístico Max-Test $(\mathrm{Q}(\mathrm{t}))$, muestran alguna forma de inestabilidad con la forma- $X$, $\mathrm{y}$ estabilidad con la forma- $R$ (excluyendo los parámetros recursivos backward). Esto sugiere que la estructura de corto plazo del VECM es inestable. ${ }^{22}$

Por su parte, los resultados sobre la estabilidad de los parámetros de largo plazo son ambiguos. El resultado reportado en NRR es el que se refiere al estadístico Max-Test $(\mathrm{Q}(\mathrm{t}))$ en la estimación recursiva hacia adelante $(\mathrm{F})$, que como puede verse del Cuadro 3 puede concluirse que la relación es estable. La mayor evidencia de inestabilidad se observa en los parámetros recursivos hacia atrás (backward), en donde se observan cambios en el valor de los parámetros. Sin embargo, en el resto de las pruebas no hay tanta claridad respecto a la inestabilidad de la relación de largo plazo. De hecho, sólo en 2 de los 16 resultados reportados en el Cuadro 3 (12.5\% de los casos) se encuentra evidencia clara de inestabilidad en la relación de largo plazo. Esta ambigüedad en los resultados puede ilustrarse perfectamente al comparar las estimaciones forward y backward de la forma- $R$ del vector de cointegración en las Gráficas AI.13 y AI.14. Como puede apreciarse las estimaciones recursivas hacia adelante lucen estables mientras que las estimaciones recursivas hacia atrás muestran una fuerte perturbación alrededor de los años 2000-2001. Debido, en parte, a estos hallazgos sobre inestabilidad en la demanda por dinero de largo plazo, en este documento reestimamos la demanda por dinero para el período 2001-2014.

\footnotetext{
${ }^{22}$ Hay que hacer notar que en NRR el procedimiento de estimación es en dos etapas. En la primera, mediante el VECM se realizan pruebas de cointegración y de exogeneidad débil, y se estima la demanda por dinero de largo plazo. En la segunda etapa, la dinámica de corto plazo es estimada por medio de un modelo uniecuacional de corrección de error siguiendo la metodología de lo General a lo Específico. Dicho modelo uniecuacional no es analizado aquí. El análisis de estabilidad de la estructura de corto plazo resumido en el Cuadro 3 es sólo sobre el VECM.
} 
Cuadro 3. Resumen de los resultados de las pruebas recursivas de estabilidad aplicadas al VECM estimado por NRR

\begin{tabular}{|c|c|c|c|c|c|c|}
\hline \multirow[t]{3}{*}{ Prueba } & \multirow{3}{*}{$\begin{array}{c}\text { Método } \\
\text { recursivo }\end{array}$} & \multirow{3}{*}{$\begin{array}{c}\text { Estructura } \\
\text { de corto } \\
\text { plazo }\end{array}$} & \multicolumn{4}{|c|}{ Estructura de largo plazo } \\
\hline & & & \multirow{2}{*}{\multicolumn{2}{|c|}{$\begin{array}{l}\text { Resultado } \\
\text { eigenvalores }\end{array}$}} & $\begin{array}{c}\text { Vector } \\
\text { Cointegrador }\end{array}$ & $\begin{array}{c}\text { Velocidad de } \\
\text { Ajuste }\end{array}$ \\
\hline & & & & & Beta & Alfa \\
\hline \multirow[t]{2}{*}{ Eigenvalores } & $\mathrm{F}$ & n.a. & ESTABLE & n.a. & n.a. & n.a. \\
\hline & B & n.a. & ESTABLE & n.a. & n.a. & n.a. \\
\hline \multirow[t]{2}{*}{ Eigenvalores transformados } & $\mathrm{F}$ & n.a. & ESTABLE & n.a. & n.a. & n.a. \\
\hline & B & n.a. & ESTABLE & n.a. & n.a. & n.a. \\
\hline \multirow[t]{2}{*}{ Fluctuation test } & $\mathrm{F}$ & INESTABLE & n.a. & ESTABLE & n.a. & n.a. \\
\hline & B & INESTABLE & n.a. & ESTABLE & n.a. & n.a. \\
\hline \multirow[t]{2}{*}{ Estadístico de la traza } & $\mathrm{F}$ & INESTABLE & n.a. & ESTABLE & n.a. & n.a. \\
\hline & $\mathrm{B}$ & INESTABLE & n.a. & ESTABLE & n.a. & n.a. \\
\hline \multirow[t]{2}{*}{ Max-test $(Q(t))$} & $\mathrm{F}$ & ESTABLE & n.a. & n.a. & ESTABLE & n.a. \\
\hline & B & ESTABLE & n.a. & n.a. & ESTABLE & n.a. \\
\hline \multirow[t]{2}{*}{$\boldsymbol{\beta}_{\boldsymbol{t}}$ igual a un $\boldsymbol{\beta}$ conocido } & $\mathrm{F}$ & INESTABLE & n.a. & n.a. & ESTABLE & n.a. \\
\hline & B & INESTABLE & n.a. & n.a. & ESTABLE & n.a. \\
\hline \multirow[t]{2}{*}{ Parámetros recursivos } & $\mathrm{F}$ & INESTABLE & n.a. & n.a. & ESTABLE & ESTABLE \\
\hline & $\mathrm{B}$ & INESTABLE & n.a. & n.a. & INESTABLE & INESTABLE \\
\hline
\end{tabular}

F: Forward; B: Backward, n.a. no aplica.

\section{Demanda por dinero en México 2001-2014}

En esta sección se estima un modelo de demanda por dinero para el periodo en el cual el Banco de México ha seguido un esquema de objetivos de inflación, es decir, de 2001 a 2014. Previo a ello, se analiza la relevancia de un conjunto de variables que parecen haber tenido influencia en la determinación de la demanda por dinero en este periodo y que se incluyen en adición a las variables tradicionales que explican la demanda por saldos reales (el PIB como medida de la escala de transacciones y la tasa de interés como variable de costo de oportunidad de mantener dinero). Una vez estudiada la relevancia de estas variables, se presentan los resultados de la estimación y el análisis de los resultados.

\subsection{Análisis de variables adicionales}

Remesas. Las remesas familiares son consideradas en este estudio como una medida complementaria del ingreso (o escala de transacciones), que históricamente han desempeñado un importante papel en la economía mexicana, y se considera podría estar 
relacionada con los movimientos de la demanda por dinero en el largo plazo. ${ }^{23}$ De esta manera, las remesas complementan a la variable de escala por elementos que no se incorporan en el PIB. Así, un incremento en el nivel de remesas conduce a un incremento en la demanda de dinero debido a un mayor volumen de transacciones, al igual que ocurre con los cambios en el ingreso. La evidencia sugiere que una parte de dichos incrementos se ahorra, y otra parte, complementa la riqueza que financia al consumo y, en algunos casos, incluso se destinan a "capital de trabajo" (Fajnzylber y Lopez (2008)). Vargas-Silva (2009) presenta un modelo para un agente representativo en una economía abierta en el cual se incorporan las remesas como determinantes de la demanda de dinero. El autor utiliza funciones de impulso respuesta derivadas del modelo estructural de vectores autorregresivos para el periodo de 1996 a 2006 en México, y encuentra evidencia que la demanda de dinero responde positivamente ante choques en las remesas. En la Gráfica 6 se muestra la evolución de las remesas en los últimos años. Como se puede apreciar, existe un aumento sustancial que se ha generado, al menos en parte, debido a una disminución en el costo de transferir dinero, el cual a su vez ha sido consecuencia de diversos factores: un mayor número de intermediarios y una creciente competencia entre ellos; y, un mayor uso de las transferencias electrónicas internacionales. En particular, se ha producido un incremento en las remesas que se envían en forma de transferencias electrónicas, impulsado en parte por los avances tecnológicos en cómputo y telecomunicaciones (Banco de México, 2007)..$^{24}$

d08T3. Variable dicotómica que toma el valor de 1 a partir del tercer trimestre del 2008. Esta variable cualitativa captura el efecto sobre la demanda por M1 que tuvieron un par de eventos que "coinciden" en la fecha de ocurrencia. Primero, esta variable mide el efecto del Impuesto a los Depósitos en Efectivo (IDE) sobre la demanda de dinero. ${ }^{25}$ Este impuesto tuvo por objeto gravar las actividades de la economía informal (siendo acreditable o compensable contra el Impuesto sobre la Renta), por lo cual crea incentivos

\footnotetext{
${ }^{23}$ Por ejemplo, en 2005 las remesas representaron el equivalente a una tercera parte de los ingresos por salarios en el sector formal de la economía mexicana. En algunos estados, el valor de las remesas fue mayor al valor de los ingresos por salarios (Banco de México, 2006). México es el receptor más grande de remesas en América Latina (Fajnzylber y López, 2008).

${ }^{24}$ A partir de 2001, el Banco de México ha mejorado la cobertura estadística de las estadísticas de remesas familiares, además que han mejorado los registros de remesas por parte de los intermediarios financieros (Banco de México, 2007).

${ }^{25}$ El IDE es un impuesto que grava los depósitos en efectivo. Se calcula sobre el total de estos depósitos que se reciban dentro del mes correspondiente en todas las cuentas en las que una persona sea titular en una misma institución del sistema financiero. El IDE entró en vigencia en julio de 2008 con una tasa del $2 \%$ para aquellos depósitos por encima de 25 mil pesos. Posteriormente, en enero de 2010 se redujo el umbral de los depósitos exentos de 25 mil a 15 mil pesos y se incrementó la tasa del 2 al $3 \%$. Este impuesto se derogó a partir de enero de 2014. Nótese que la variable dicotómica d08T3, que refleja (parcialmente) el efecto de este impuesto, mantiene su valor de 1 para la (última) observación 2014T1, para la cual el IDE ya no estaba en operación. Esto se decidió así, ya que el cambio en la conducta de los individuos respecto a su demanda por el agregado monetario M1 es muy difícil que se vea reflejado cabalmente en una sola observación, además de las dificultades estadísticas conocidas para la estimación, al tratarse del último trimestre incluido en la muestra. Sin embargo, la evidencia empírica sugiere que la derogación del IDE, así como la implementación de otras medidas fiscales, han conducido a un mayor uso relativo del efectivo como medio de pago. Otras medidas fiscales que han afectado dicho uso son los cambios en las deducciones autorizadas sobre el ISR y el incremento del IVA en la frontera. Ver el Informe sobre la Inflación Enero-Marzo 2015, Banco de México.
} 
para disminuir los depósitos en efectivo. El agregado monetario M1 incluye tanto a billetes y monedas como a las cuentas de cheques y los depósitos en cuenta corriente en los bancos del país, por lo que el IDE por un lado podría estar aumentando la tenencia de billetes y monedas, pero por el otro podría estar reduciendo los depósitos en cuenta corriente y en cuentas de cheques. Segundo, esta variable cualitativa se activa en el tercer trimestre de 2008 que coincide con el trimestre en que se declara la bancarrota de Lehman-Brothers (septiembre de 2008), fecha considerada con elevada frecuencia como referencia de la crisis financiera internacional reciente. Así, esta variable cualitativa también podría estar capturando la reacción de los agentes económicos ante el escenario de crisis financiera (por ejemplo, aumentando la demanda de dinero debido a lo que Keynes llama el motivo precautorio). Además, la interpretación de esta variable cualitativa no es tan clara al haber un par de acontecimientos alrededor del tercer trimestre de 2008 que pudieron tener un efecto sobre la demanda de dinero. ${ }^{26}$

Gráfica 6. Remesas y demanda por dinero

(datos ajustados por estacionalidad en logaritmos)
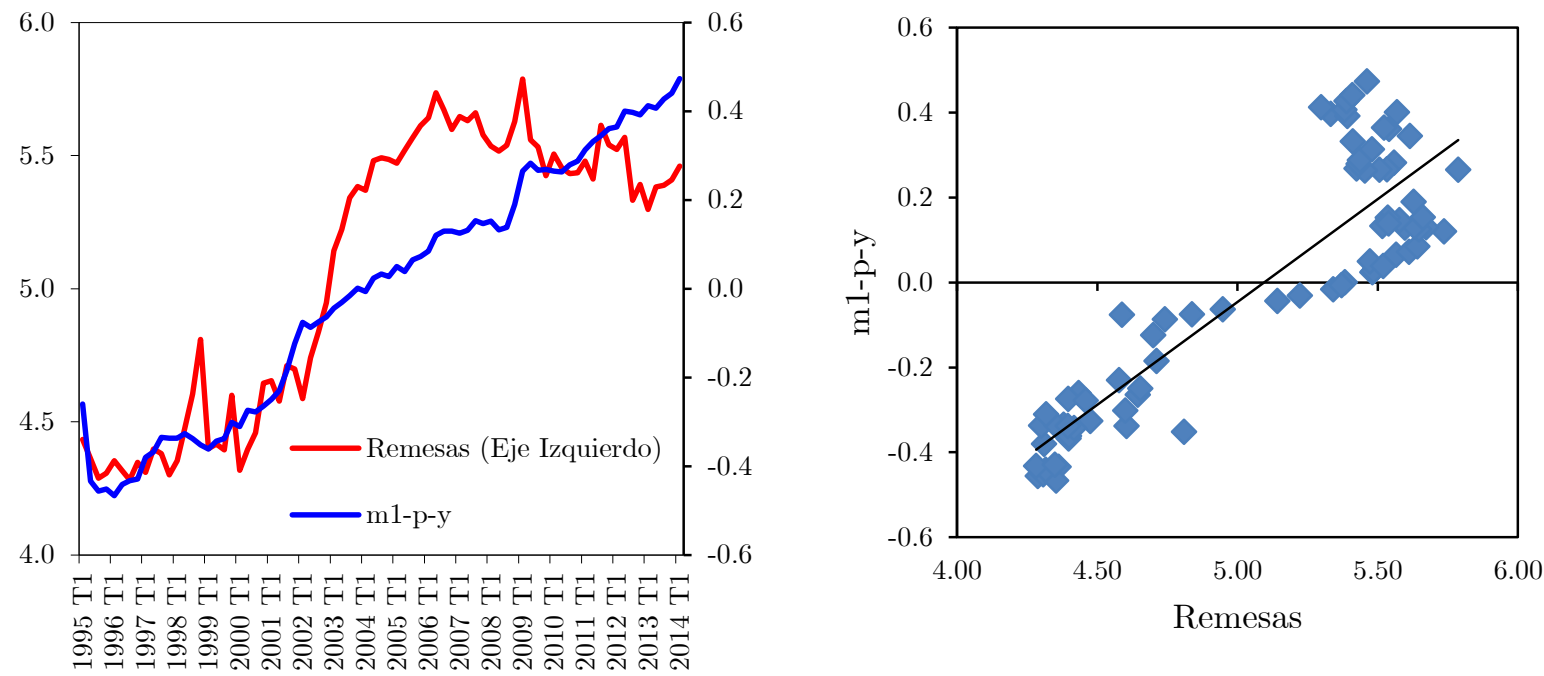

Decisiones de Portafolio (Efecto Balance de Portafolio). En una economía abierta, factores externos tales como las variaciones en el tipo de cambio y en las tasas de interés extranjeras pueden afectar la composición óptima de los saldos monetarios. Por ejemplo, en su estudio de la demanda de dinero para la Unión Europea, De Santis, Favero y Roffia (2008) encuentran que la propiedad de estabilidad en la demanda de dinero sólo se consigue una vez que son considerados los flujos internacionales de portafolio que se presentaron en el periodo posterior al 2001. Así, los flujos internacionales de capitales que ocurren cuando existen diferencias entre las tasas de interés doméstica y extranjera pueden tener un papel importante en la demanda de dinero. Sin embargo, dichos flujos de capitales no pueden

${ }^{26}$ Cabe aclarar que para modelar este posible efecto de la crisis financiera internacional sobre la demanda por dinero, se probaron diferentes variables dicotómicas en diferentes fechas, puesto que es complicado establecer con precisión una fecha del inicio de la crisis. Los mejores resultados estadísticos se obtienen con esta variable que coincide exactamente con la introducción del IDE. 
ser capturados en el modelo convencional de demanda de dinero que únicamente incluye el ingreso y la tasa de interés. Así, en este modelo de demanda por dinero se considera que los agentes económicos tienen acceso a cuatro tipos de activos: moneda local, moneda extranjera, bonos domésticos y extranjeros.

En un modelo de portafolio, los agentes pueden mantener alguna moneda extranjera como un activo por motivos de precaución o especulación. Este fenómeno ha sido estudiado, entre otros, por Arango y Nadiri (1981). Estos modelos pueden analizarse empíricamente aumentando la función de demanda de dinero convencional con una variable que capture el rendimiento de mantener activos extranjeros, es decir, la tasa de interés extranjera más la depreciación esperada del tipo de cambio, lo cual permite capturar lo que se conoce como efecto de balance de portafolio. Un ejemplo del estudio empírico de este tipo de modelos para México, que consideran variables internacionales en la función de demanda de dinero, puede encontrarse en Cuthberson y Galindo (1999). ${ }^{27,28}$

Siguiendo la especificación de De Santis, Favero y Roffia (2008), en nuestro estudio se utiliza el diferencial entre la tasa de interés doméstica y el rendimiento de los activos extranjeros para medir el efecto de balance de portafolio. Además, se utiliza la tasa de depreciación observada, como sugiere el modelo de Cuthberson y Galindo (1999). Entonces, nuestra variable se define como: $e b p_{t}=i_{t}-i_{t}^{u s}-\Delta e_{t}$. Donde $i_{t}^{u s}$ es la tasa de interés de los Bonos del Tesoro a 3 meses para Estados Unidos, y $\Delta e_{t}$ es la tasa de depreciación del tipo de cambio peso-dólar. ${ }^{29}$ La relación entre esta variable y la cantidad de dinero en términos reales puede apreciarse en la Gráfica 7. Así al incluir esta variable en la demanda de dinero se puede estimar la respuesta a los rendimientos en pesos que se obtengan al invertir en el exterior. Estos rendimientos están compuestos por la tasa de interés exterior más las posibles ganancias obtenidas por las expectativas de depreciación del tipo de cambio.

Arango y Nadiri (1981), Bahmani-Oskoee y Rhee (1994) y Bahmani-Oskoee y Ng (2002) argumentan que las variaciones en la tasa de rendimiento de los activos en el extranjero pueden tener dos efectos sobre la demanda de dinero, un efecto sustitución y un efecto riqueza. Si el incremento en dicha tasa de rendimiento se da a través de la tasas de interés

\footnotetext{
${ }^{27}$ Otro tipo de modelos son aquellos que se denominan de "sustitución de monedas", en donde la pérdida esperada en el valor de la moneda local es tan elevada que pierde su función como resguardo de valor. En efecto, en este caso el público empieza a llevar a cabo transacciones en moneda extranjera. Este tipo de modelos ha sido estudiado por Miles (1978), Girton y Roper (1981), McKinnon (1982) y Ramirez-Rojas (1985).

${ }^{28}$ A diferencia de trabajos como los de Ortiz (1983), Ramírez-Rojas (1985) y Rogers (1992), que explican el grado de "dolarización" o "sustitución de monedas", es decir, las proporciones relativas de pesos y dólares mantenidas por los agentes en bancos nacionales, el presente estudio se concentra únicamente en la demanda de moneda local, como lo hacen Cuthbertson y Galindo (1999) y Bahmani-Oskooee y Ng (2002). De este modo se evita el problema de medición de los saldos de moneda extranjera en circulación que suele presentarse en la literatura sobre sustitución de monedas, al tiempo que se considera que dicho fenómeno dejó de ser relevante para el caso de México hace ya varios años.

${ }^{29}$ Nótese que para Estados Unidos se usa una tasa de interés de madurez de 3 meses, esto se debe a que la tasa de madurez de 4 semanas se encuentra disponible sólo a partir de julio de 2001. Cabe mencionar que el nivel de ésta tasa es muy cercano al tasa de interés de los Bonos del Tesoro a 3 meses y su correlación es de alrededor de 0.9.
} 
extranjera, la demanda de activos extranjeros relativa a la de activos domésticos se incrementará, lo cual reducirá la demanda de dinero a través de la movilidad de capitales. Por su parte, si dicho incremento se debe a un aumento en la tasa de depreciación, se puede generar un efecto sustitución de moneda, en el cual las expectativas de los inversionistas tienen un papel importante. Si los agentes esperan que el tipo de cambio se siga depreciando ante la depreciación inicial, éstos responderán incrementando la proporción de activos extranjeros en su portafolio. En este sentido, la depreciación de la moneda significa un mayor costo de oportunidad de mantener dinero, por lo cual se puede utilizar la sustitución de moneda para protegerse de dicho riesgo, con lo cual disminuye la demanda de dinero. Por otro lado, un incremento en la tasa de rendimiento de los activos extranjeros genera un efecto riqueza al incrementar el valor de esos activos, suponiendo que los agentes evalúan su portafolio en pesos. De esta manera, incrementarán las tenencias de activos domésticos, incluyendo la demanda de dinero. En suma, el efecto final del incremento en la tasa de rendimiento extranjera sobre la demanda de dinero puede ser positivo o negativo, dependiendo de la magnitud de los efectos riqueza y sustitución. Debido a ello, dicho efecto final deberá determinarse empíricamente.

Gráfica 7. Decisiones de Portafolio y demanda por dinero (datos ajustados por estacionalidad en logaritmos)
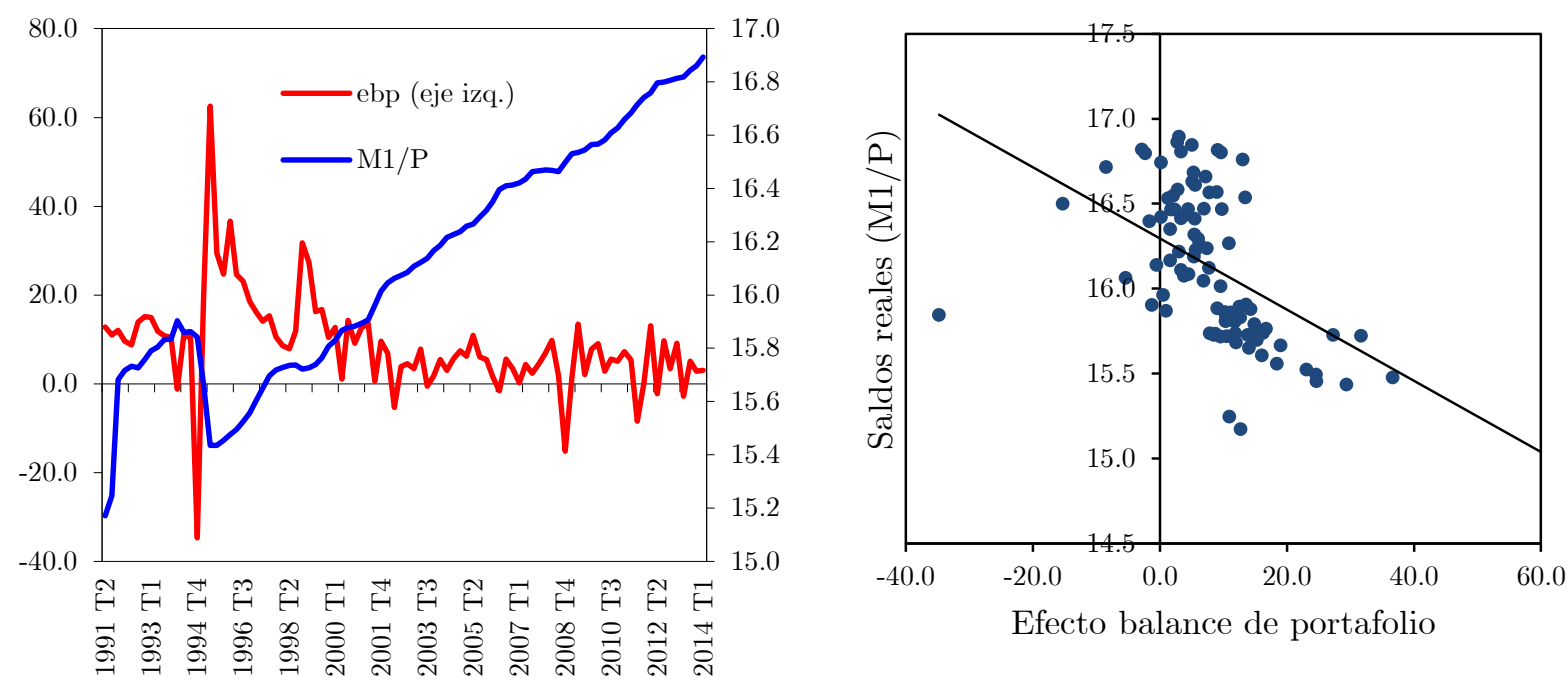

Gasto en los procesos electorales. Otro factor que ha contribuido a incrementar la demanda de dinero en México es un mayor uso de efectivo en el gasto asociado a los procesos electorales federales. Esta variable tiene un comportamiento totalmente vinculado al ciclo político, ya que en cada período de elecciones federales en la muestra (1997, 2000, 2003, 2006, 2009 y 2012) se ve incrementado en forma sustancial (prácticamente triplicándose). La Gráfica 8 muestra la relación positiva entre M1 y el gasto del sector 
público en el Instituto Federal Electoral. ${ }^{30,31}$ En el panel de la izquierda se aprecia como la tasa de crecimiento nominal de M1 tiende a aumentar y a llegar a un máximo local en los años en que se celebran elecciones federales, mientras que el panel de la derecha muestra la relación positiva entre las variables en términos reales. Por ejemplo, en el segundo trimestre de 2012, correspondiente al último ciclo electoral federal en nuestra muestra, el agregado monetario M1 tuvo un crecimiento real anual de alrededor de 12 por ciento, la cual excede considerablemente el crecimiento de 3 por ciento observado en el segundo trimestre de 2008 (período sin elecciones federales y anterior a la fecha de referencia de la crisis financiera internacional).

Gráfica 8. Gasto del IFE y demanda por dinero (datos ajustados por estacionalidad)
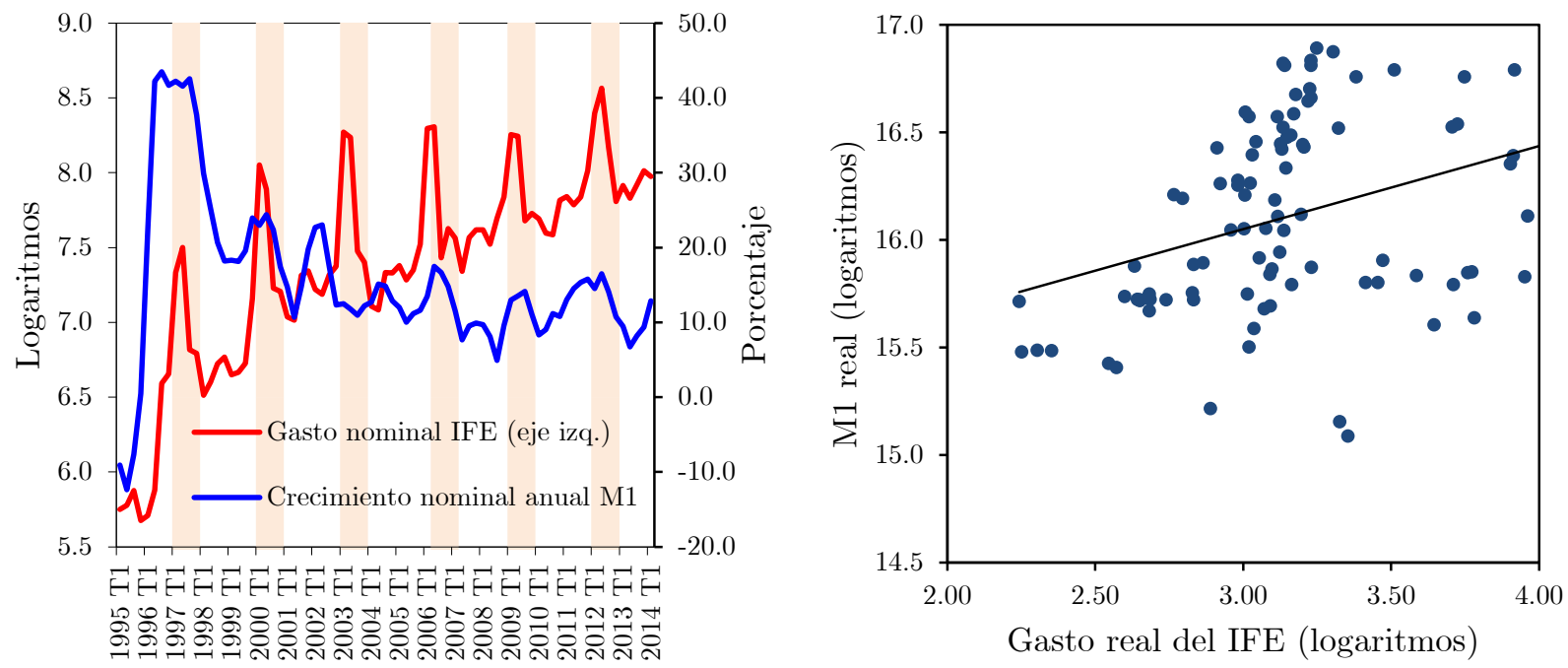

\subsection{Estimación y resultados}

Para estimar la demanda por dinero primeramente se sigue la metodología desarrollada por Pesaran, Shin y Smith (2001, PSS en adelante) que prueba la existencia de una relación de largo plazo entre las variables involucradas. En caso de que esta relación exista, entonces la demanda por saldos reales se estima utilizando un modelo autoregresivo de rezagos distribuidos (ARDL, por las siglas en inglés Autoregressive Distributed Lag).

Hay dos ventajas por las que se decidió utilizar esta metodología. En primer lugar, el modelo ARDL es una forma funcional flexible que admite diversas reparametrizaciones. ${ }^{32}$ Por ejemplo, el modelo puede reparametrizarse como un modelo de corrección de errores.

\footnotetext{
${ }^{30}$ Con la reforma constitucional en materia electoral, publicada en febrero de 2014, el IFE se transformó en el Instituto Nacional Electoral (INE).

${ }^{31}$ Se considera que el gasto del INE (IFE anterior) sea una aproximación para el aumento estacional total del gasto en meses previos a elecciones.

${ }^{32}$ Por ejemplo, el modelo de rezagos distribuidos popularizados por Goldfeld (1973) para la estimación de demandas de dinero, así como el modelo de corrección de error utilizado por Baba, Hendry y Starr (1992) son casos especiales del ARDL.
} 
Ello ayuda a que sea más fácil investigar distintos aspectos de la relación entre las variables (Banerjee, Dolado, Galbraith y Hendry, 1993). De la misma manera, la flexibilidad de este modelo permite incorporar la dinámica que exista en los datos, a través del uso de rezagos, una característica importante al tratarse de series de tiempo. En segundo lugar, como lo demuestran PSS, el modelo ARDL puede capturar relaciones de largo plazo entre las variables, sin importar si dicha relación es una relación de cointegración o no. Es decir, si las variables son integradas de orden 1 y existe una relación de cointegración entre ellas, entonces la estimación de un ARDL puede capturar dicha relación. Adicionalmente, si las variables son estacionarias, pero aun así existe una relación de largo plazo entre ellas, la estimación de un ARDL también capturará dicha relación. Esto es importante para estimar una demanda de dinero para el caso de México ya que, como lo muestran Capistrán y Ramos-Francia (2009), Chiquiar et al. (2010), y Noriega et al. (2013) la inflación en México parece haber transitado de ser una variable no estacionaria a una estacionaria coincidiendo aproximadamente con la fecha en la que el Banco de México adoptó formalmente un esquema de objetivos de inflación (2001). En efecto, encontrar relaciones de largo plazo puede dificultarse si no se utiliza una estrategia de estimación robusta al grado de persistencia de las series. Los detalles técnicos de esta metodología se presentan en el Apéndice II.

A continuación, se presentan los resultados de la estimación de la demanda por dinero para el periodo en que el Banco de México ha seguido el esquema de política monetaria de objetivos de inflación. Primeramente, se enlistan las variables consideradas en la estimación de la demanda por dinero.

Variables

$(m-p)_{t}$ : logaritmo de M1 en términos reales;

$y_{t}^{p i b}$ : logaritmo del Producto Interno Bruto (base 2008); $;^{33}$

$y_{t}^{\text {rem }}$ : logaritmo del total de remesas en pesos en términos reales; ${ }^{34}$

$i_{t}$ : tasa de interés de los CETES a 28 días promedio del trimestre;

$d 08 T 3_{t}$ : Variable dicotómica que toma el valor de 1 a partir del tercer trimestre del 2008 .

$e b p_{t}=i_{t}-i_{t}^{u s}-\Delta e_{t}$ : efecto balance de portafolio

$i_{t}^{u s}$ : tasa de interés de los Billetes del Tesoro a 3 meses para Estados Unidos;

$\Delta e_{t}$ : tasa de depreciación del tipo de cambio peso-dólar;

\footnotetext{
${ }^{33}$ A partir del 20 de agosto de 2013 el Instituto Nacional de Estadística y Geografía (INEGI) modificó el año base de la información correspondiente al Sistema de Cuentas Nacionales de México (SCNM), actualizándolo a 2008. Entre las series que se reemplazan se encuentran el PIB trimestral a precios de 2008, y el PIB a precios corrientes, base 2008 .

${ }^{34}$ Para el caso de las remesas, se utiliza el total de remesas familiares, serie obtenida del Banco de México. Las remesas se expresan en pesos constantes, por lo cual se transforman utilizando el tipo de cambio promedio del periodo, se deflactan utilizando el INPC, y finalmente se convierten en logaritmos.
} 
if $e_{t}$ : logaritmo del gasto neto en términos reales del sector público en el Instituto Federal Electoral;

$\boldsymbol{D}_{t}=[D S 1, D S 2, D S 4]$ : variables dicotómicas centradas para controlar por factores estacionales.

En el proceso de estimación de la demanda por dinero se probaron diferentes combinaciones entre este conjunto de variables, pero en general no se encontró una relación estadísticamente significativa entre los niveles de $(m-p)_{t}, e b p_{t}$ e if $e_{t}{ }^{35}$ Sin embargo, estas variables sí son estadísticamente significativas cuando son incluidas en diferencias $\left[\begin{array}{ll}\Delta e b p_{t} \text { y } \Delta i f e_{t}\end{array}\right]$, esto es, el gasto en el proceso electoral y las decisiones de portafolio no tienen una relación de largo plazo con la demanda por dinero, más sí tienen un impacto sobre ésta en el corto plazo.

Sea $\boldsymbol{x}_{t}=\left[y_{t}^{p i b}, y_{t}^{r e m}, i_{t}\right]$ entonces, siguiendo la notación en PSS, el modelo de corrección de error para realizar la prueba de una relación de largo plazo entre las variables es el siguiente: ${ }^{36}$

$$
\begin{aligned}
\Delta(m-p)_{t} & =\pi_{y}(m-p)_{t-1}+\boldsymbol{\pi}_{\boldsymbol{x}} \boldsymbol{x}_{t-1}+\delta d 08 T 3_{t}+\sum_{i=1}^{q-1} \Gamma_{\mathrm{i}} \Delta(m-p)_{t-i}+\sum_{i=0}^{q-1} \psi_{i} \Delta \boldsymbol{x}_{t-i} \\
& +\boldsymbol{\Phi} \boldsymbol{D}_{t}+u_{t}
\end{aligned}
$$

En el Cuadro 4 se resumen los resultados de la estimación del modelo de corrección de error para efectuar la prueba de relación de niveles entre $(m-p)_{t} \mathrm{y}\left[y_{t}^{\text {pib }}, y_{t}^{\text {rem }}, i_{t}\right]$ para diferentes rezagos $(q=1, \ldots, 4)$. La estimación se realiza para diferentes valores de $q$ debido a que, como menciona PSS, esta especificación supone que los errores $u_{t}$ no presentan correlación serial, por lo que es importante que el orden del rezago $q$ se elija apropiadamente. Por tanto, en las columnas 2 y 4 del Cuadro 4 se presenta el estadístico de multiplicador de Lagrange (LM) para probar la hipótesis de ausencia de correlación serial de orden 1 y 4, además de su correspondiente valor-p (columnas 3 y 5 ). Adicionalmente, con la finalidad de verificar la normalidad de los residuales, en la columna 6 se presenta el valor-p del estadístico Jarque-Bera (JB) para las diferentes especificaciones estimadas. En la columna 7 se muestra el estadístico F que prueba la hipótesis conjunta $\pi_{y}=0$ y $\boldsymbol{\pi}_{x}=\mathbf{0}$ (bajo esta hipótesis, no existe relación de largo plazo entre la cantidad real de dinero y sus determinantes). Dado que el modelo en la ecuación (2) no incluye

\footnotetext{
${ }^{35}$ Por motivos de síntesis y claridad, estos resultados no son presentados en el texto, sin embargo, están disponibles previa petición a los autores.

${ }^{36}$ Obsérvese que la notación en la ecuación (2) se usa para clarificar la aplicación de la prueba conjunta $\pi_{y}=0$ y $\boldsymbol{\pi}_{x}=\mathbf{0}$, separando los parámetros como en PSS. Sin embargo, esta ecuación parte de la formulación tradicional de los modelos de corrección de error. Para ver esto, considérese el vector $\boldsymbol{z}_{t}=\left(y_{t}, \boldsymbol{x}_{t}\right)$. Entonces, omitiendo las variables dicotómicas por simplicidad, la ecuación (2) puede ser escrita en forma de un modelo de corrección de error de la siguiente manera: $\Delta y_{t}=\boldsymbol{\pi}^{\prime} \mathbf{z}_{t-1}+\sum_{i=1}^{q-1} \boldsymbol{\varphi}_{i}^{\prime} \Delta \boldsymbol{z}_{t-i}+\boldsymbol{\omega}^{\prime} \Delta \boldsymbol{x}_{\boldsymbol{t}}+u_{t}$, donde $\boldsymbol{\pi}, \boldsymbol{\varphi}$ у $\boldsymbol{\omega}$ son vectores de parámetros. Así, bajo el supuesto de que hay una relación de largo plazo entre los niveles de las variables (las condiciones detalladas para que esto se dé pueden ser consultadas en PSS), es posible expresar a $\boldsymbol{\pi}=\alpha \boldsymbol{\beta}^{\prime}$, tal que: $\Delta y_{t}=\alpha \boldsymbol{\beta}^{\prime} \mathbf{z}_{t-1}+\sum_{i=1}^{q-1} \boldsymbol{\varphi}_{i}^{\prime} \Delta \mathbf{z}_{t-i}+\boldsymbol{\omega}^{\prime} \Delta \boldsymbol{x}_{\boldsymbol{t}}+u_{t}$, en donde $\alpha$ es el parámetro que puede interpretarse como la velocidad de ajuste del modelo de corrección de error, y $\boldsymbol{\beta}$ como el vector de parámetros de la relación de largo plazo.
} 
constante, este estadístico se debe comparar con los valores críticos denominados como Caso I en PSS para $k=3$ (número de variables explicativas en el vector $\boldsymbol{x}_{t}$ ) que se reproducen en el Cuadro AII en el Apéndice II.

Cuadro 4. Estadístico F para probar la existencia de una relación en niveles Muestra: 2001 T1-2014 T1

\begin{tabular}{ccccccc}
\hline \hline $\boldsymbol{q}$ & LM(1) & valor-p & LM(4) & valor-p & JB & F \\
\hline 1 & 2.408 & 0.128 & 1.617 & 0.190 & 0.480 & $14.258^{* * *}$ \\
2 & 0.037 & 0.849 & 1.553 & 0.209 & 0.976 & $3.960^{* *}$ \\
3 & 1.475 & 0.233 & 0.435 & 0.783 & 0.887 & $5.718^{* * *}$ \\
4 & 2.664 & 0.113 & 1.063 & 0.395 & 0.803 & $4.541^{* * *}$ \\
\hline \hline
\end{tabular}

$*, * *,{ }^{* * *}$ Denotan el rechazo de la hipótesis nula tanto en el caso en que las variables son $\mathrm{I}(0)$ como cuando son I(1) al nivel de significancia de $0.10,0.05$ y 0.01 , respectivamente.

Como puede apreciarse del Cuadro 4, ninguna de las cuatro especificaciones de rezagos estimada manifiesta problemas de correlación serial ni de no normalidad al nivel de significancia de 0.05. Entonces, de los resultados del Cuadro 4 se concluye que para cualquier número de rezagos $(q=1, \ldots, 4)$ utilizados en la estimación de la ecuación $(2)$, se rechaza la hipótesis nula de no existencia de una relación en niveles entre las variables, al menos al nivel de significancia de 0.05, sin importar si éstas son estacionarias o integradas de orden uno. Por tanto, esta evidencia revela que existe una relación de largo plazo entre $(m-p)_{t} \mathrm{y}\left[y_{t}^{p i b}, y_{t}^{r e m}, i_{t}\right]$.

Para estimar la correspondiente relación en niveles, el modelo de corrección de error descrito por la ecuación (2) se reparametriza en la forma de un modelo ARDL como el discutido en Pesaran y Shin (1999). Dado que el modelo con un rezago $(q=1)$ es el que rechaza con mayor potencia la hipótesis de ausencia de relación entre los niveles de las variables, y por cuestiones de grados de libertad y parsimonia en la estimación, se deja el valor de $q$ en 1 . Entonces, la especificación ARDL queda de la siguiente manera:

$$
\begin{aligned}
(m-p)_{t} & =\beta_{p i b} y_{t}^{p i b}+\beta_{r e m} y_{t}^{r e m}+\beta_{i} i_{t}+\gamma d 08 T 3_{t}+\phi_{1}(m-p)_{t-1} \\
& +\psi_{p i b} \Delta y_{t}^{p i b}+\psi_{r e m} \Delta y_{t}^{r e m}+\psi_{i} \Delta i_{t}+\boldsymbol{\Phi} \boldsymbol{D}_{\boldsymbol{t}}+u_{t}
\end{aligned}
$$

Sin embargo, para estimar adecuadamente los parámetros de largo plazo, esta especificación se aumenta para incluir hasta cuatro rezagos de las variables del cambio en el gasto en el proceso electoral $\left(\Delta i f e_{t}\right)$ y el cambio en el efecto de portafolio $\left(\Delta e b p_{t}\right)$, que como fue discutido anteriormente, tienen un impacto en la demanda por saldos reales en el corto plazo y su ausencia en el modelo puede llevar a incurrir en un sesgo en los parámetros estimados por omisión de variables. Así se llega a nuestro modelo general ARDL para estimar la demanda por dinero

$$
\begin{gathered}
(m-p)_{t}=\beta_{p i b} y_{t}^{p i b}+\beta_{r e m} y_{t}^{r e m}+\beta_{i} i_{t}+\gamma d 08 T 3_{t}+\phi_{1}(m-p)_{t-1}+\psi_{p i b} \Delta y_{t}^{p i b}(4) \\
+\psi_{r e m} \Delta y_{t}^{r e m}+\psi_{i} \Delta i_{t}+\sum_{i=0}^{4} \lambda_{i} \Delta e b p_{t-i}+\sum_{i=0}^{4} \mu_{i} \Delta i f e_{t-i}+\boldsymbol{\Phi} \boldsymbol{D}_{\boldsymbol{t}}+u_{t}
\end{gathered}
$$


Con la finalidad de obtener un modelo ARDL parsimonioso y estadísticamente sólido se plantea una reducción de este modelo general, ecuación (4), siguiendo la metodología de lo General a lo Específico, para lo cual se emplea el algoritmo de selección de modelos llamado Autometrics. ${ }^{37}$ A continuación se presentan los resultados del modelo ARDL reducido (errores estándar en paréntesis) ${ }^{38}$

$$
\begin{aligned}
& (m-p)_{t}=0.07 y_{t}^{p i b}+0.013 y_{t}^{r e m}-0.36 i_{t}+0.009 d 08 T 3+0.92(m-p)_{t-1} \\
& \begin{array}{llll}
(0.03) & (0.008) & (0.12) & (0.005)
\end{array} \\
& -0.07 \Delta e b p_{t-1}+0.05 \Delta e b p_{t-4}+0.02 \Delta \text { ife }_{t}-0.04 D S 1-0.04 D S 2-0.04 D S 3 \\
& \begin{array}{lllll}
(0.03) & (0.02) & (0.01) & (0.01) & (0.01)
\end{array}
\end{aligned}
$$

$$
\begin{aligned}
& \text { Estimación por } M C O, 2001 T 1-2014 T 1(T=53), \widehat{\sigma_{\epsilon}}=0.013, F_{A R C H(1)}(1,50)=0.962, F_{A R C H(4)}(4,44)=0.472, \\
& F_{R E S E T}(1,39)=0.184, F_{\operatorname{ar}(1)}(1,39)=0.448, F_{\operatorname{ar}(1-4)}(4,36)=0.649, F_{h e t}(18,32)=0.082, N(D H)=0.583 .
\end{aligned}
$$

donde $\widehat{\sigma_{\epsilon}}$ denota el error estándar de la regresión. Por otro lado, para facilitar la interpretación de las pruebas de diagnóstico los resultados se reportan en forma de su valor- $p$ correspondiente. $F_{A R C H(j)}$ es la prueba de errores ARCH de orden $j, F_{\text {het }}$ corresponde a la prueba de White de heteroscedasticidad, $F_{\operatorname{ar}(j)}$ la prueba de correlación serial de orden $j, N(D H)$ la prueba de normalidad de Doornik-Hansen y $F_{R E S E T}$ la prueba de no-linealidades. Dados estos resultados se puede concluir que el modelo ARDL estimado no tiene problemas de errores ARCH, autocorrelación, heteroscedasticidad incondicional, no normalidad y no-linealidades. En la Gráfica 9 se ilustran los residuales y su distribución.

\footnotetext{
${ }^{37}$ En el uso del algoritmo Autometrics es necesario seleccionar las pruebas de diagnóstico y especificación a las que se somete el modelo econométrico estimado; además de elegir el correspondiente nivel de significancia para efectuar dichas pruebas. Específicamente, en nuestra estimación las siguientes pruebas de diagnóstico fueron aplicadas: prueba LM de correlación serial, normalidad, heteroscedasticidad, heteroscedasticidad condicional o errores ARCH. Además, el modelo se somete a las pruebas de especificación de no-linealidad, y de un cambio estructural en el tercer trimestre de 2008. Para todas las pruebas se elige el nivel de significancia de 5\%. Para una discusión detallada sobre Autometrics véase Doornik y Hendry (2007), Doornik (2009), y Ericssson y Kamin (2008). Autometrics es implementado por el módulo PcGive versión 13.1 del software Oxmetrics 6.1.

${ }^{38}$ Como se explica más adelante, la ecuación (5) es sometida a diversas pruebas de estabilidad de los parámetros. Con la finalidad de mejorar el desempeño de la ecuación estimada ante dichas pruebas, el modelo general en la ecuación (4) incluye dos variables dicotómicas adicionales de pulso (no mostradas) que toman el valor de 1 en el cuarto trimestre de 2001 y en el segundo de 2012, y cero en el resto de las observaciones. Estas variables son el resultado del procedimiento de detección de observaciones aberrantes de Autometrics y, por tanto, también son estimadas en la ecuación (5), resultando estadísticamente distintas de cero. Es importante mencionar que el análisis que se presenta en la siguiente sección sobre indicadores basados en agregados monetarios, no se ve en lo absoluto modificado si estas variables dicotómicas son eliminadas de la estimación. Los resultados pueden ser solicitados a los autores.
} 
Gráfica 9. Residuales (ecuación 5) y su densidad
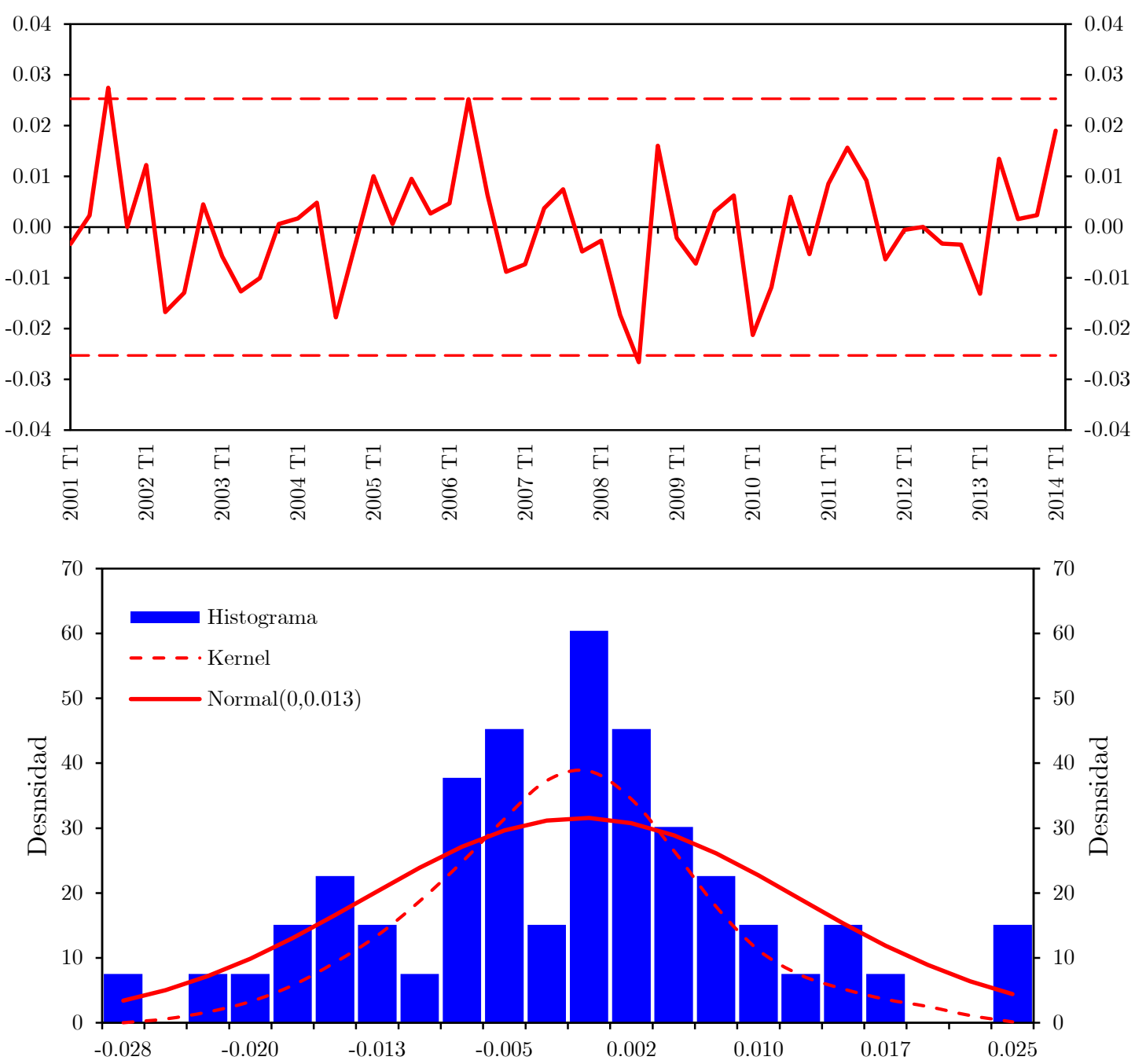

De la ecuación (5) es posible calcular los parámetros de largo plazo como se describe en el Apéndice II. ${ }^{39}$ Entonces, la demanda por dinero de largo plazo está dada por la siguiente ecuación (errores estándar en paréntesis):

$$
(m-p)_{t}=\underset{(0.03)}{0.98 y_{t}^{p i b}}+\underset{(0.09)}{0.18} y_{t}^{\text {rem }}-\underset{(1.55)}{4.66 i_{t}}+\underset{(0.07)}{0.12 d 08 T 3_{t}}
$$

La demanda por dinero de largo plazo estimada presenta una elasticidad unitaria respecto al ingreso, al igual que la obtenida por NRR, véase ecuación (1). Sin embargo, las diferencias respecto a la demanda por dinero estimada por NRR se manifiestan en el resto de los coeficientes (los cuales resultan todos estadísticamente significativos a niveles

\footnotetext{
${ }^{39}$ Los parámetros de largo plazo son calculados como una función no lineal de los parámetros de la ecuación (5), las cifras pueden no coincidir debido al redondeo.
} 
convencionales). Primero, nótese que la semi-elasticidad de la tasa de interés es más del doble de la reportada en la ecuación (1). ${ }^{40}$ Esto es, una vez que se considera un período muestral que inicia con la implementación del esquema de política monetaria de metas de inflación, y el cumplimiento de las diferentes condiciones que ello implica, se encuentra una mayor respuesta de la demanda por saldos reales a los movimientos en la tasa de interés. ${ }^{41}$ En lo que se refiere a las remesas, la estimación arroja una elasticidad de largo plazo de 0.18, mostrando la relevancia de esta variable en la determinación de largo plazo de la demanda por dinero. Por último, la variable dicotómica que se activa en el tercer trimestre de 2008 tiene un efecto positivo en la demanda por dinero. Como se discutió previamente, dados los diferentes acontecimientos presentados en tal fecha no es posible distinguir específicamente a que se puede adjudicar tal variación.

Adicional a las pruebas de diagnóstico y especificación, se lleva a cabo el análisis de estabilidad de los parámetros del modelo estimado de demanda por dinero. Específicamente, se realizan pruebas recursivas tanto hacia adelante como hacia atrás sobre el ARDL en (5); todos los resultados se presentan gráficamente en el Apéndice III. Primeramente, en la Gráfica AIII.1 se presentan los residuales recursivos que en general sirven para detectar observaciones aberrantes o cambios en los coeficientes, de los cuales no se puede rechazar que el modelo es estable. Por otro lado, en las Gráficas AIII.2 a AIII.5 se despliegan cuatro pruebas recursivas de cambio estructural: (i) prueba de Chow de un paso adelante, en la que se comparan la suma de residuales al cuadrado de las estimaciones recursivas sólo incluyendo una observación adicional; (ii) prueba de Chow de punto de quiebre, que compara la estimación recursiva con la estimación de la muestra completa; (iii) prueba de Chow de pronóstico, que compara la estimación recursiva con la estimación de la muestra base; y (iv) prueba de Chow clásica, donde la muestra se divide en dos y se prueba si los coeficientes de largo plazo son iguales en ambas submuestras. ${ }^{42}$

Primeramente, obsérvese de la prueba de Chow de un paso hacia adelante (Gráfica AIII.2) hay sólo un periodo que rechaza la nula de parámetros constantes al nivel de

${ }^{40}$ Otras estimaciones del valor de esta semi-elasticidad para México pueden encontrarse, por ejemplo, en Cuthbertson y Galindo (1999), quienes reportan un valor de -1.2 en la muestra 1978-1990, y en Garcés (2002), cuya estimación para el período 1980-2000 resulta en -1.5. Para una comparación internacional del valor estimado de esta semi-elasticidad véase Sriram (2001), en donde se reporta una semi-elasticidad de entre - 2.8 y -9.6 para Estados Unidos, y de entre -0.1 y -0.3 para Singapur, por citar algunos ejemplos.

${ }^{41}$ En Svensson (2011), por ejemplo, se discute sobre las condiciones para establecer un esquema de metas de inflación exitoso en economías emergentes. Menciona que algunos de los elementos, que de acuerdo a la evidencia, hicieron más factible la implementación de este esquema de política monetaria son: (i) la estabilidad de precios como el objetivo principal de la política monetaria; (ii) la ausencia de dominancia fiscal; (iii) la independencia del banco central; (iv) el consenso en la economía doméstica respecto a la importancia de la meta de inflación; (v) un cierto entendimiento del mecanismo de transmisión, y una razonable capacidad para afectar a las tasas de interés a corto plazo; y (vi) que mercados y sistema financiero funcionen razonablemente bien.

${ }^{42}$ Estas pruebas de estabilidad del modelo no escogen endógenamente el punto de quiebre sino que prueban la hipótesis de que existe un cambio estructural en los parámetros del modelo en una fecha predeterminada. Como se muestra en los resultados gráficos del Apéndice III, las fechas examinadas involucran aproximadamente el 70 por ciento de la muestra. Como ya se explicó con anterioridad, esto se debe a que en la mayoría de estas pruebas es necesario establecer una submuestra inicial, la cual se considera en aproximadamente el 30 por ciento del total de la muestra. 
significancia de 0.05 , pero ninguno lo hace al nivel de $0.01 .{ }^{43}$ Cabe aclarar, que al comparar estadísticamente la suma de residuales al cuadrado en una muestra con otra estimación que incluye sólo una observación adicional, este período es sugerente de una observación aberrante (en efecto, para el caso de la Gráfica AIII.2 en la prueba recursiva hacia atrás el rechazo ocurre durante el cambio referido en el sistema nominal de la economía (20012002)). En lo que se refiere a las pruebas de Chow de punto de quiebre (Gráfica AIII.3), de pronóstico (Gráfica AIII.4) y clásica (Gráfica AIII.5) no se revela ninguna evidencia de inestabilidad en el modelo estimado en la ecuación (5). Así, los resultados sugieren que no se puede rechazar la hipótesis nula de que los parámetros son constantes al nivel de $5 \%$, es decir de que la demanda por dinero estimada en la ecuación (5) es estable.

Para completar este análisis de estabilidad del modelo, las Gráficas AIII.6 a AIII.9 presentan los resultados de la estimación recursiva de los parámetros de largo plazo de la demanda por dinero. Al igual que en la sección 2.3, los coeficientes recursivos hacia adelante y hacia atrás son analizados usando tanto la forma- $X$ como la forma- $R$.

En términos generales, como era de esperarse, los parámetros lucen mucho más estables en el ejercicio recursivo forward que en el backward. Además, es de destacar que los resultados backward de la forma- $R$ lucen más estables que los de la forma- $X$. Esto es, una vez que se "pulen" los parámetros de largo plazo de los efectos de corto plazo es más fácil apreciar que éstos han permanecido estables a lo largo del período. En particular, la elasticidad de la demanda por dinero al PIB (Gráfica AIII.6) se muestra consistentemente estable tanto en el ejercicio recursivo hacia atrás (backward) como hacia adelante (forward), sobretodo en su forma-R. Un fenómeno muy parecido puede verse en el caso de la elasticidad a las remesas (véase Gráfica AIII.7). Por su parte, la Gráfica AIII.8 revela que la semielasticidad a la tasa de interés se ha mantenido relativamente estable, si acaso observando una muy ligera disminución (volviéndose más negativa). Por último, la Gráfica AIII.9 presenta los resultados recursivos para la variable dicotómica que se activa en el tercer trimestre de 2008. Debido a esto, el ejercicio forward sólo se puede realizar a partir de que la variable se activa. Sin embargo, en ambos ejercicios luce bastante estable aunque en el caso del recursivo backward se observa que esta variable casi siempre está al límite de la significancia estadística.

Considerando en su conjunto la evidencia del análisis de estabilidad sobre el modelo ARDL estimado, es posible concluir que la demanda por dinero ha permanecido (estadísticamente, a un nivel elevado de confianza) estable a lo largo del periodo analizado.

\footnotetext{
${ }^{43}$ Estas pruebas fueron verificadas tomando en consideración los niveles de significancia usuales (0.10, 0.05 y 0.01). Sin embargo, por motivos de espacio y para ser consistentes con el resto de las pruebas estadísticas que se emplean en el resto del estudio, se decidió sólo mostrar gráficamente las pruebas al nivel del 0.05 . El resto de los resultados puede ser solicitado a los autores. En general, este tipo de resultados de estabilidad basados en pruebas recursivas, típicamente suelen ilustrase normalizando el valor del estadístico de prueba en relación al valor crítico a cierto nivel de significancia, con la finalidad de que la interpretación sea más sencilla.
} 


\section{Estimación de dos indicadores que utilizan agregados monetarios}

En esta sección se emplea la demanda de dinero de largo plazo estimada para calcular dos indicadores que pueden utilizarse para evaluar presiones inflacionarias. El primero es el denominado "brecha del dinero", que consiste en medir la desviación de M1 real de su relación de largo plazo con el PIB y con la tasa de interés (Siklos, 2010). El segundo indicador es el propuesto por Reynard (2007), llamado $m^{*}$. Este indicador se basa en la estimación del índice de precios que es congruente con la cantidad de M1 en la economía una vez que ésta se ajusta por las tendencias de largo plazo del PIB y de la tasa de interés. ${ }^{44,45}$

\subsection{Brecha del dinero}

A partir de la demanda de dinero de largo plazo estimada en la sección anterior (ecuación (6)), es posible construir una medida de la diferencia entre los saldos reales medidos con M1, y los saldos reales que la demanda estima para cada momento en el tiempo:

$$
(\text { Brecha del dinero })_{t}=(m-p)_{t}-\left[0.98 y_{t}^{p i b}+0.18 y_{t}^{r e m}-4.66 i_{t}+0.12 d 08 T 3_{t}\right](7)
$$

La medida es conocida en términos generales como error de corrección debido a que, cuando existe una relación de equilibrio de largo plazo entre las variables, las desviaciones del equilibrio (de largo plazo) tienden a corregirse. De esta forma, cuando los saldos reales observados están por arriba de los estimados por la relación de largo plazo, se interpreta como un exceso de dinero en la economía que puede generar inflación en un futuro (de ahí que a este indicador también se le conozca como "exceso de dinero"). Esto último ya que existiría presión sobre los precios para aumentar, de tal forma que los saldos reales disminuyan y regresen a su relación de largo plazo con el ingreso y la tasa de interés. Por otro lado, si los saldos reales observados están por abajo de los estimados por la relación de largo plazo, entonces existiría presión para que los precios disminuyeran para elevar los saldos reales y restaurar el equilibrio. De esta forma, errores de corrección positivos podrían

\footnotetext{
${ }^{44} \mathrm{El}$ indicador $m^{*}$ se calcula de forma parecida al indicador $p^{*}$, utilizado en algunas ocasiones para pronosticar la inflación, principalmente en los $90 \mathrm{~s}$. La diferencia entre $m^{*}$ y $p^{*}$ es que el primero se calcula utilizando la tendencia de largo plazo del PIB y la tendencia de largo plazo de la tasa de interés, mientras que para el segundo se utilizan los valores observados del PIB real y de la tasa de interés. También existen algunas diferencias en cuanto a interpretación. El indicador $p^{*}$ corresponde a una medida de exceso de liquidez, mientras que para Reynard, $m^{*}$ corresponde a un indicador de la postura de política monetaria una vez que se ajusta por la velocidad del dinero en equilibrio. Respecto al indicador $p^{*}$, ver Halman, Porter, y Small (1991).

${ }_{45}$ Siguiendo a Reynard (2007) en el cálculo de este par de indicadores empleamos una constante de normalización que es elegida de la siguiente forma. En el cálculo de brecha del dinero la constante es tal que el promedio de $(m-p)_{t}$ es igual al promedio de su relación de largo plazo. En el caso del indicador $m^{*}$, la constante se ajusta para que el promedio de $p_{t}$ sea igual al de $m_{t}^{*}$.
} 
sugerir presiones al alza sobre los precios, mientras que errores de corrección negativos indican lo contrario (ver Kirchgassner y Wolters (2010)).

La Gráfica 10 presenta la brecha del dinero que se obtiene para México a partir de la ecuación de demanda de dinero de largo plazo estimada (ecuación 6), así como la inflación anual del INPC. Es posible observar como la brecha del dinero en general ha sido reducida a lo largo del periodo contemplado. Al principio de la muestra la brecha del dinero es mayormente negativa, mientras que hacia el final de la muestra la brecha del dinero se hace moderadamente positiva. Sin embargo, es importante resaltar el relativamente reducido crecimiento del producto durante 2013 y 2014, en combinación con una brecha del producto registrando una tendencia negativa, inclusive llegando a estimarse en $-0.1 \%$ para el último trimestre de 2013 , y en $-0.82 \%$ para el primer trimestre de 2014 . Esto podrá apreciarse en la siguiente sección.

Gráfica 10. Brecha del dinero calculada con M1 e inflación anual del INPC

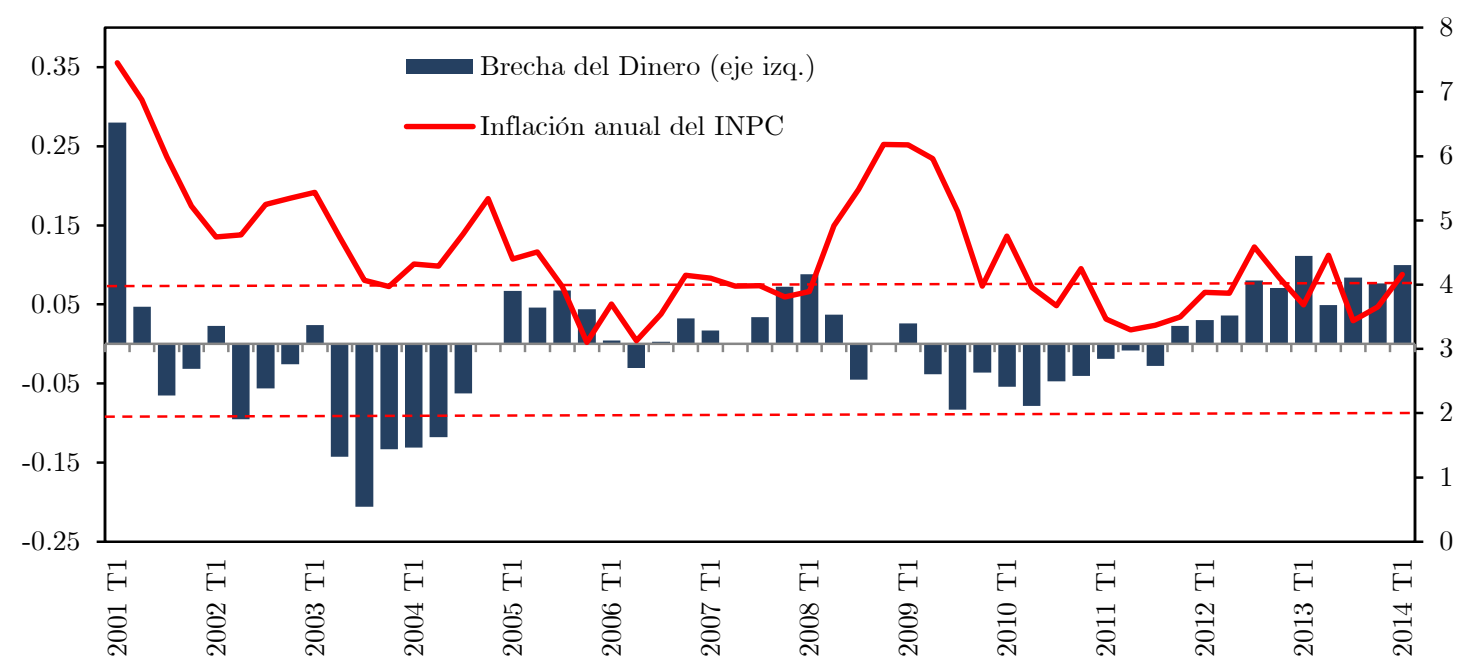

\subsection{Indicador $m^{*}$}

Otro indicador de presiones inflacionarias es el propuesto por Reynard (2006, 2007). Éste se obtiene también a partir de la ecuación (6), pero despejando $p$ y usando el valor de $m$. Sin embargo, un aspecto importante es que, debido a que se está utilizando la ecuación de largo plazo, Reynard argumenta que en vez de utilizar el valor observado de las variables que determinan la demanda por dinero se debe utilizar la tendencia de largo plazo de éstas. De tal forma, el indicador $m^{*}$ se define como:

$$
m^{*} \equiv \hat{p}=m-\left[0.98 y^{\text {pib_tendencia }}+0.18 y^{\text {rem_tendencia }}-4.66 i^{\text {tendencia }}+0.12 d 08 T 3\right]
$$

en donde $y^{\text {pib_tendencia }}, y^{\text {rem_tendencia }}$ e $i^{\text {tendencia }}$ son las tendencias de largo plazo del PIB, remesas y tasa de interés, respectivamente. Estas tendencias son calculadas con el filtro 
Hodrick-Prescott. ${ }^{46}$ De esta manera tenemos que la cantidad de dinero nominal observada (M1) se ajusta por el efecto de la tendencia de largo plazo del PIB, de las remesas y de la tasa de interés. Al ser $m^{*}$ una estimación del nivel de precios que es congruente en el largo plazo con la tendencia del PIB, las remesas y la tasa de interés, este indicador es útil para medir la postura monetaria y para evaluar futuras presiones sobre los precios. Cuando $\mathrm{m}^{*}$ está por arriba del nivel de precios quiere decir que, tanto por el motivo transaccional como por el costo de oportunidad, y dada la cantidad de M1 en la economía, el nivel de precios debería ser mayor al observado. Es decir, una vez que la cantidad de dinero se ajusta por la tendencia de largo plazo del PIB, por la tendencia de largo plazo de las remesas, y por el nivel de la tasa de interés de largo plazo, aquélla es mayor que la que es congruente con los precios. Para corregir este desequilibrio, a menos que ocurra una reducción importante en la cantidad nominal de M1, o un aumento en la tasa de interés, o ambos, el nivel de precios aumentará en el futuro para que los saldos reales sean congruentes con su relación de largo plazo. En el caso anterior, se consideraría que la postura monetaria es laxa, en el sentido de que hay más dinero en la economía del necesario para satisfacer la demanda de dinero, lo que podría sugerir posibles presiones futuras al alza sobre los precios. Como se verá subsecuentemente, esto no fue así.

Reynard (2007) documenta para los casos de Estados Unidos, el área del euro y Suiza que, cuando el indicador $m^{*}$ aumenta por arriba del nivel de precios (aumentando el nivel de la razón dinero a precios por arriba de su nivel de equilibrio), después ocurre un incremento del PIB real por arriba de su tendencia de largo plazo y, eventualmente, un aumento proporcional en el nivel de precios. Sin embargo, dichos ajustes ocurren con rezagos, y tanto la tasa de crecimiento de los precios, como sus rezagos varían con el tiempo, con un ajuste más rápido en ambientes de alta inflación. Reynard también documenta una asimetría importante, en cuanto a que, cuando $m^{*}$ se encuentra por debajo del nivel de precios, no hay una disminución de dicho nivel aunque la inflación se reduce con un cierto rezago. Por lo tanto " $m$ * atrae al nivel de precios para arriba cuando $m^{*}$ aumenta por arriba de $p$, pero una disminución o un nivel relativamente bajo de dinero con respecto a los precios (i.e., $m^{*}<p$ ) es seguido únicamente por una disminución en la tasa de inflación". ${ }^{47}$ Un aspecto más a destacar de lo encontrado por Reynard es que en ninguna de las muestras que analizó encontró aumentos significativos de precios sin que antes hubieran existido los correspondientes incrementos en el dinero (i.e., $m^{*}>p$ ).

La Gráfica 11 presenta el indicador $m^{*}$ y el nivel de precios (observado), $p$, para el caso de México. Resulta útil para la interpretación de $m^{*}$ considerar al mismo tiempo la Gráfica 12 , donde se presenta la diferencia entre $m^{*}$ y el nivel del precios, así como la tasa de inflación anual. Se puede observar que $m^{*}$ ha estado por arriba de $p$, por lo menos dos trimestres consecutivos, en tres ocasiones en la muestra: 2001T1-2002T4, 2006T2-2008T2 y 2011T3-2014T1. Estos episodios, de acuerdo con el indicador $m^{*}$, podrían considerarse

\footnotetext{
${ }^{46}$ Para aplicar esta técnica se utiliza el filtro Hodrick-Prescott con un parámetro de suavizamiento $\lambda=1600$. Los resultados que aquí se analizan son robustos a la utilización de una combinación de distintos filtros, en vez del Hodrick-Prescott.

${ }^{47}$ Reynard utiliza M2- para Estados Unidos (1959.I - 2006.II), para el área del euro (1973.I - 2005.IV) y para Suiza (1975.I - 2005.IV).
} 
como periodos en los que la postura monetaria fue relativamente relajada. En las dos últimas ocasiones hubo un aumento posterior en el nivel de precios.

\section{Gráfica 11. Indicador $\mathrm{m}^{*} \mathrm{y}$ precios} (logaritmos)

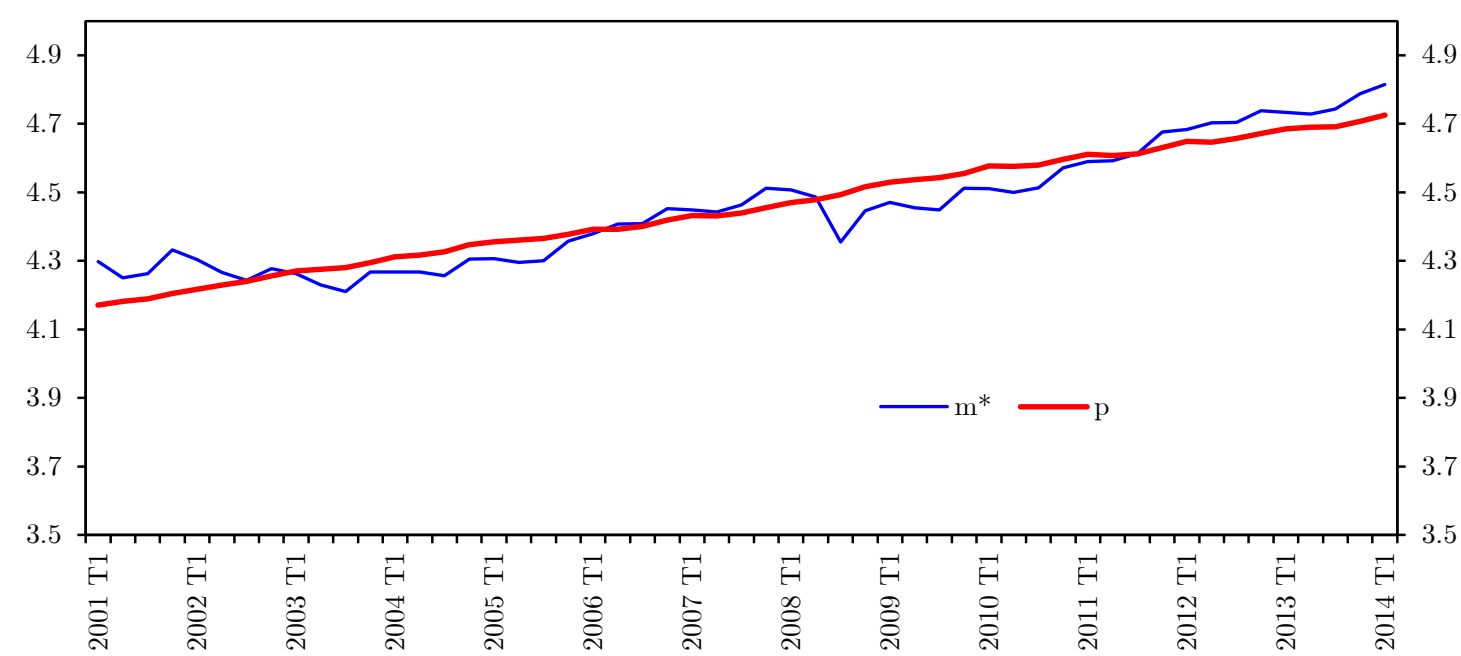

Gráfica 12. m*-p e inflación anual del INPC

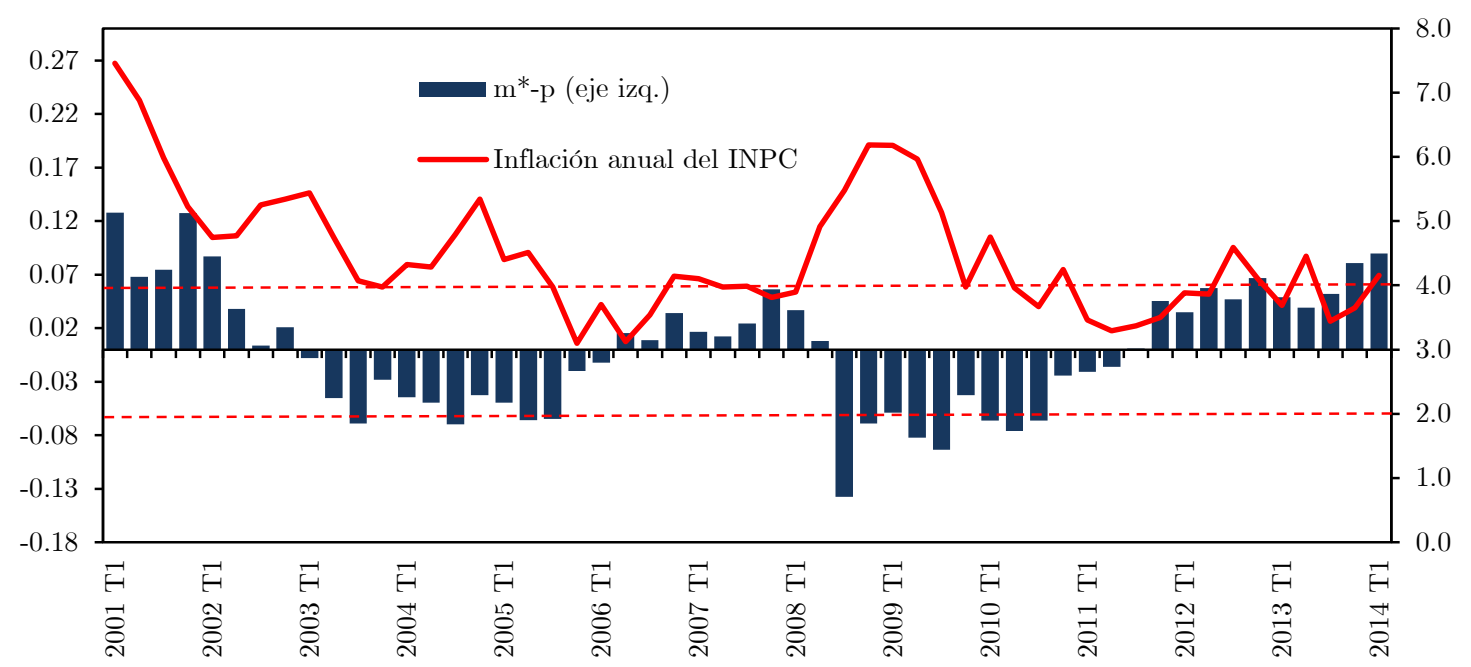

Como se mencionó anteriormente, Reynard (2007) encuentra que cuando el indicador $m^{*}$ está por arriba de $p$, ocurre primero un aumento del nivel del PIB real por arriba de su tendencia de largo plazo (brecha del producto positiva) y después un aumento en el nivel de precios y en la inflación. Ello es indicativo de que el exceso de dinero en la economía genera primero presiones de demanda y posteriormente afecta a los precios. Sin embargo, esta secuencia no se ha observado del todo en el caso de México. 
En la Gráfica 13 se aprecia el indicador $m^{*}$, el nivel de precios (observado), $p$, así como la variable $p+\left(y-y^{\text {pib_tendencia }}\right)$, que es la brecha del producto sumada al nivel de precios para el caso de México. ${ }^{48}$ De los periodos en los que $m^{*}$ ha estado por arriba de $p$ (áreas sombreadas en la Gráfica 13), en el primero existe una brecha del producto negativa que con rezago tiende a cerrarse hasta volverse positiva, mientras que en el segundo se observó, casi simultáneamente, una brecha del producto positiva, y en el último parece haber una brecha del producto ligeramente positiva que se cierra para después volverse negativa.

\section{Gráfica 13. Indicador $\mathrm{m}^{*}$, precios y brecha del producto}

(logaritmos)

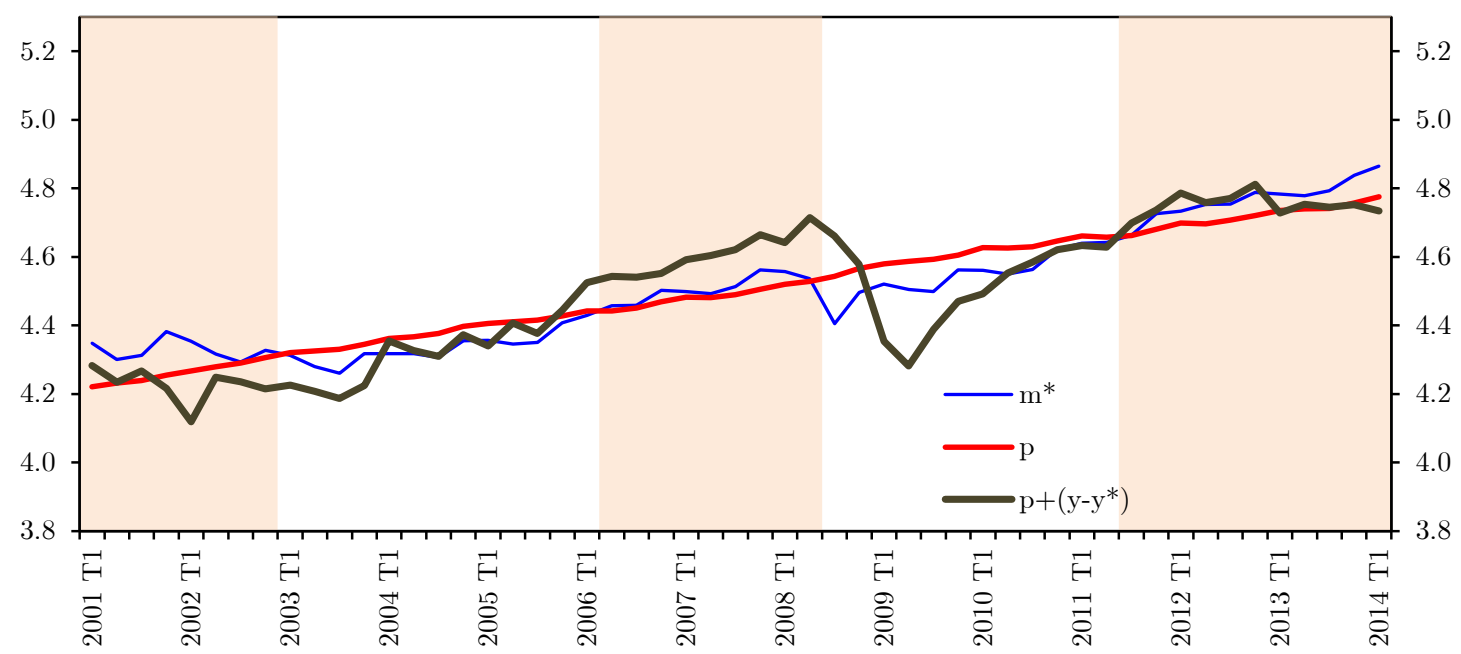

Cabe mencionar que el segundo periodo de brechas positivas coincide con el extraordinario grado de relajamiento monetario en las economías avanzadas, sobre todo en los Estados Unidos. Este relajamiento monetario se transmite a economías como México a través de diferentes canales, a pesar de que, como México, varias de dichas economías operan con un régimen de flotación cambiaria (Rey (2014)). Asimismo, y contrario a lo que se esperaría dado el signo de la brecha del dinero en ese episodio, la economía presentó durante 2013 y 2014, tasas relativamente reducidas de crecimiento, con un grado importante de holgura en sus mercados de insumos. Todo ello es necesario considerarlo en la evaluación de este episodio en cuanto a su señal sobre presiones futuras sobre los precios. En general, al considerar todos los elementos referidos, el mantener una postura monetaria como la mostrada en la Gráfica 13 posiblemente evitó una situación de crecimiento con aún mayor debilidad, sin haber afectado a la inflación y sus perspectivas. En este sentido, nótese que durante dicho episodio la inflación permaneció la mayor parte del tiempo al interior del intervalo de variabilidad de $+/-1$ punto porcentual alrededor de la meta del $3 \% .^{49}$

\footnotetext{
${ }^{48}$ Con fines de que la brecha del producto sea gráficamente ilustrativa, en la Gráfica 13 la brecha del producto $\left(y-y^{\text {pib_tendencia }}\right)$ es multiplicada por 5 .

${ }^{49}$ Incluso, aunque nuestra muestra no considere los últimos tres trimestres de 2014 y los primeros dos de 2015, la inflación general anual actualmente (segundo trimestre de 2015) se encuentra alrededor de su meta
} 


\subsection{Algunas consideraciones sobre el crecimiento de M1, la inflación y el objetivo de inflación}

El indicador $m^{*}$ es en realidad una estimación del índice de precios derivado de la demanda por dinero de largo plazo. Es el índice de precios determinado (implícito) por la cantidad de dinero en la economía, una vez que ésta es ajustada por la cantidad necesaria por el motivo transaccional, así como por el costo de oportunidad de mantener dinero. En este contexto, es ilustrativo calcular la tasa de crecimiento de $m^{*}$ :

$$
\Delta m^{*}=\Delta m-0.98 \Delta y^{\text {pib_tendencia }}-0.18 \Delta y^{\text {rem_tendencia }}+4.66 \Delta i^{\text {tendencia }}-0.12 \Delta d 08 T 3
$$

Así, en la ecuación anterior puede verse que la tasa de crecimiento del indicador $\Delta m^{*}$ puede interpretarse como la tasa de crecimiento de los precios determinada por la tasa de crecimiento de M1, una vez que ésta se ajusta por el crecimiento de la tendencia de largo plazo del PIB, por cambios en las tendencias de largo plazo de las remesas y de la tasa de interés, y por la variable dicotómica (todas ajustadas por sus respectivos coeficientes de largo plazo). ${ }^{50}$ Así, si se calcula la tasa de crecimiento anual de $\Delta m^{*}$, es posible comparar dicha tasa con la tasa de inflación anual así como con el objetivo de inflación del Banco de México.

En el Cuadro 5 se compara la tasa de crecimiento promedio de $m^{*}$ con la inflación anual para el período en que se ha seguido el esquema de política monetaria de metas de inflación. Adicionalmente, se presenta la descomposición de la tasa de crecimiento del indicador $m^{*}$ para apreciar cómo se pasa del crecimiento de M1 al de $m^{*}$.

Como puede observarse, el crecimiento de la tendencia de largo plazo del PIB estimado explica alrededor de 2.2 puntos de los 11.83 del crecimiento de M1 (el 19\%), mientras que la tasa de interés explica alrededor de 4.5 puntos (el 38\%). Por su parte, el incremento en las remesas parece explicar 1.1 puntos (el 9\%), y la variable cualitativa d08T3 explica 0.9 punto del crecimiento de M1 (el 8\%). De esta manera, la tasa de crecimiento promedio de $m^{*}$ es de 3.09\%. Así, el crecimiento de $m^{*}$ durante el periodo 2001-2014 es inferior a la

de 3 por ciento y la inflación subyacente más de medio punto por debajo de dicha cifra. Las perspectivas para los siguientes trimestres es que esta situación continúe.

${ }^{50}$ Nótese que al ser $\Delta m^{*}$ una combinación lineal de los parámetros estimados de la demanda por dinero de largo plazo y de las tasas de crecimiento de las tendencias de largo plazo de las variables, entonces es posible calcular la varianza de $\Delta m^{*}$ como la varianza de una combinación lineal de variables aleatorias. Considérese un vector de variables aleatorias $X$. Si se realiza una transformación lineal del vector $X$ de manera que el nuevo vector aleatorio $Z$ sea: $Z=b_{0}+b_{1} X_{1}+b_{2} X_{2}+\cdots+b_{n} X_{n}$. Entonces la varianza (Var) de esta combinación lineal de variables aleatorias puede ser calculada como: $\operatorname{Var}(Z)=\sum_{i=1}^{n} b_{i}^{2} \operatorname{Var}\left(X_{i}\right)+$ $\sum_{j=1}^{n} \sum_{i=1}^{n} b_{i} b_{j} \operatorname{Cov}\left(X_{i} X_{j}\right)$. Siguiendo lo anterior, el cálculo de la varianza de $\Delta m^{*}$ puede efectuarse al considerar que las variables aleatorias son los parámetros estimados de la demanda por dinero de largo plazo, y los coeficientes $\left(b_{i}{ }^{\prime} s\right)$ son las tasas de crecimiento promedio de las tendencias de las variables de la demanda por dinero (nótese que estas tasas de crecimiento las interpretamos como determinísticas, puesto que son eventos observados). 
inflación anual general y subyacente, además de ser muy parecida a la meta de inflación del Banco de México.

Cuadro 5. Tasa de crecimiento de $\boldsymbol{m}^{*}: 2001 \mathrm{~T} 1-2014 \mathrm{~T} 1^{1 /}$

(Porcentaje promedio anual)

\begin{tabular}{l|c|c|c}
\hline \hline Componente & Promedio & Coef. & $\%$ \\
\hline Crecimiento promedio anual M1 & 11.83 & - & 11.83 \\
\hline Crecimiento anual de la tendencia del PIB & 2.29 & -0.98 & -2.24 \\
Crecimiento anual Remesas tendencia & 6.00 & -0.18 & -1.08 \\
Crecimiento Tasa de Interés tendencia & -0.96 & 4.66 & -4.49 \\
Diferencia d08T3 & 7.67 & -0.12 & -0.92 \\
\hline \hline Crecimiento promedio anual $\boldsymbol{m}^{*}$ & & & 3.09 \\
$\quad$ Desviación estándar $\Delta m^{*}$ & & & $(1.14)$ \\
Inflación general promedio anual & & & 4.37 \\
Inflación subyacente promedio anual & & & 3.93 \\
\hline I/Lifo."
\end{tabular}

1/ Las cifras pueden no coincidir debido al redondeo.

Para tener un punto de referencia y un contexto más claro del valor estimado de $\Delta m^{*}$, se realiza un ejercicio de simulación Monte Carlo para obtener la forma en que éste se distribuye. Los resultados son ilustrados en la Gráfica 14, y los detalles de este ejercicio son explicados en el Apéndice IV.

Gráfica 14. Distribución del crecimiento anual de $\mathrm{m}^{*}$

(Simulación Monte Carlo 10,000 simulaciones de la ecuación 9)

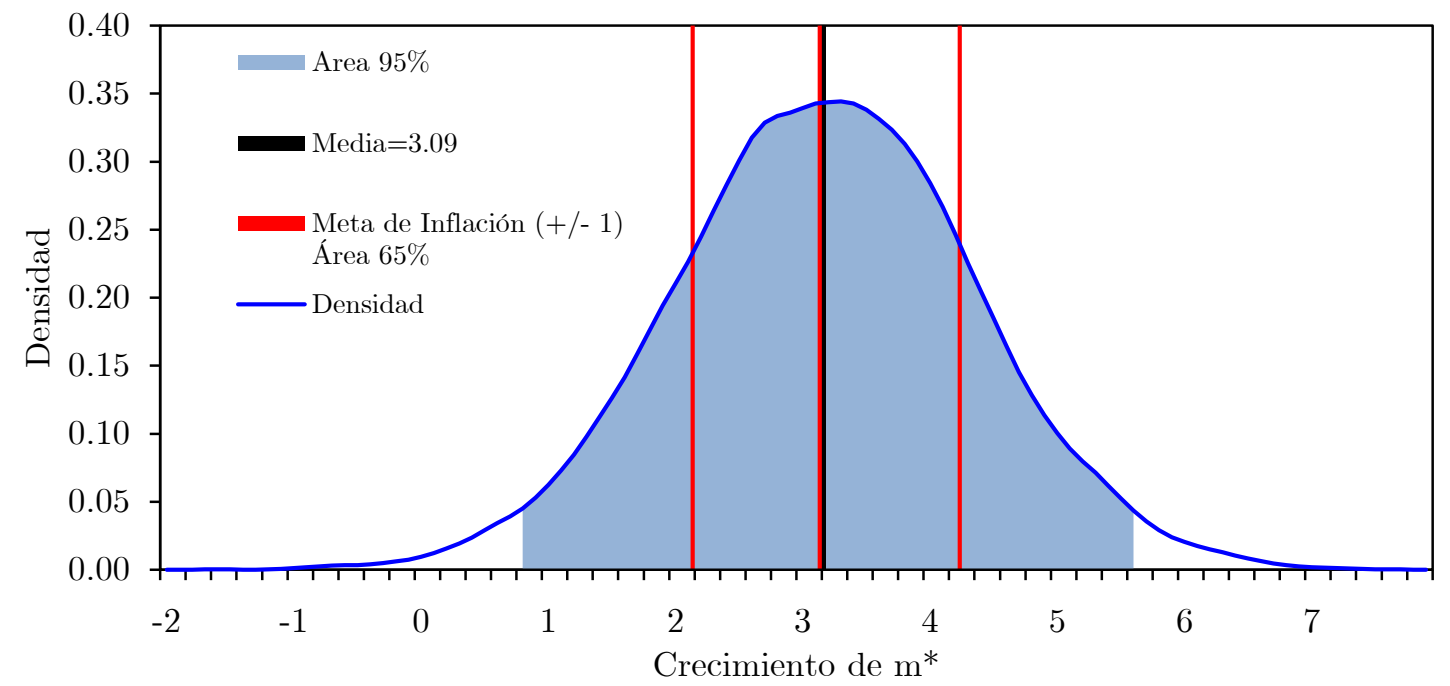

Como se puede apreciar, la distribución de $\Delta m^{*}$ se centra, por construcción, en el valor estimado en el Cuadro 5 (3.09), el cual es muy cercano de la meta de inflación de 3.0 por ciento. Lo más relevante de este ejercicio de simulación es apreciar la dispersión del estimador de $\Delta m^{*}{ }^{51}$ Si consideramos el intervalo de confianza de 95 por ciento, podemos

${ }^{51}$ En general, la varianza del crecimiento de $m^{*}$ depende tanto de la varianza estimada de los parámetros de la demanda de dinero de largo plazo, como del valor promedio de las tendencias de largo plazo de sus determinantes. Por tanto, la dispersión de la distribución del crecimiento de $m^{*}$ sería menor si, por un lado, 
ver que tanto la meta de inflación como el intervalo de variabilidad están contenidos en éste. De hecho, entre el 2 y 4 existe un área de aproximadamente $65 \%$.

La Gráfica 15 presenta un ejercicio donde se compara el promedio recursivo de la inflación anual y de $\Delta m^{*}$, junto con el intervalo de confianza de una desviación estándar de éste último. Para clarificar la gráfica nótese, por ejemplo, que los valores en el tercer trimestre de 2001 para estas dos variables corresponden al promedio de la inflación anual y del crecimiento anual del indicador $m^{*}$ en la submuestra 2001T1-2001T3, respectivamente. Los valores subsecuentes se calculan dejando fijo el inicio de la submuestra en 2001T1 pero añadiendo recursivamente un dato adicional hacia el final de la muestra. Este cálculo recursivo continúa hasta que los promedios abarcan el periodo completo bajo análisis, que de hecho es el porcentaje promedio anual reportado en el Cuadro 5.

Gráfica 15: Inflación, crecimiento de $\boldsymbol{m}^{*}$ e intervalo de confianza (promedio recursivo)

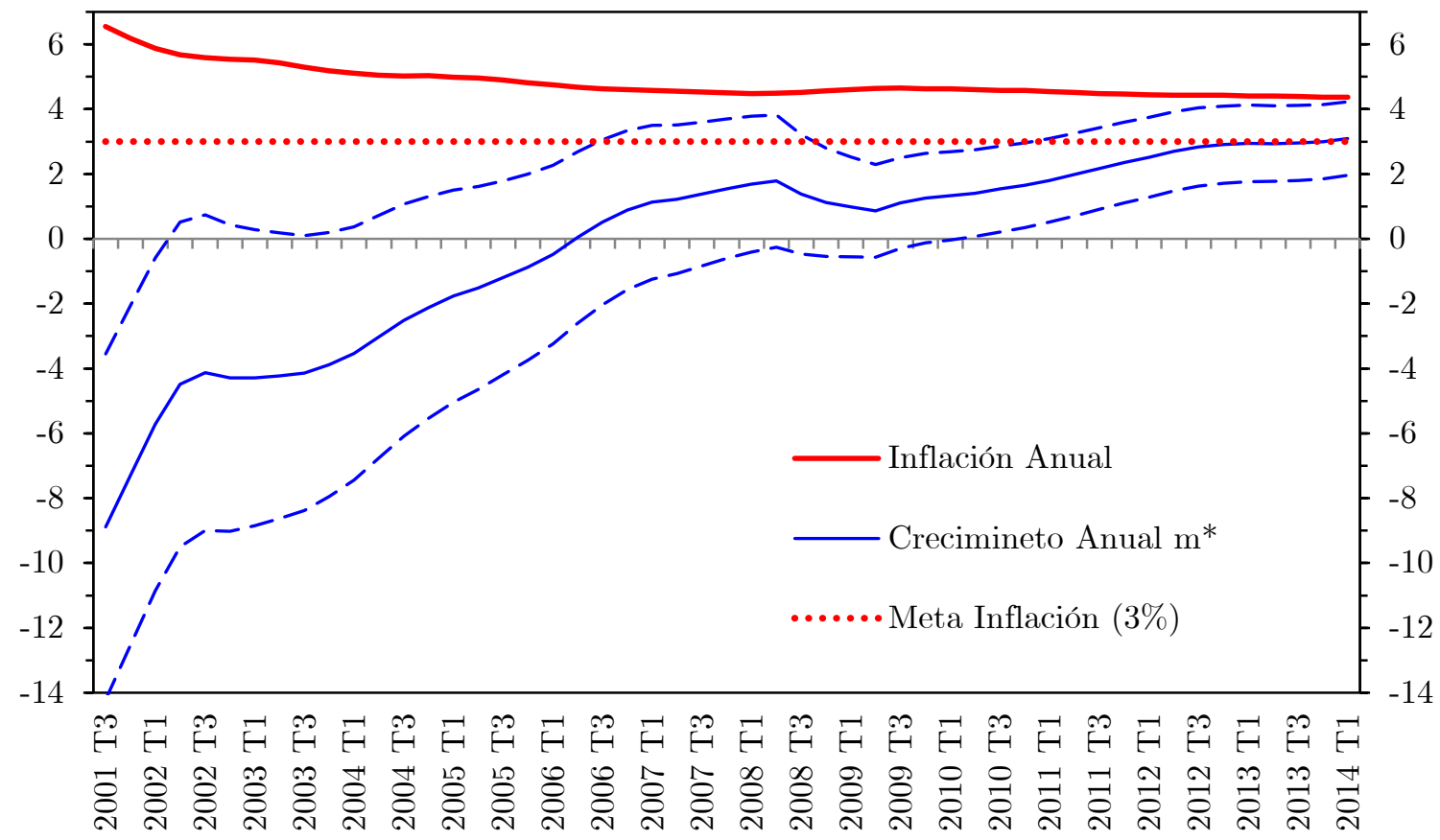

De la Gráfica 15, que a nuestro juicio es de las más relevantes de este documento, se puede apreciar como en los primeros años de la muestra el crecimiento promedio de $m^{*}$ (incluso negativo) es consistente con (y posiblemente una de las principales causas de) la

la muestra para la estimación de la demanda por dinero fuera más grande, lo cual nos llevaría a tener una estimación de los parámetros de largo plazo más precisa, es decir, con menor varianza y, por otro, si la muestra considerada no abarcara la peor crisis financiera internacional desde la Gran Depresión, lo cual seguramente se traduciría en tasas de crecimiento de las tendencias de largo plazo de las variables más estables. 
tendencia descendente mostrada por la inflación (véase Gráfica 1) ${ }^{52}$ La Gráfica 15 ilustra el esfuerzo de la política monetaria por hacer converger a la inflación a la meta establecida de 3 por ciento. Como se puede apreciar, de aproximadamente el año 2001 a mediados de 2006, el crecimiento de $m^{*}$, aunque gradualmente incrementándose, fue negativo. Dicho esfuerzo fue necesario para reducir a la inflación y sus expectativas hacia su meta. Asimismo, se puede apreciar que el esfuerzo de desinflación, con $0<\Delta m^{*}<3 \%$ continuó hasta aproximadamente mediados de 2012, a partir de cuando $\Delta m^{*}$ convergió a aproximadamente 3 por ciento. En suma, en la Gráfica 15 se muestra el esfuerzo por reducir a la inflación y sus expectativas hacia su meta. Las condiciones inflacionarias de largo plazo derivadas de la inyección neta monetaria en la economía (esto es, el crecimiento del agregado monetario ajustado por el crecimiento de la demanda de dinero) reflejadas en $\Delta m^{*}$ convergieron aproximadamente hacia mediados de 2012 al 3 por ciento.

Esta evidencia en su conjunto es indicativa de que, en efecto, la inflación parece ser un fenómeno monetario en la baja frecuencia, siempre y cuando el agregado monetario que se utilice se ajuste adecuadamente. Esto, a su vez, implica que la política monetaria ha sido congruente con el objetivo de hacer converger a las condiciones inflacionarias de largo plazo al nivel de $3 \%$. Diversos cambios (y/o choques) en precios relativos principalmente han dado lugar, a lo largo del período muestral, a que la inflación promedio anual se sitúe en $4.37 \%$. El punto a resaltar aquí es que la cantidad monetaria no ha validado, a través de la postura de política, los efectos de dichos choques sobre las condiciones inflacionarias en la economía. En particular, de los ejercicios se puede inferir que la política monetaria ha evitado que dichos choques tengan efectos de segundo orden y que, por lo tanto, se convirtieran en un problema generalizado de inflación. Esto es, de los ejercicios presentados y de las inflaciones registradas en ese periodo, se aprecia que los efectos de los referidos choques fueron temporales.

Finalmente, es importante resaltar el cuidado que debe tenerse al utilizar tanto la brecha del dinero, como el $m^{*}$ como indicadores de presiones inflacionarias, sobre todo en el margen, es decir, al final de la muestra. Así mismo, es indispensable que dichos indicadores se construyan con base a una función de demanda de dinero estable. Por lo tanto, el análisis requiere de realizar distintas pruebas de estabilidad a la demanda de dinero como, por ejemplo, las mencionadas anteriormente. En este contexto, deben de tomarse en cuenta diversos cambios estructurales que pueden ocurrir en la economía, como es el caso del cambio en la naturaleza estadística del proceso inflacionario. Además, debe tenerse en cuenta que existen distintos factores que pudieran afectar a la demanda por dinero (incremento en las remesas, introducción o derogación de impuestos que impactan directamente sobre ésta, reacción de los agentes ante ciertos acontecimientos económicos, variaciones en el tipo de cambio y en las tasas de interés extranjeras, y el aparente uso

\footnotetext{
${ }^{52}$ Hay que señalar que dada la característica de $\Delta m^{*}$ de ser un indicador de largo plazo, habría que ser cuidadoso al interpretar las primeras observaciones de la Gráfica 15, siendo que evidentemente los promedios calculados incluyen muy pocas observaciones. En la medida que el periodo para la construcción del promedio de $\Delta m^{*}$ se va alargando, dicho problema se va reduciendo. Aun así, la historia que se deriva de la Gráfica 15 para el período 2001-2014 es congruente con un esfuerzo de desinflación importante que hizo que $\Delta m^{*}$ convergiera a 3 por ciento alrededor de mediados de 2012.
} 
más intensivo del efectivo en los procesos electorales). Es posible que algunos de estos factores que han generado cambios en la demanda por dinero alcancen eventualmente un nivel de equilibrio de largo plazo, en cuyo caso no será necesario introducirlos en la ecuación de la demanda por dinero. Sin embargo, en plazos menores, aunque no reducidos, deben de ser considerados a fin de anticipar correctamente movimientos futuros en la tasa de inflación, y de esta forma permitir a la autoridad monetaria, de ser necesario, actuar con el fin de cumplir con el objetivo de inflación establecido.

\section{Conclusiones}

Los resultados presentados en este artículo muestran cómo se puede utilizar a los agregados monetarios como indicadores de presiones inflacionarias al existir una relación de largo plazo entre éstos y los precios. En particular, se estimó una demanda de dinero para México, utilizando M1 para encontrar la relación de largo plazo entre dicho agregado monetario en términos reales y sus determinantes. Respecto a la tendencia de largo plazo de la inflación, el indicador $m^{*}$ para el periodo 2001-2014 sugiere que el crecimiento del dinero durante el periodo de objetivos de inflación primeramente fue congruente con un importante esfuerzo de desinflación, para después converger a $\Delta m^{*} \approx 3 \%$, esto es, a condiciones inflacionarias congruentes con la meta de 3 por ciento para la inflación. Más aún, el promedio para $\Delta m^{*}$ comenzó a ser congruente con el 3 por ciento a partir de mediados de 2012, habiéndose mantenido.

La razón por la cual la inflación ha promediado más de $3 \%$ en la muestra utilizada en nuestro análisis no es monetaria. Más bien tiene que ver con la serie de choques de oferta que la economía ha experimentado desde hace más de una década. De los resultados obtenidos, claramente no ha habido efectos secundarios sobre los precios de dichos choques.

Desde un punto de vista cíclico, recientemente la inyección monetaria neta parecería ser ligeramente mayor que la necesaria para que la demanda de dinero de largo plazo esté en equilibrio, lo que podría ejercer alguna presión al alza sobre los precios para restablecerlo. Sin embargo, como se aprecia en el análisis presentado, durante este periodo la brecha del producto se tornó negativa, por lo que la política monetaria posiblemente ha sido un apoyo importante para que la actividad económica no haya presentado efectos adversos de mayor magnitud, sin haber afectado a la inflación y a sus expectativas.

Evidentemente es importante resaltar que los hechos aquí presentados no implican que todos los movimientos en precios sean ocasionados por el dinero. Sin embargo, es cierto que choques exógenos al nivel de precios tienen que ser acomodados para volverse permanentes. En este sentido, los indicadores mostrados pueden constituir una herramienta útil para evaluar la postura de política monetaria. Asimismo, estos indicadores pueden ser útiles para prever movimientos futuros en el nivel de precios, y no sólo para prever movimientos de los precios respecto a su tendencia de largo plazo. De esta forma, tanto la brecha del dinero como $m^{*}$ pueden utilizarse como complemento de otros modelos

e indicadores utilizados en el Banco de México para anticipar movimientos en los precios y en la inflación, y así poder actuar para cumplir con el objetivo de inflación establecido. 


\section{Referencias}

Arango, S. y M. I. Nadiri (1981), "Demand for money in open economies", Journal of Monetary Economics, 7(1), 69-83.

Baba, Y., D. F. Hendry, y R. Starr (1992), "The Demand for M1 in the U.S.A., 19601988", Review of Economic Studies, 59(1), 25-61.

Bahmani-Oskooee, M. y H. Y. Rhee (1994), "Long-Run Elasticities Of The Demand For Money In Korea: Evidence From Cointegration Analysis", International Economic Journal, 8(2), 83-93.

Bahmani-Oskooee, M., y R. C. W. Ng (2002), "Long Run Demand for Money in Hong Kong: An Application of ARDL Model", International Journal of Business and Economics 1, 147-155.

Banco Central Europeo (2004), "The Monetary Policy of the ECB", disponible en: www.ecb.europa.eu/pub/pdf/other/monetarypolicy2004en.pdf

Banco Central Europeo (2011), "The Monetary Policy of the ECB", disponible en: www.ecb.europa.eu/pub/pdf/other/monetarypolicy2011en.pdf

Banco de México (2006), Informe sobre la Inflación Octubre-Diciembre 2005 y Programa Monetario para 2006.

Banco de México (2007), Informe sobre la Inflación Octubre-Diciembre 2006 y Programa Monetario para 2007.

Banco de México (2015), Informe sobre la Inflación Enero-Marzo 2015.

Banerjee, A., J. Dolado, J. W. Galbraith, y D. F. Hendry (1993), Co-integration, ErrorCorrection, and the Econometric Analysis of Non-Stationary Data. Advanced Texts in Econometrics. Oxford University Press.

Benati, L. (2009), "Long Run Evidence on Money Growth and Inflation", Working Paper Series 1027, European Central Bank.

Capistrán, C. y M. Ramos-Francia (2009), "Inflation Dynamics in Latin America", Contemporary Economic Policy, 27(3), 349-362.

Cayen, J., M. Gosselin, y S. Kozicki (2009), "Estimating DSGE-Model-Consistent Trends for Use in Forecasting", Bank of Canada Working Paper 2009-35.

Chau-Rodríguez, M. y P. Turner (2003), "Currency substitution and the demand for money in Mexico", Applied Economics Letters, 10(1), 59-62.

Chiquiar, D., A. E. Noriega y M. Ramos-Francia (2010), "A Time Series Approach to Test a Change in Inflation Persistence: The Mexican Experience", Applied Economics, 42(24), 3067-3075. Documento de Investigación No. 2007-01, Banco de México.

Cuthbertson, K. y L. Galindo (1999), "The Demand for Money in Mexico", The Manchester School, 67(2), 154-66.

De Santis, R. A., Favero, C.A. y B. Roffia (2008), "Euro area money demand and international portfolio allocation. A contribution to assessing risks to price stability", Working Paper Series 926, European Central Bank.

Doornik, J. A. (2009), "Autometrics", en J. L. Castle y N. Shephard (eds.), The Methodology and Practice of Econometrics, Oxford University Press.

Doornik, J. A., y D. F. Hendry (2007), PcGive 12, Timberlake Consultants Ltd, London. 
Ericsson, N. R., y S. B. Kamin (2008), "Constructive Data Mining: Modeling Argentine Broad Money Demand", International Finance Discussion Papers 943, Board of Governors of the Federal Reserve System.

Estrella, A. y F. S. Mishkin (1997), "Is There a Role for Monetary Aggregates in the Conduct of Monetary Policy?", Journal of Monetary Economics, 40(2), 279-304.

Fajnzylber, P. y H. López (2008), Remittances and Development: Lessons from Latin America, The World Bank, Washington, D.C.

Feenstra, R. C. (1986), "Functional equivalence between liquidity costs and the utility of money", Journal of Monetary Economics, 17(2), 271-291.

Fisher, I., (1930), The Theory of Interest, Macmillan, New York.

Friedman, M., (1963), Inflation Causes and Consequences, Asian Publishing House.

Frisch, R. y F. V. Waugh (1933), "Partial Time Regressions as Compared with Individual Trends", Econometrica, 1(4), 387-401.

Galí, J. (2008), Monetary Policy, Inflation, and the Business Cycle. An Introduction to the New Keynesian Framework. Princeton University Press.

Garcés, D. G. (2003), "Agregados Monetarios, Inflación y Actividad Económica en México", Estudios Económicos, 18(1), 37-78.

Girton, L. y D. E. Roper (1981), "Theory and Implications of Currency Substitution", Journal of Money, Credit and Banking, 13(1), 12-30.

Goldfeld, S. M. (1973), "The Demand for Money Revisited", Brookings Papers on Economic Activity, 3, 577-683.

Halman, J. J., R. D. Porter, y D. H. Small (1991), "Is the Price Level Tied to the M2 Monetary Aggregate in the Long Run?," The American Economic Review, 81, 841-858.

Hamilton, J., (1994), Time Series Analysis, Princeton University Press.

Hansen, H., y S. Johansen (1999), "Some Tests for Parameter Constancy in Cointegrated VAR-Models", Econometrics Journal, 2(2), 306-333.

Hodrick, R. y E. Prescott, (1997), "Post-War U.S. Business Cycles: An Empirical Investigation", Journal of Money, Credit and Banking, 29, 1-16.

Johansen, S. (1988), "Statistical Analysis of Cointegrated Vectors", Journal of Economic Dynamics and Control, 12, 231-254.

Juselius, K., (2006), The Cointegrated VAR Model: Methodology and Applications, Oxford University Press, Inc., New Cork.

Khamis, M. y A. M. Leone (2001), "Can Currency Demand Be Stable Under a Financial Crisis? The Case of Mexico", IMF Staff Papers, 48(2), 344-366.

Kirchgassner, G. y J. Wolters (2010), "The Role of Monetary Aggregates in the Policy Analysis of the Swiss National Bank", CESifo Working Paper No. 2928.

Levy, D. (2002), "Cointegration in Frequency Domain", Journal of Time Series Analysis, 23(3), 333-339.

Lucas, R. E. (1980), "Two Illustrations of the Quantity Theory of Money", The American Economic Review, 70(5), 1005-1014.

Lucas, R. E. Jr. (1988), "Money Demand in the United States: A Quantitative Review", Carnegie-Rochester Conference Series on Public Policy 29, 137-168.

McCallum, B. T. y E. Nelson (2011), "Money and inflation: some critical issues", Handbook of Monetary Economics, 3, 97-153. 
McCandless Jr, G. T. y W. E. Weber (1995), "Some Monetary Facts", Federal Reserve Bank of Minneapolis Quarterly Review, 19(3), 2-11.

McKinnon, R. I. (1982), "Currency Substitution and Instability in the World Dollar Standard", The American Economic Review, 72(3), 320-333.

Miles, M. A, (1978), "Currency Substitution, Flexible Exchange Rates, and Monetary Independence," The American Economic Review, 68(3), 428-436.

Noriega, A. E., C. Capistrán y M. Ramos-Francia (2013), "On the dynamics of inflation persistence around the world", Empirical Economics, 44(3), 1243-1265. Documento de Investigación No. 2009-02, Banco de México.

Noriega, A. E., M. Ramos-Francia y C. A. Rodríguez-Pérez, (2011), "Demanda por dinero en México: 1986-2010", El Trimestre Económico, 312, 699-749.

Nyblom, J. (1989), "Testing for the constancy of parameters over time", Journal of the American Statistical Association, 84(405), 223-230.

Ortiz, G. (1982), "La Demanda de Dinero en México: Primeras Estimaciones," Monetaria, (1), 37-82.

Ortiz, G. (1983), "Currency Substitution in Mexico: The Dollarization Problem", Journal of Money, Credit and Banking, 15(2), 174-185.

Pesaran, M. H., y Y. Shin (1999), "An autoregressive distributed lag modelling approach to cointegration analysis", Chapter 11 in Econometrics and Economic Theory in the 20th Century: The Ragnar Frisch Centennial Symposium, Strom S (ed.). Cambridge University Press: Cambridge.

Pesaran, M. H., Y. Shin y J. Smith (2001), "Bounds Testing Approaches to the Analysis of Level Relationships", Journal of Applied Econometrics, 16, 289-326.

Pétursson, T. G. (2000), "The Representative Household's Demand for Money in a Cointegrated VAR Model", Econometrics Journal, 3(2), 162-176.

Ramirez-Rojas, C. L. (1985), "Currency Substitution in Argentina, Mexico, and Uruguay", IMF Staff Papers, 32(4), 629-667.

Ramos-Francia, M. (1993), "The Demand for Money in an Unstable Economy. A Cointegration Approach for the Case of Mexico," Centro de Análisis e Investigación Económica, ITAM, Documento de discusión 9306.

Rey, H. (2013), "Dilemma not Trilemma: The Global Financial Cycle and Monetary Policy Independence," Paper presented at the 25th Jackson Hole symposium, Wyoming, August.

Reynard, S. (2006), "Money and the Great Disinflation", Swiss National Bank Working Papers, 2006-7.

Reynard, S. (2007), "Maintaining Low Inflation: Money, Interest Rates, and Policy Stance", Journal of Monetary Economics, 54, 1441-1471.

Rogers, J. H. (1992), "The Currency Substitution Hypothesis and Relative Money Demand in Mexico and Canada", Journal of Money, Credit and Banking, 24(3), 300-318.

Román-Aguilar, F. y A. E. Vela-Dib (1996), "La Demanda de Dinero en México", Documento de Investigación 9602, Banco de México.

Serletis, A. (2007), The Demand for Money. Theoretical and Empirical Approaches. 2a edición. Springer.

Siklos, P. L. (2010), "Taking Monetary Aggregates Seriously", e-brief, C.D. Howe Institute. Disponible en www.cdhowe.org 
Sriram, S. (2001), "A Survey of Recent Empirical Money Demand Studies", IMF Staff Papers, 47(3).

Svensson, L. E. O. (2011), "Inflation Targeting", Handbook of Monetary Economics, Vol. 3B, 1237-1302.

Vargas-Silva, C. (2009), "The Tale of Three Amigos: Remittances, Exchange Rates, and Money Demand in Mexico", Review of Development Economics, 13(1), 1-14.

Woodford, M. (2008), "How Important Is Money in the Conduct of Monetary Policy?", Journal of Money, Credit and Banking, 40(8), 1561-1598. 


\section{Apéndice I. Análisis de Estabilidad "Demanda por dinero en México (1986-2010)"}

Primeramente, en este apéndice se presenta la descripción de las denominadas forma- $X$ y forma- $R$ del modelo VECM (Vector Error Correction Model). Esta sección intenta resumir lo desarrollado en la sección 7.1 de Juselius (2006), que se sugiere consultar para más detalles.

Posteriormente, se presentan gráficamente los resultados de la batería de pruebas recursivas (hacia adelante y hacia atrás) aplicadas al VECM utilizado en la estimación de la demanda por dinero en NRR (tanto en su forma- $X$ como en su forma- $R$ ).

\section{Forma-X y forma-R}

Para ver los detalles de la forma- $X$ y forma- $R$, supóngase que se tiene un modelo $\operatorname{VAR}(2)$ que puede ser descrito por la siguiente expresión (las matrices son denotadas en negritas):

$$
\boldsymbol{x}_{t}=\Pi_{1} \boldsymbol{x}_{t-1}+\Pi_{2} \boldsymbol{x}_{t-2}+\boldsymbol{\Phi D _ { t }}+\varepsilon_{t}
$$

donde $\mathbf{D}_{t}$ es un vector de términos deterministas, $t=1, \ldots, T, \boldsymbol{\varepsilon}_{t} \sim \operatorname{IN}(\mathbf{0}, \boldsymbol{\Omega})$, y $\boldsymbol{\Omega}$ es la matriz de varianza-covarianza de $\boldsymbol{\varepsilon}_{t}$. Esta especificación de las variables en niveles puede ser reparametizada en forma de un VECM. Así, la formulación de corrección de error es especificada como:

$$
\Delta x_{t}=\Pi x_{t-1}+\Gamma_{1} \Delta x_{t-1}+\Phi D_{t}+\varepsilon_{t}
$$

donde $\boldsymbol{\Pi}=-\left(\mathbf{I}-\boldsymbol{\Pi}_{1}-\boldsymbol{\Pi}_{2}\right)$, y $\boldsymbol{\Gamma}_{1}=-\boldsymbol{\Pi}_{2}$. Toda la información respecto a los efectos de largo plazo en el modelo es resumida en la matriz $\Pi$. Bajo la hipótesis de que existe cointegración en los datos, entonces $\boldsymbol{\Pi}$ debe tener un rango reducido, y puede escribirse como el producto de dos vectores de parámetros $\boldsymbol{\Pi}=\boldsymbol{\alpha} \boldsymbol{\beta}^{\prime}$. Entonces, el modelo VAR-cointegrado está dado por:

$$
\Delta x_{t}=\alpha \boldsymbol{\beta}^{\prime} x_{t-1}+\Gamma_{1} \Delta x_{t-1}+\boldsymbol{\Phi} \mathbf{D}_{t}+\varepsilon_{t},
$$

donde $\boldsymbol{\beta}^{\prime} \boldsymbol{x}_{t-1}$ es un vector estacionario de relaciones de cointegración, que puede interpretarse como la relación de largo plazo de los niveles de las variables. Esta formulación completa es la que denominaremos forma- $X$.

Una vez definido brevemente el modelo VECM (forma- $X$ ), nos enfocaremos a mostrar cómo la dinámica de corto plazo puede ser desasociada del modelo VAR, con la finalidad de concentrarse en la relación de cointegración o de largo plazo. Esta idea es básicamente una aplicación del teorema Frisch-Waugh. ${ }^{53}$ Entonces, considérense las siguientes modelos auxiliares:

\footnotetext{
${ }^{53}$ Esta aplicación del teorema Frisch-Waugh, puede explicarse de una forma más simple al tomar como ejemplo, un modelo de regresión uniecuacional multivariado. Considérese la siguiente regresión lineal $y_{t}=$ $\beta_{1.2} x_{1 t}+\beta_{2.1} x_{2 t}+\varepsilon_{t}$; entonces, el estimador de MCO de $\beta_{2.1}$ puede obtenerse en los siguientes pasos: (i) se
} 


$$
\begin{aligned}
& \Delta \boldsymbol{x}_{t}=\boldsymbol{\Gamma}_{1}^{o l s} \Delta \boldsymbol{x}_{t-1}+\boldsymbol{\Phi}_{1}^{o l s} \mathbf{D}_{t}+\boldsymbol{R}_{0 t} \\
& \boldsymbol{x}_{t-1}=\Gamma_{2}^{o l s} \Delta \boldsymbol{x}_{t-1}+\boldsymbol{\Phi}_{2}^{o l s} \mathbf{D}_{t}+\boldsymbol{R}_{1 t}
\end{aligned}
$$

De este par de especificaciones $\boldsymbol{R}_{0 t}\left(\boldsymbol{R}_{1 t}\right)$ representa la dinámica lineal de $\Delta_{\boldsymbol{t}}\left(\boldsymbol{x}_{t-1}\right)$ "limpia" de la dinámica de corto plazo del modelo VECM. Así, se obtiene el siguiente modelo "concentrado":

$$
\boldsymbol{R}_{0 t}=\boldsymbol{\alpha} \boldsymbol{\beta}^{\prime} \boldsymbol{R}_{1 t}+\text { error }_{t}
$$

De esta representación se obtiene un mecanismo de ajuste "limpio", en el cual el ajuste toma lugar únicamente hacia la relación de equilibrio de largo plazo. Esta última ecuación es la que se denomina forma- $R$.

\section{Pruebas recursivas del VAR-cointegrado}

Por motivos de espacio no se presentan los pormenores de las pruebas de diagnóstico de parámetros constantes en los modelos VECM. Sin embargo, una revisión detallada de estas pruebas puede consultarse en Hansen y Johansen (1999) y Juselius (2006, cap.9). A continuación se presentan los resultados de aplicar las diferentes pruebas recursivas, los cuales agrupamos en tres categorías para su interpretación.

1. Eigenvalores. Estas pruebas pueden dar evidencia de la estabilidad de las relaciones de cointegración debido a que los eigenvalores son una función cuadrática de $\boldsymbol{\alpha}$ y $\boldsymbol{\beta}$. Así, la idea de estas pruebas es que si los eigenvalores son constantes, entonces tanto la velocidad de ajuste como el vector cointegrador también lo serán.

\subsection{Eigenvalores recursivos (Gráficas AI.1 y AI.2)}

Forward: Se observa una ligera caída en el eigenvalor de 1994 (0.4) hacia 1995 (0.3), sin embargo, de ahí en adelante se observa bastante estable.

Backward: En este caso el eigenvalor estimado presenta una mayor varianza, sin embargo, parece fluctuar alrededor de su media (0.26).

\subsection{Transformación logarítmica de los eigenvalores (Gráficas AI.3 y AI.4)}

El comportamiento observado es muy parecido al de los eigenvalores recursivos en las Gráficas AI.1 y AI.2.

\subsection{La prueba de fluctuaciones (fluctuation test) (Gráficas AI.5 y AI.6)}

Esta es una prueba de la hipótesis nula de parámetros constantes que se calcula recursivamente a partir de los eigenvalores.

\footnotetext{
corre la regresión de $y_{t}$ contra $x_{1 t}$, y se obtienen los residuales $r_{1 t}$ como $y_{t}=\hat{b}_{1} x_{1 t}+r_{1 t}$; (ii) se corre la regresión de $x_{2 t}$ contra $x_{1 t}$, y se obtienen los residuales $r_{2 t}$ como $x_{2 t}=\hat{b}_{2} x_{1 t}+r_{2 t}$; (iii) se corre la regresión de $r_{1 t}$ contra $r_{2 t}$ y se obtiene el estimador de $\beta_{2.1}$, esto es, se efectúa la regresión $r_{1 t}=\beta_{2.1} r_{2 t}+$ error $_{t}$. Esto es, se elimina el efecto de $x_{1 t}$ sobre $y_{t}$ y $x_{2 t}$, entonces se realiza la regresión entre las variables "limpias de $x_{1 t} "$, esto es, $r_{1 t}\left(y_{t}\right.$-limpia) contra $r_{2 t}\left(x_{2 t}\right.$-limpia). Para más detalles véase Frisch y Waugh (1933).
} 
Forward: Sólo en el caso de la forma- $X$ se observa evidencia estadística de inestabilidad en el primer lustro de los noventa.

Backward: En el caso de la forma- $X$ hay un par de rechazos de la hipótesis nula de estabilidad en 1999T1 Y 2001T1, y después se rechaza a partir de 2003T3. Por su parte, en el caso de la forma- $R$ sólo se rechaza marginalmente en $2004 \mathrm{~T} 1$ y $2005 \mathrm{~T} 1$.

\subsection{Estadístico de la traza recursivo (Gráficas AI.7 y AI.8)}

Las figuras muestran el estadístico de la traza calculado recursivamente para probar la hipótesis nula de $r$ relaciones de cointegración contra la alternativa de $p=3$ variables estacionarias $[H(r) / H(p)]$.

Forward: la gráfica de la forma- $X$, exhibe más inestabilidad que la de la forma- $R$, indicando inestabilidad en el corto plazo. En el caso de la forma- $R$ el estadístico crece en forma lineal, sugiriendo que la relación de cointegración ha sido estable del 1991T1-2010T2 (con una ligera caída en 1995).

Backward: En este caso la evidencia de estabilidad no es contundente, sin embargo el patrón de comportamiento es parecido.

De este primer conjunto de pruebas se puede resumir lo siguiente: (i) de las pruebas de eigenvalor y eigenvalor trasformado, no se observa una clara evidencia de inestabilidad en el modelo; y (ii) del estadístico de la traza y de la prueba de fluctuaciones (fluctuation test), la diferencia de los resultados entre los modelos en la forma- $X$ y forma- $R$ sugiere una posible inestabilidad en la estructura de corto plazo del VECM.

2. Espacio cointegrador. En este bloque presentamos los resultados de realizar las pruebas recursivas de la estabilidad (constancia) del espacio cointegrador. A diferencia de las pruebas basadas en los eigenvalores que no distingue entre la inestabilidad de $\boldsymbol{\alpha}$ y $\boldsymbol{\beta}$, este grupo de pruebas se concentra en la constancia de los parámetros de la relación de cointegración $(\boldsymbol{\beta})$.

\subsection{Max-test $(\mathrm{Q}(\mathrm{t}))$ (Gráficas AI.9 y AI.10)}

Esta es una prueba tipo multiplicador de Lagrange dónde la hipótesis nula es que el parámetro $\boldsymbol{\beta}$ es constante. En el ejercicio recursivo hacia adelante, en ninguno de los períodos se puede rechazar la nula de parámetros constantes, mientras que en el caso del ejercicio hacia atrás, resaltan un par de puntos, en 1988T1 y 1988T2, implicando cierto grado de inestabilidad. Sin embargo, estos rechazos de la hipótesis nula parecen la excepción, por lo que en general de los resultados de esta prueba recursiva se podría concluir que el modelo es estable. ${ }^{54}$

\subsection{Prueba de " $\boldsymbol{\beta}_{\boldsymbol{t}}$ igual a un $\boldsymbol{\beta}$ conocido" (Gráficas AI.11 y AI.12)}

Esta prueba consiste en probar recursivamente si el vector estimado en una submuestra $\widehat{\boldsymbol{\beta}_{\boldsymbol{t}}}$ es igual a un determinado $\boldsymbol{\beta}$. En nuestro ejercicio recursivo, el $\boldsymbol{\beta}$ conocido es precisamente el estimado para la muestra completa. Como puede apreciarse de las gráficas

\footnotetext{
${ }^{54}$ De hecho, un ejercicio del máximo estadístico $\mathrm{Q}(\mathrm{t})[$ Max-Test $(\mathrm{Q}(\mathrm{t}))]$ del tipo recursivo hacia adelante (forward) es uno de los que NRR reportan en su análisis de estabilidad.
} 
los resultados de la forma- $X$ sí sugieren inestabilidad en el vector cointegrador, mientras que los de la forma- $R$ más bien sugieren estabilidad, por lo que de esta evidencia sería posible concluir que hay cierta inestabilidad en la estructura de corto plazo del modelo VECM.

En resumen, estos resultados recursivos del espacio cointegrador indican cierta inestabilidad principalmente en la estructura de corto plazo del VECM.

3. Parámetros recursivos (Gráficas AI.13 a AI.16). Se analiza gráficamente el valor estimado recursivamente tanto del vector cointegrador como de la velocidad de ajuste.

Forward: Para el caso de la forma- $R$ los parámetros $\boldsymbol{\beta}$ (Gráfica AI.13) y $\boldsymbol{\alpha}$ (Gráfica AI.15) lucen estables, mientras que los resultados de la forma- $X$ revelan inestabilidad durante 1994-1996.

Backward: En este ejercicio recursivo hacia atrás se observa una clara evidencia de inestabilidad en los parámetros $\boldsymbol{\alpha}$ y $\boldsymbol{\beta}$, después de la crisis de 1995 y después de 2000-2002, tanto en la forma- $X$ como en la forma- $R$ (véanse Gráficas AI.14 y AI.16). Sí nos concentramos en la forma- $R$, esta inestabilidad se ve como un incremento en la semielasticidad respecto a la tasa de interés, mientras que en el caso de la elasticidad del producto después de 1994 se encuentra fluctuando alrededor de cero. En lo que se refiere a la velocidad de ajuste de la tasa de interés y del producto, a pesar de la volatilidad que se observa en los resultados, ésta parece fluctuar en torno al cero (lo cual es evidencia de exogeneidad débil). Por su parte, la velocidad de ajuste de los saldos reales permanece negativa aunque no se distingue claramente un cambio en la magnitud. 


\subsection{Eigenvalores $^{1 /}$}

\section{Pruebas recursivas basadas en los eigenvalores}

Gráfica AI.1. Hacia adelante (Forward)

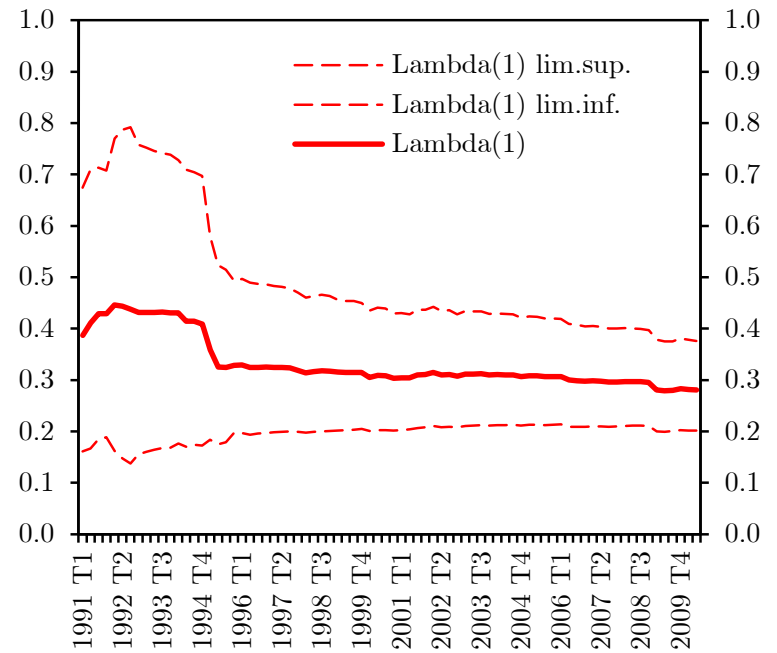

Gráfica AI.2. Hacia atrás (Backward)

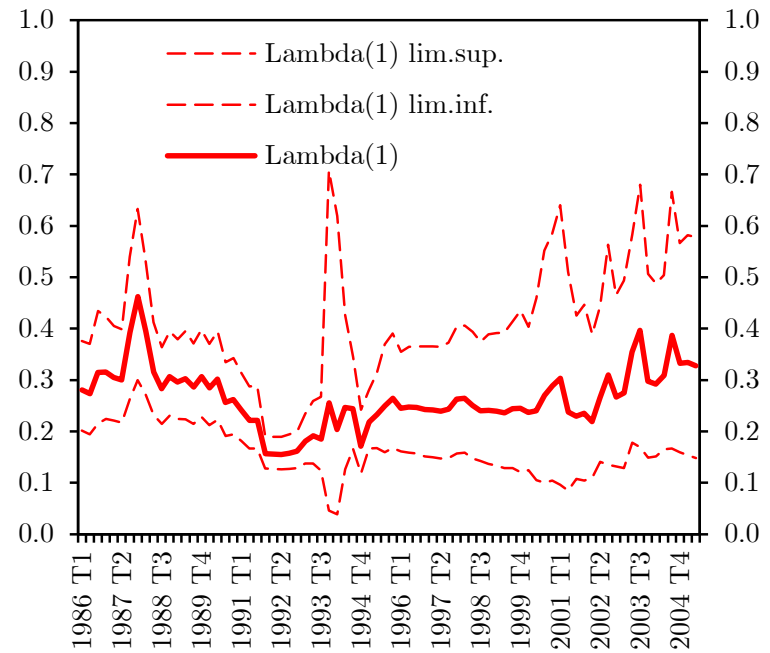

1/ Las líneas discontinuas muestran la banda de confianza al 95 por ciento.

\subsection{Eigenvalores transformados ${ }^{1 /}$}

Gráfica AI.3. Hacia adelante (Forward)

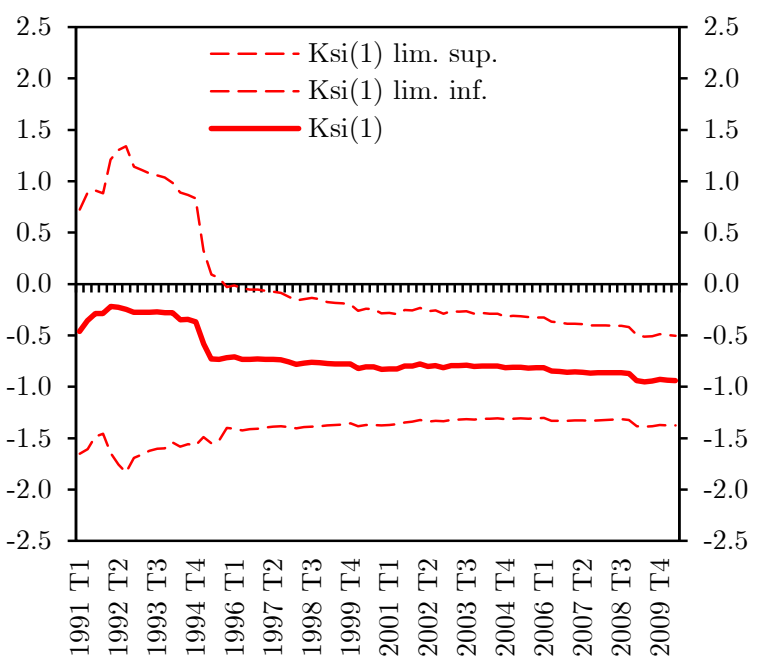

Gráfica AI.4. Hacia atrás (Backward)

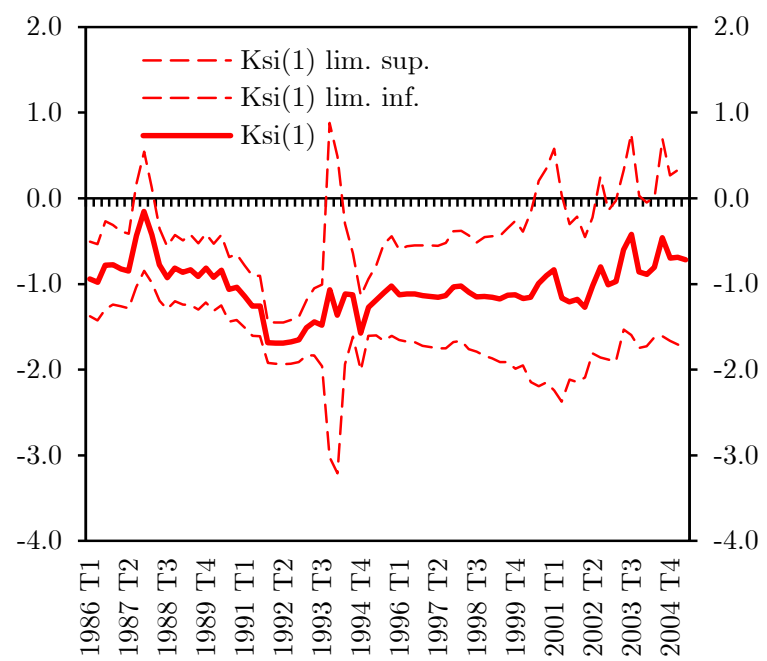

1/ Las líneas discontinuas muestran la banda de confianza al 95 por ciento. 


\section{$1.3 \quad$ Fluctuation test}

Gráfica AI.5. Hacia adelante (Forward)

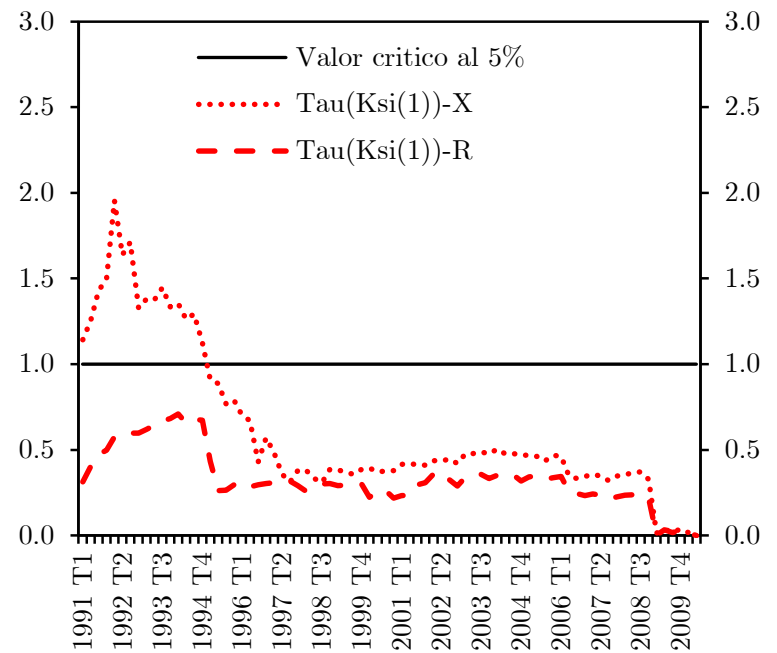

Gráfica AI.6. Hacia atrás (Backward)

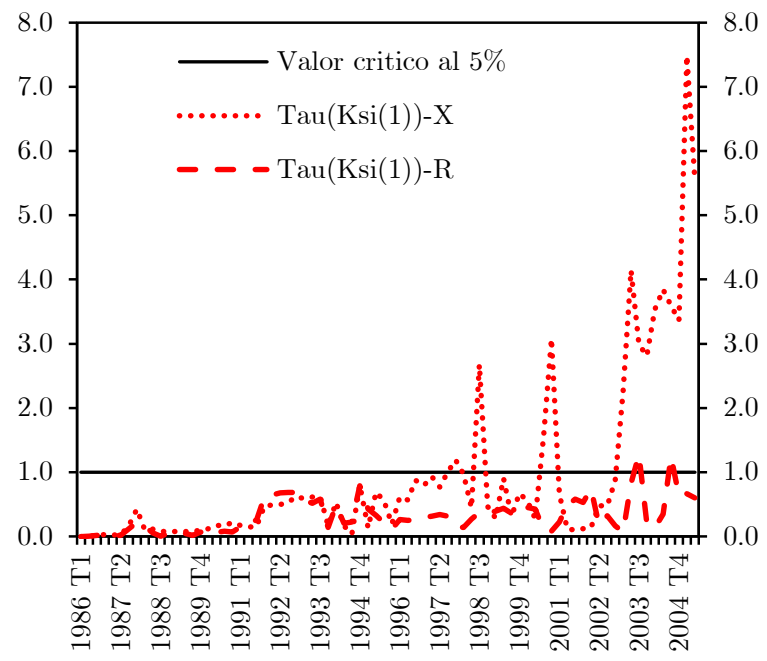

\subsection{Estadístico de la traza recursivo}

\section{Forma-X}

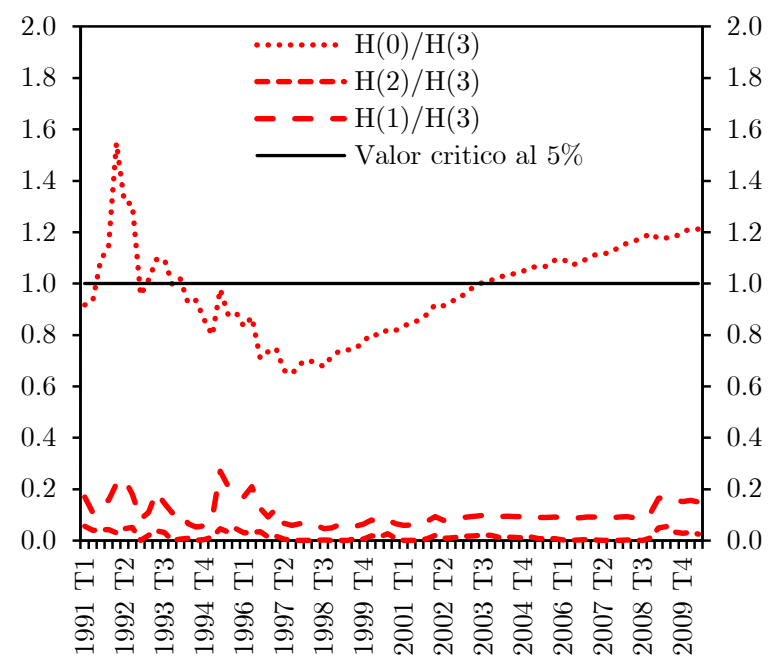

Gráfica AI.7. Hacia adelante (Forward) Forma-R

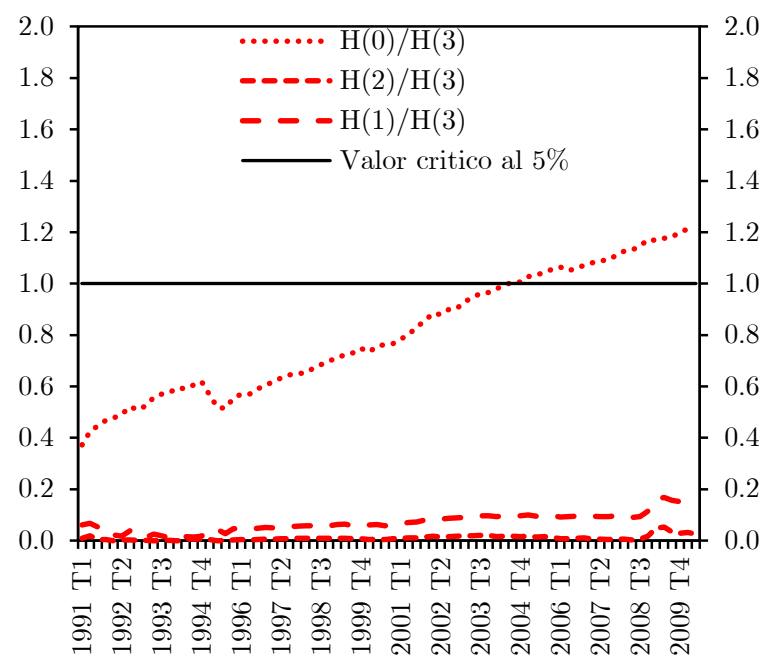




\section{Gráfica AI.8. Hacia atrás (Backward)}

\section{Forma- $X$}

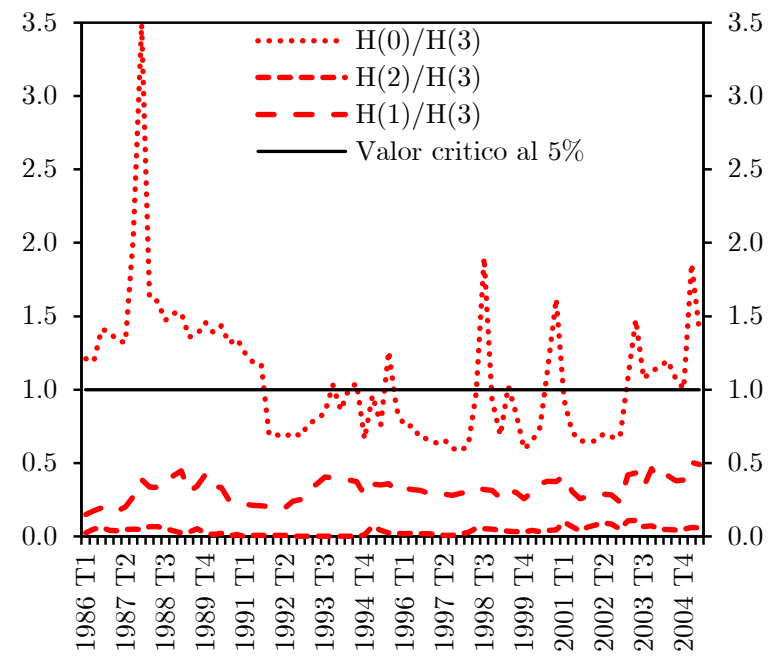

Forma- $R$

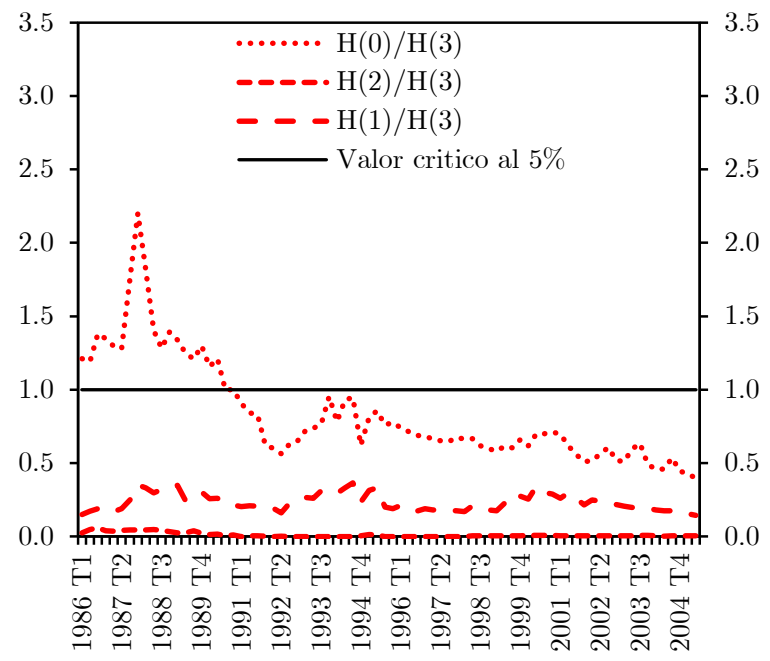

\section{$2.1 \quad$ Max-test $(\mathrm{Q}(\mathrm{t}))$}

\section{Espacio cointegrador}

\section{Gráfica AI.9. Hacia adelante (Forward)}

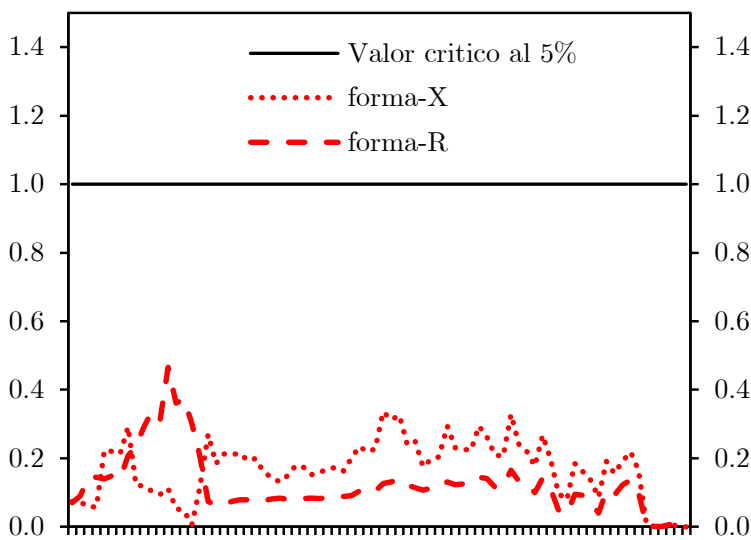

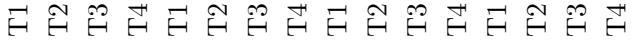

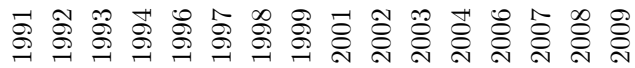

Gráfica AI.10. Hacia atrás (Backward)

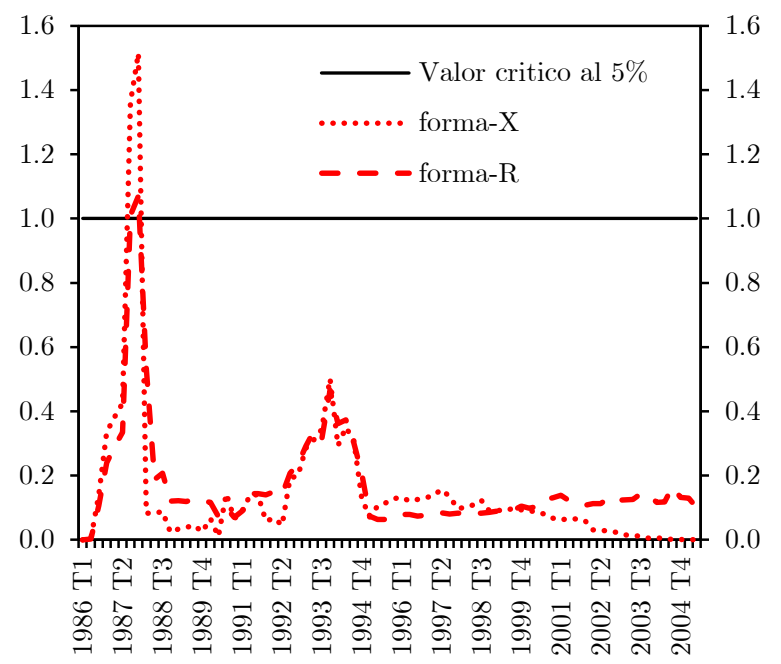




\subsection{Prueba de $\boldsymbol{\beta}_{t}$ igual a un $\boldsymbol{\beta}$ conocido}

Gráfica AI.11. Hacia adelante (Forward)

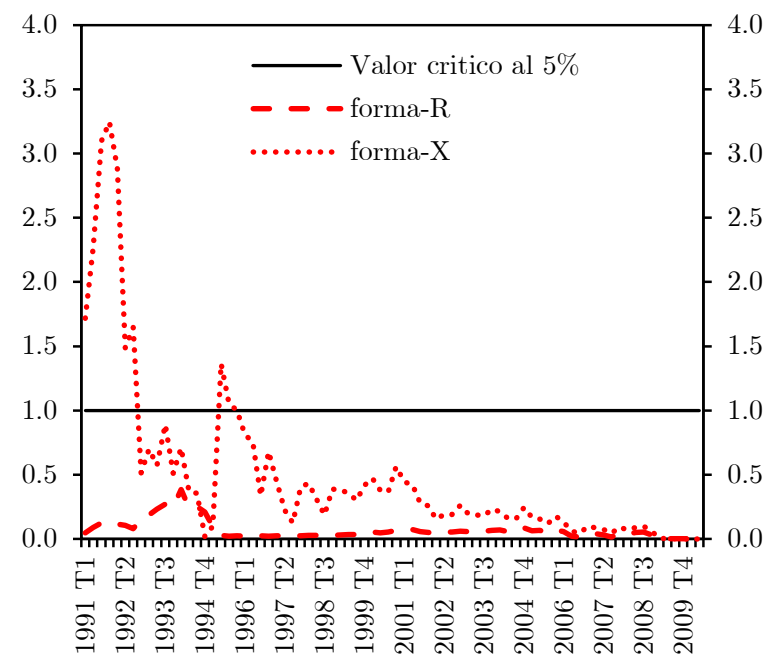

Gráfica AI.12. Hacia atrás (Backward)

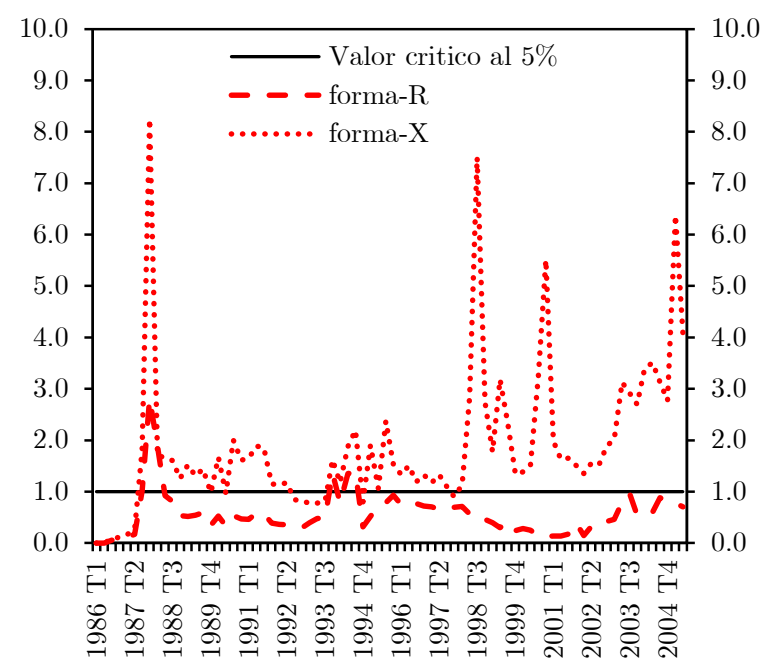




\section{Parámetros recursivos (vector cointegrador y velocidad de ajuste) Vector cointegrador. \\ Gráfica AI.13. Hacia adelante (Forward)}

Elasticidad ingreso

Semielasticidad de la tasa de interés

Forma-X
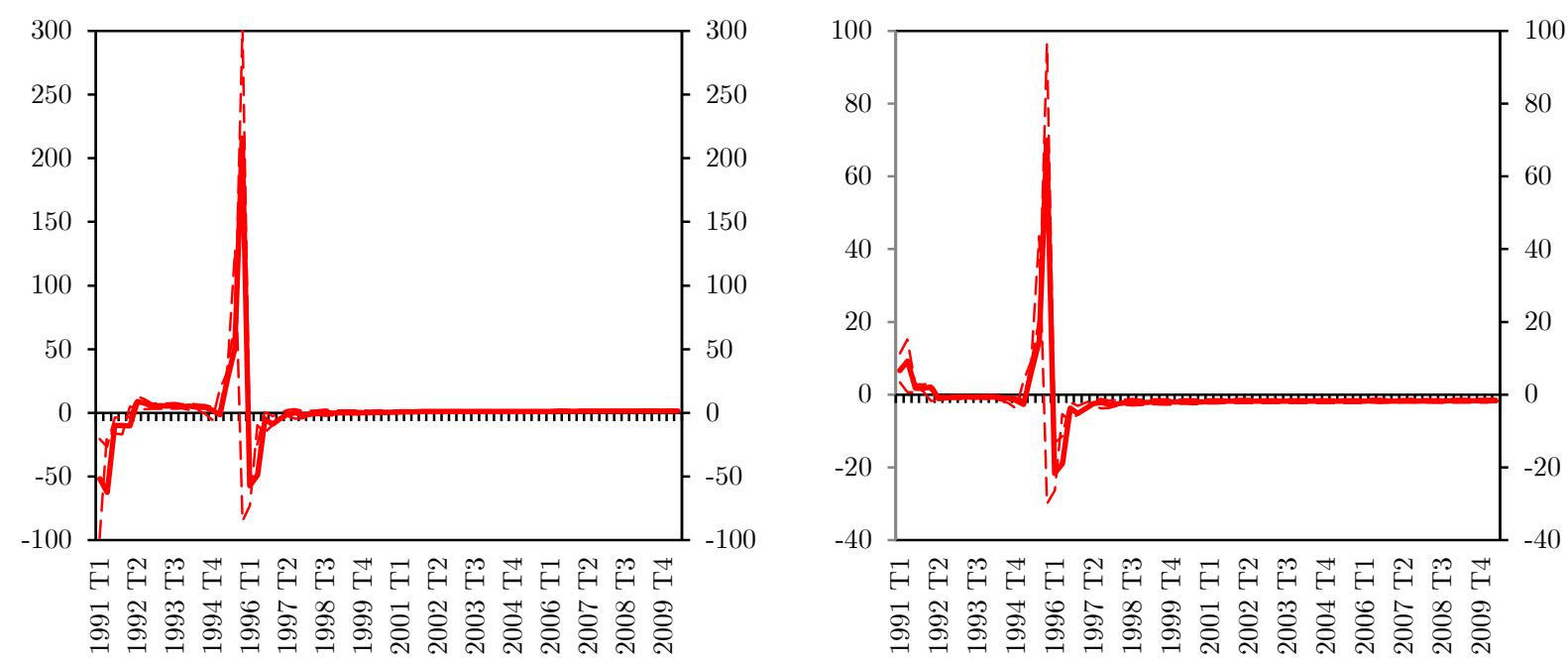

\section{Forma- $R$}
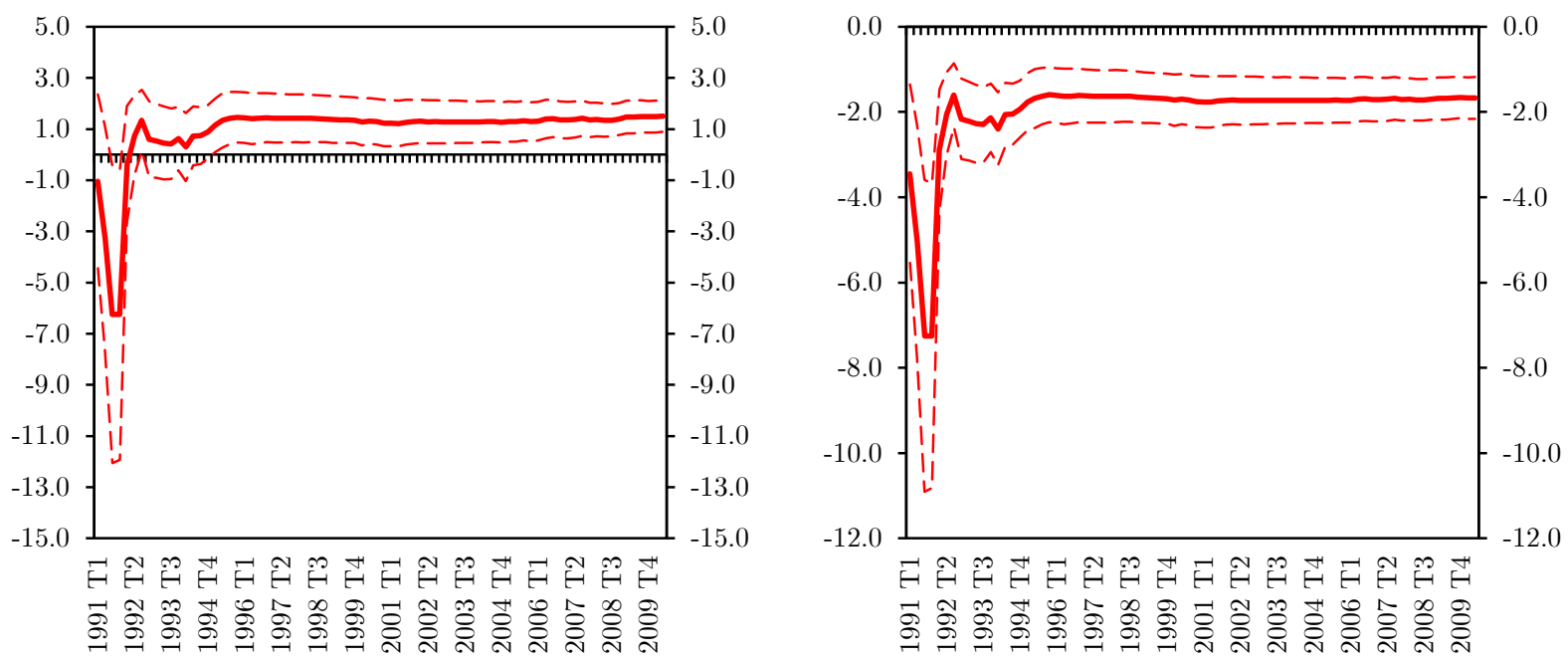

1/ Las líneas discontinuas muestran la banda de confianza al 95 por ciento. 
Gráfica AI.14. Hacia atrás (Backward)

Elasticidad ingreso

Semielasticidad de la tasa de interés Forma-X
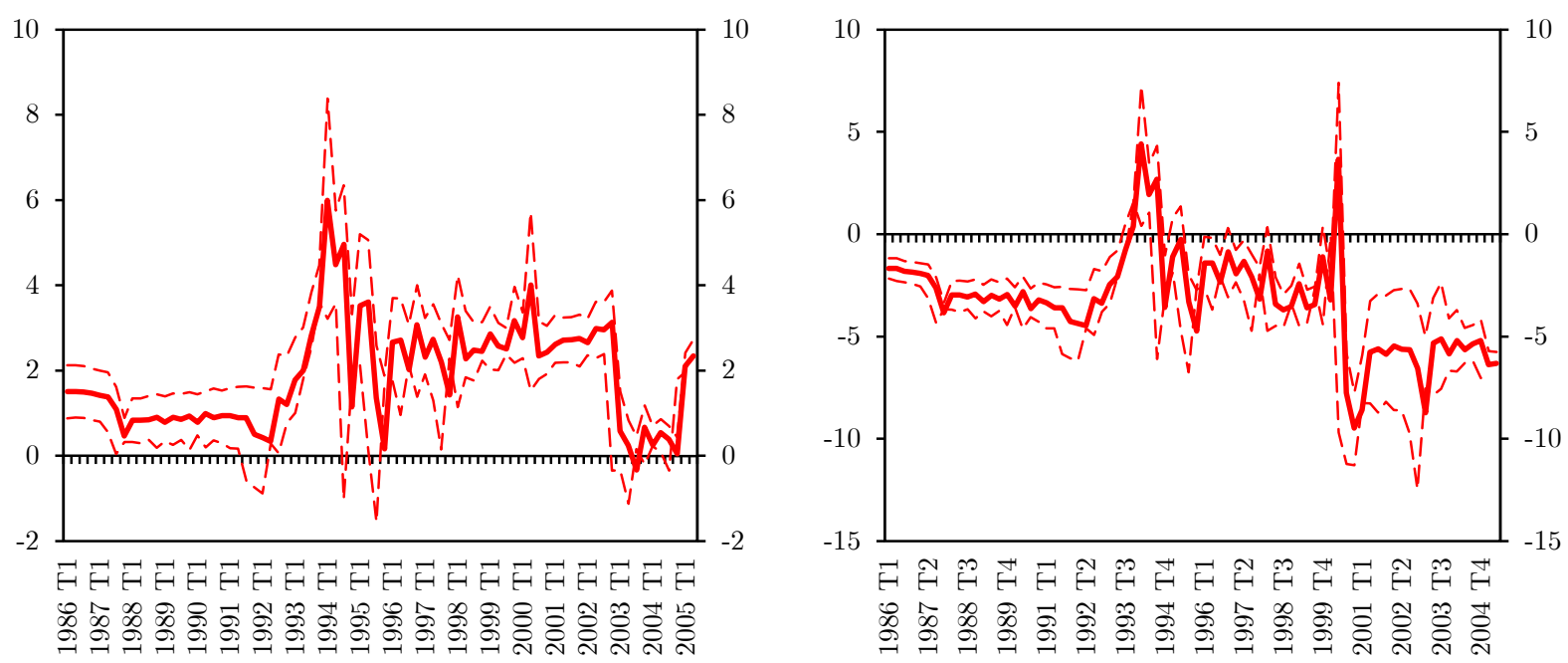

Forma- $R$
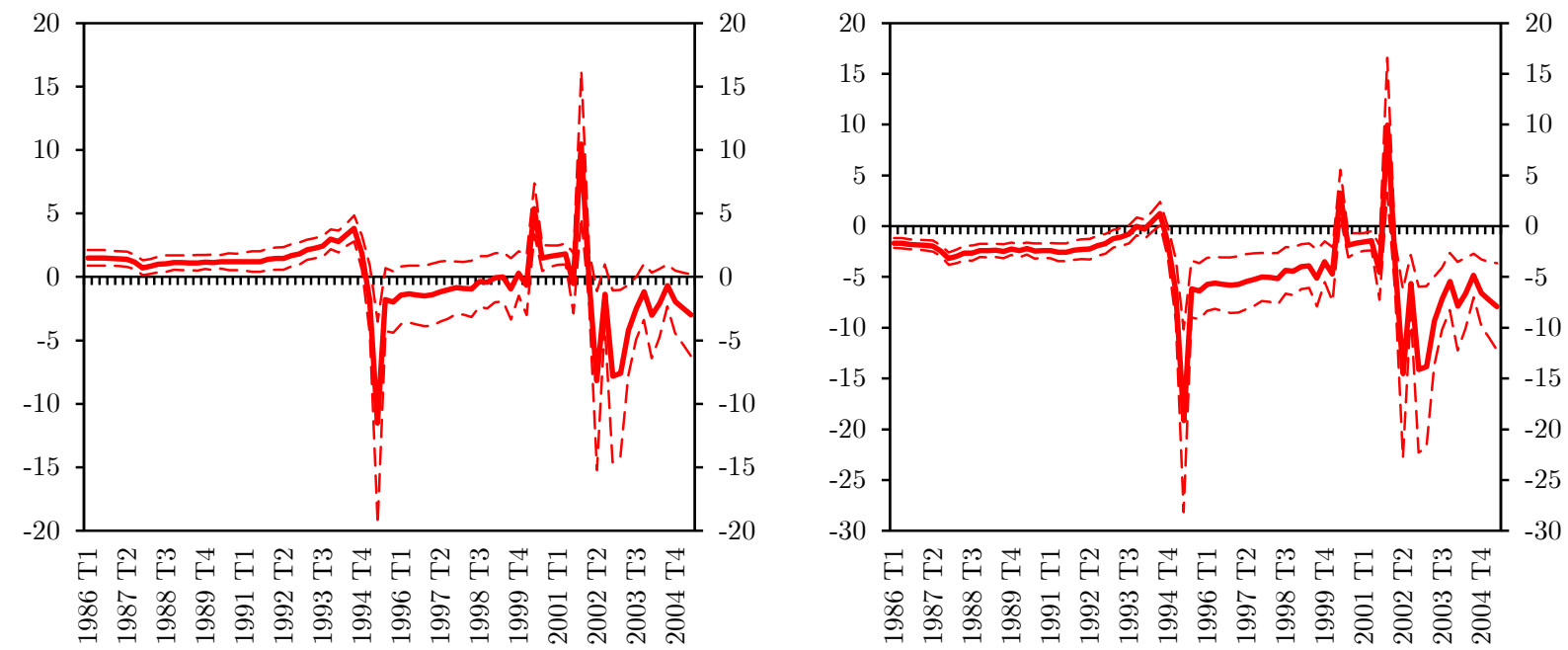

1/ Las líneas discontinuas muestran la banda de confianza al 95 por ciento. 


\section{Gráfica AI.15. Hacia adelante (Forward) M1 Ingreso \\ Forma-X}
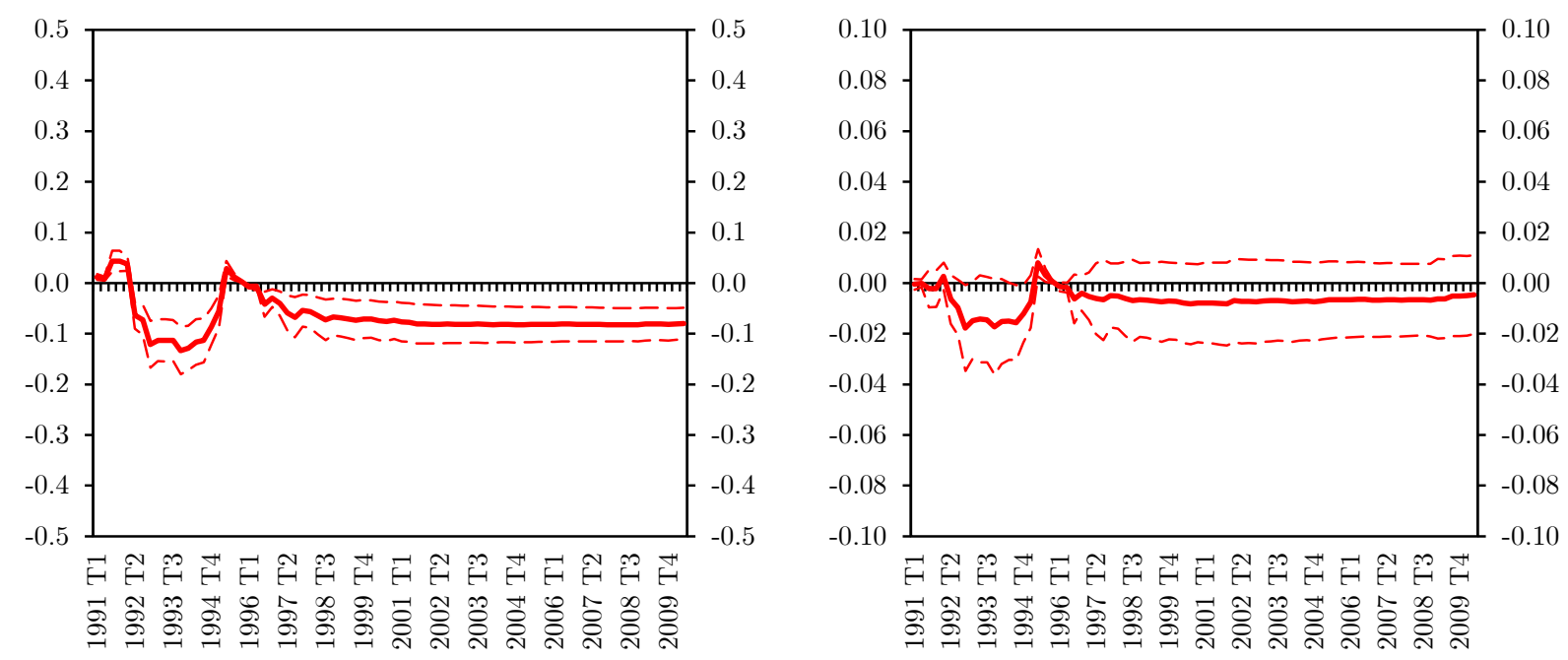

Tasa de interés

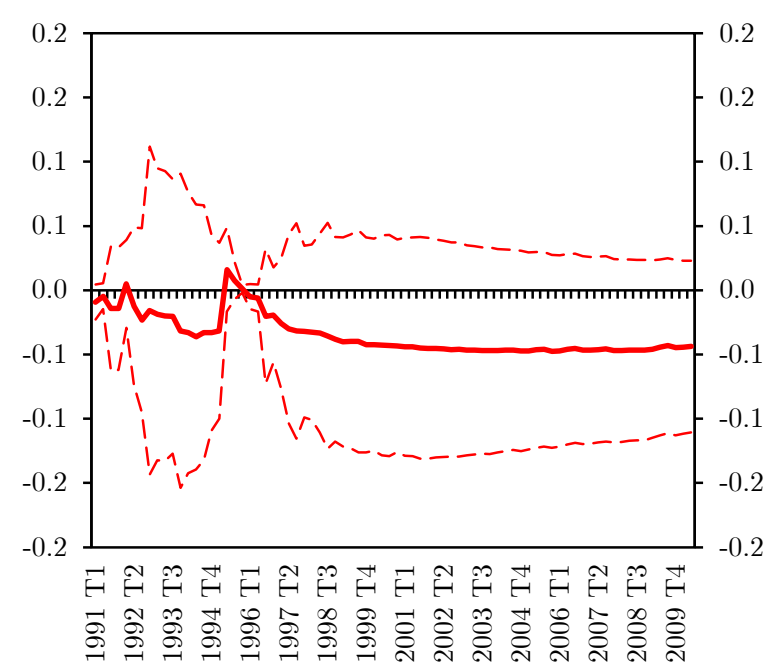

1/ Las líneas discontinuas muestran la banda de confianza al 95 por ciento. 


\section{Gráfica AI.15 (continuación). Hacia adelante (Forward) \\ M1 \\ Ingreso \\ Forma- $R$}
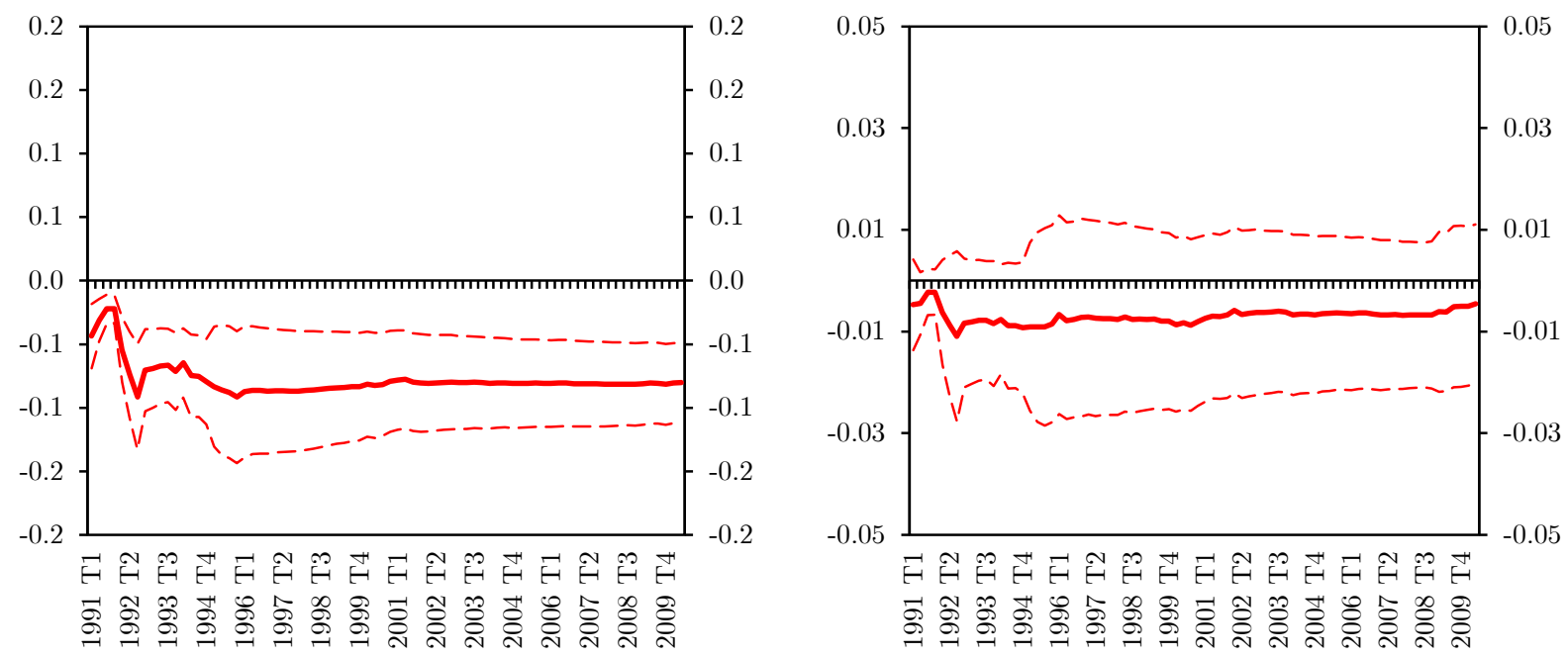

Tasa de interés

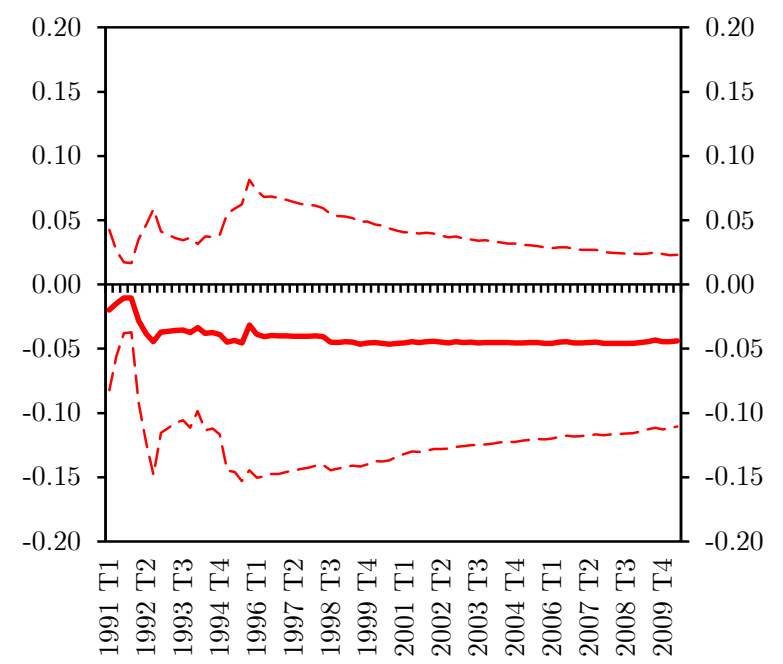

1/ Las líneas discontinuas muestran la banda de confianza al 95 por ciento. 
Gráfica AI.16. Hacia adelante (Backward)

M1

Ingreso

\section{Forma-X}
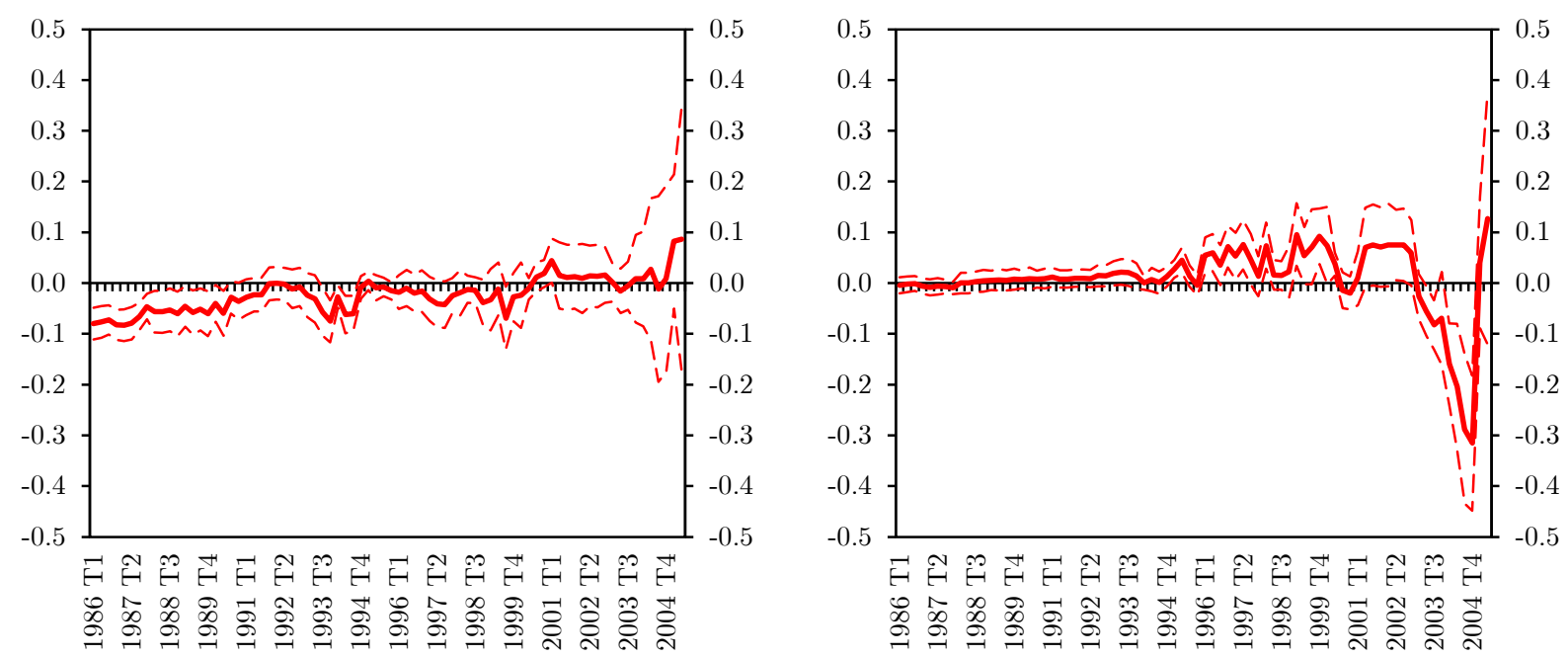

Tasa de interés

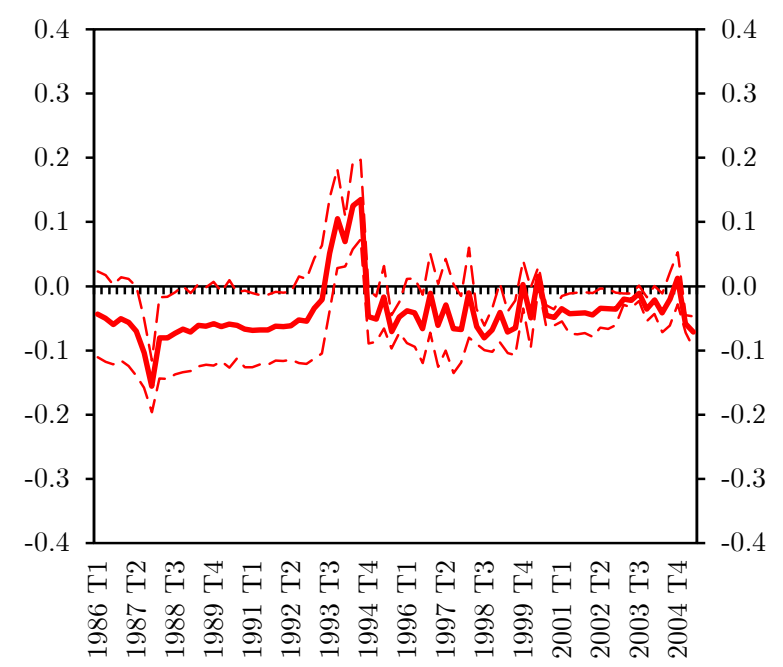

1/ Las líneas discontinuas muestran la banda de confianza al 95 por ciento. 


\section{Gráfica AI.16 (continuación). Hacia adelante (Backward) \\ M1 \\ Ingreso}
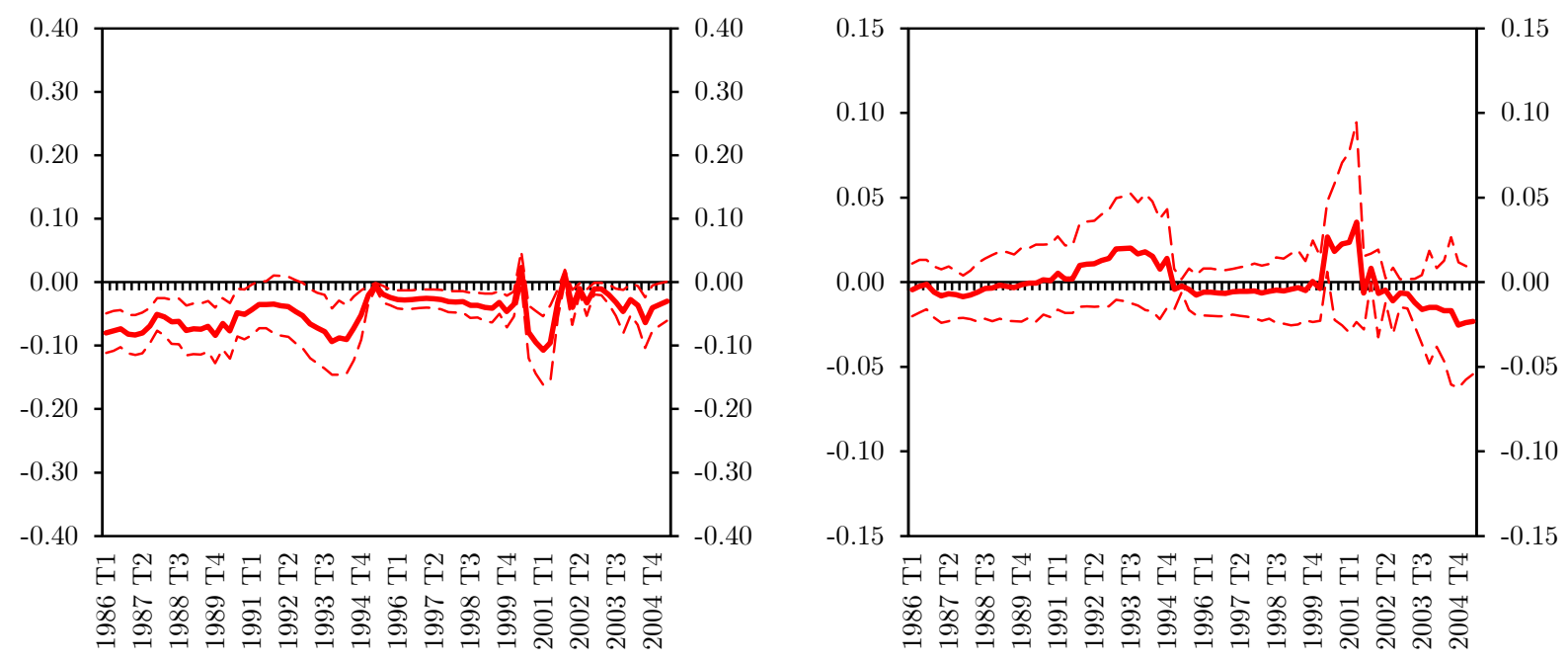

Tasa de interés

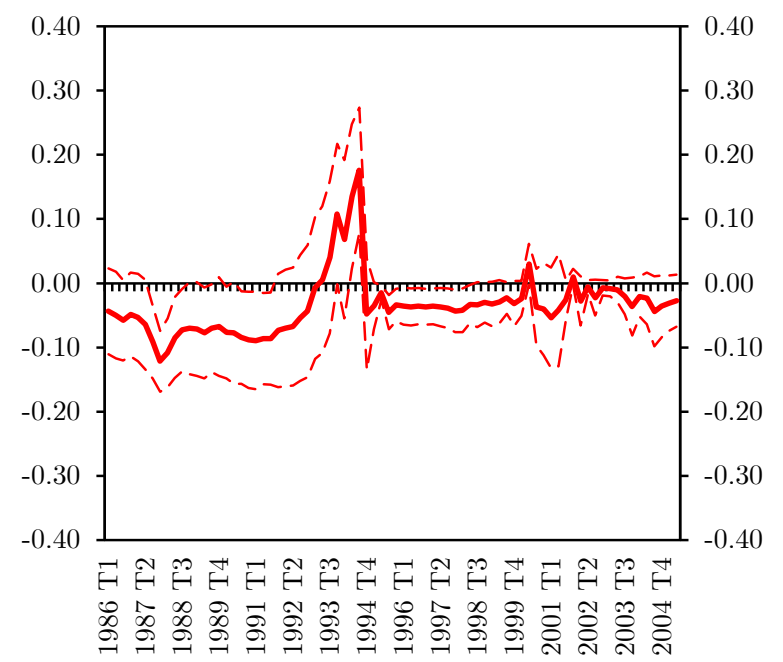

1/ Las líneas discontinuas muestran la banda de confianza al 95 por ciento. 


\section{Apéndice II. Metodología de estimación de la relación de largo plazo}

Para presentar esta metodología con más detalle, considérese el vector $\boldsymbol{z}_{t}=\left(y_{t}, \boldsymbol{x}_{t}\right)$ de dimensión $(k+1)$ de variables relevantes en el modelaje de la demanda por dinero. Entonces, es posible modelar este vector como un Vector Autoregresivo (VAR) de orden $q$ que a su vez puede ser escrito en forma de un modelo de corrección de error de la siguiente manera:

$$
\Delta \mathbf{z}_{t}=\Pi \mathbf{z}_{t-1}+\sum_{i=1}^{q-1} \boldsymbol{\Gamma}_{i} \Delta \mathbf{z}_{t-i}+\mathbf{\Phi} \boldsymbol{D}_{t}+u_{t}
$$

donde $\boldsymbol{D}_{t}$ es un vector de variables deterministas, $\Delta=1-L, L$ es el operador de rezagos, $\boldsymbol{\Pi}, \boldsymbol{\Gamma}_{i}$ y $\boldsymbol{\Phi}$ son matrices de parámetros, y $u_{t}$ es un vector de innovaciones i.i.d. $\left(0, \Sigma_{u}\right)$, donde $\Sigma_{u}$ es la matriz de varianza-covarianza de los errores. Suponiendo exogeneidad débil de las variables $\boldsymbol{x}_{t}$, esto es, que no existe retroalimentación del nivel de $y_{t}$ sobre $\boldsymbol{x}_{t}$, y que existe a lo más una relación en niveles entre $y_{t}$ y $\boldsymbol{x}_{t}$, se obtiene el siguiente modelo condicional para $\Delta y_{t}$

$$
\Delta y_{t}=\pi_{y} y_{t-1}+\pi_{x} \boldsymbol{x}_{t-1}+\sum_{i=1}^{q-1} \boldsymbol{\Gamma}_{i} \Delta y_{t-i}+\sum_{i=0}^{q-1} \psi_{i} \Delta \boldsymbol{x}_{t-i}+\boldsymbol{\Phi} \boldsymbol{D}_{t}+u_{t}
$$

Para probar la existencia de una relación en niveles entre las variables se calcula el estadístico $\mathrm{F}$ que prueba la hipótesis conjunta $\pi_{y}=0$ y $\boldsymbol{\pi}_{x}=\mathbf{0}$, y se compara con los valores críticos reportados en PSS que son mostrados en el Cuadro AII. Cubriendo todas las posibles clasificaciones de las variables como $\mathrm{I}(0), \mathrm{I}(1)$ o mutuamente cointegradas, los valores críticos se presentan en PSS como dos conjuntos distintos. Si el estadístico F cae fuera de los límites de este par de valores críticos, es posible llegar a una conclusión respecto a la existencia o no de una relación en niveles entre $y_{t}$ y $\boldsymbol{x}_{t}$. Sin embargo, existen zonas de indeterminación, por lo que si el estadístico F cae en dichas zonas, no es posible concluir ni a favor ni en contra de la existencia de la relación entre las variables.

Si de acuerdo a la prueba es posible concluir a favor de una relación de largo plazo entre las variables, entonces lo siguiente es estimar esta relación usando un modelo ARDL como el planteado en Pesaran y Shin (1999). Así, el modelo condicional de corrección de error en la ecuación (AII.1) puede ser reparametrizado de la siguiente forma

$$
y_{t}=\boldsymbol{\beta} \boldsymbol{x}_{t}+\sum_{i=1}^{q} \phi_{i} y_{t-i}+\sum_{i=0}^{q-1} \boldsymbol{\beta}_{i} \Delta \boldsymbol{x}_{t-i}+\boldsymbol{\Phi} \boldsymbol{D}_{t}+u_{t}
$$

De esta especificación es posible obtener los coeficientes de largo plazo como $\boldsymbol{\theta}=$ $\frac{\boldsymbol{\beta}}{1-\sum_{i=1}^{p} \phi_{i}}$, mientras que los errores estándar asociados a los parámetros de largo plazo pueden calcularse, por ejemplo, con el método delta como $V[\boldsymbol{\theta}]=\left(\frac{\partial \theta}{\partial \beta}\right)^{2} V[\boldsymbol{\beta}]$. Así, la relación de largo plazo entre las variables está dada por $y_{t}=\boldsymbol{\theta} \boldsymbol{x}_{t}$. 
Cuadro AII. Valores críticos asintóticos para el estadístico F.

\begin{tabular}{ccc|cccccc}
\multicolumn{8}{c}{ Caso I: Sin intercepto y sin tendencia } \\
\hline \multirow{2}{*}{$k$} & \multicolumn{2}{c|}{0.100} & \multicolumn{2}{c}{0.050} & \multicolumn{2}{c}{0.025} & \multicolumn{2}{c}{0.010} \\
\cline { 2 - 10 } & $\mathrm{I}(0)$ & $\mathrm{I}(1)$ & $\mathrm{I}(0)$ & $\mathrm{I}(1)$ & $\mathrm{I}(0)$ & $\mathrm{I}(1)$ & $\mathrm{I}(0)$ & $\mathrm{I}(1)$ \\
\hline \hline 0 & 3.000 & 3.000 & 4.200 & 4.200 & 5.470 & 5.470 & 7.170 & 7.170 \\
1 & 2.440 & 3.280 & 3.150 & 4.110 & 3.880 & 4.920 & 4.810 & 6.020 \\
2 & 2.170 & 3.190 & 2.720 & 3.830 & 3.220 & 4.500 & 3.880 & 5.300 \\
3 & 2.010 & 3.100 & 2.450 & 3.630 & 2.870 & 4.160 & 3.420 & 4.840 \\
4 & 1.900 & 3.010 & 2.260 & 3.480 & 2.620 & 3.900 & 3.070 & 4.440 \\
\hline \hline
\end{tabular}

Fuente: Pesaran, Shin y Smith (2001, pp. 300). $k$ denota el número de variables en el vector $\boldsymbol{x}_{t}$ 


\section{Apéndice III. Pruebas de estabilidad}

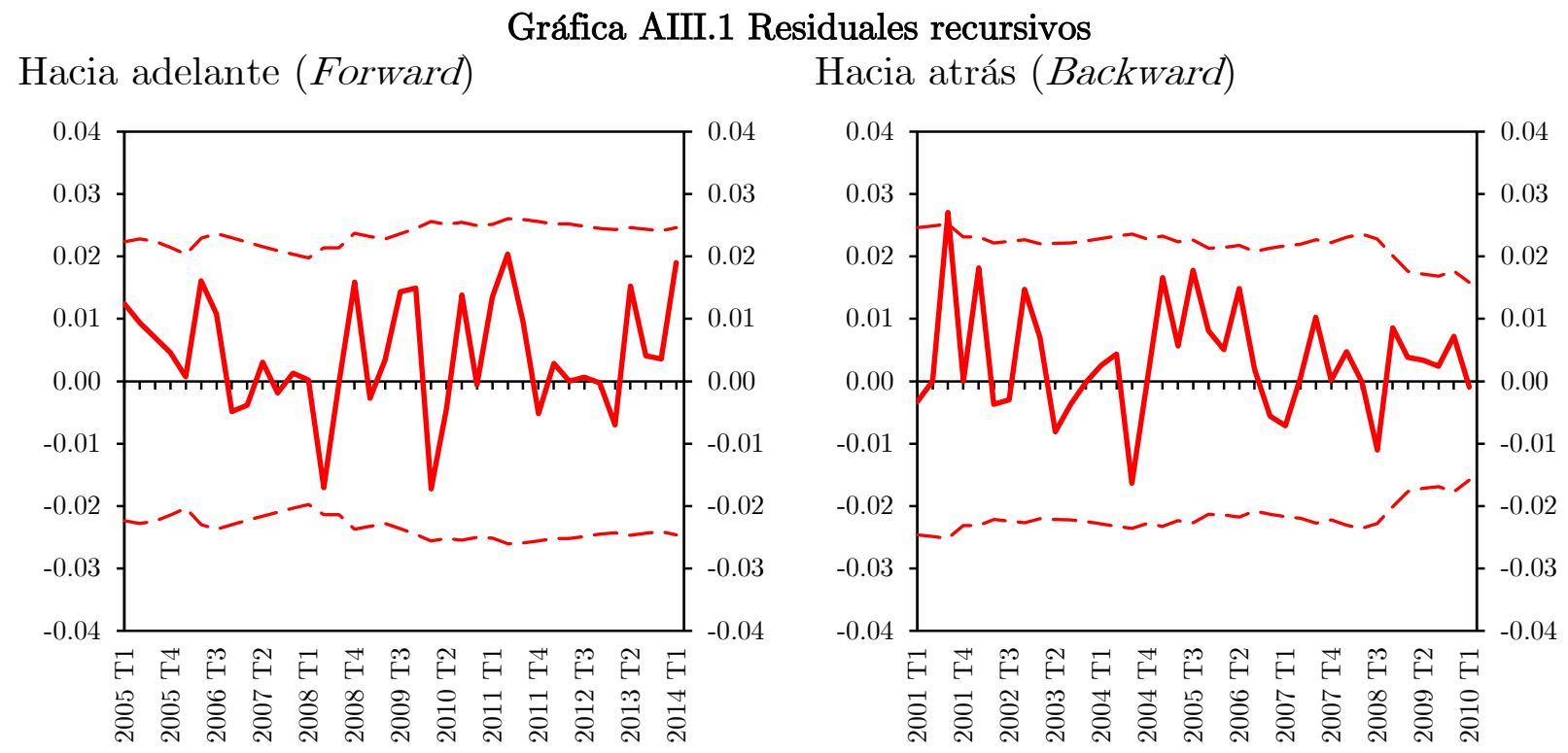

1/ Las líneas discontinuas muestran la banda de confianza al 95 por ciento.

Hacia adelante (Forward)

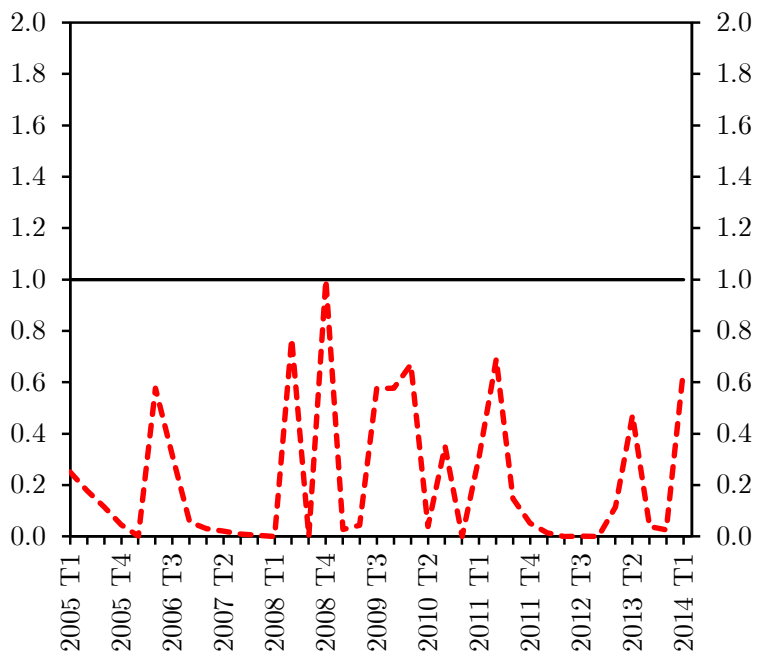

Chow de un paso adelante ${ }^{1 /}$

Hacia atrás (Backward)

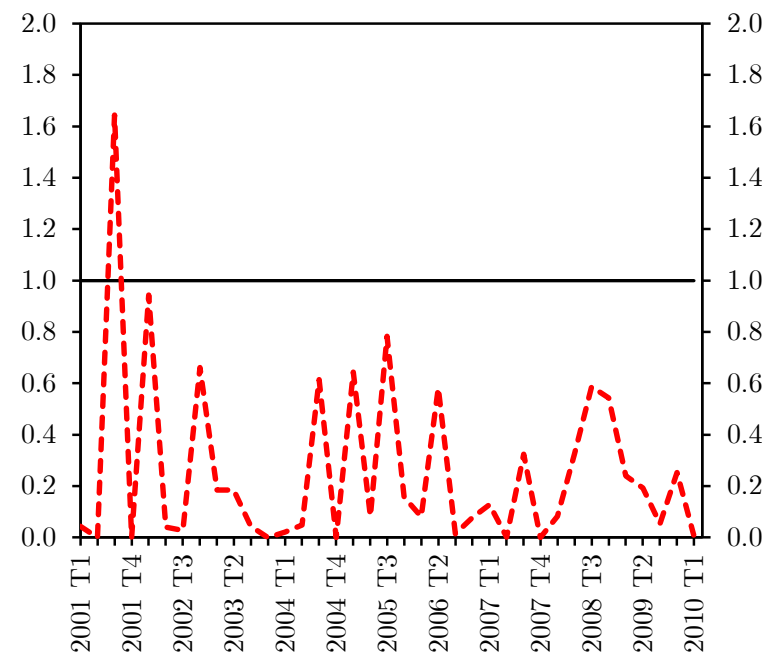

$1 /$ La línea horizontal en el valor de 1 representa el valor crítico al $5 \%$ de la prueba. 
Gráfica AIII.3 Prueba de Chow de punto de quiebre recursivo ${ }^{1 /}$ Hacia adelante (Forward) Hacia atrás (Backward)
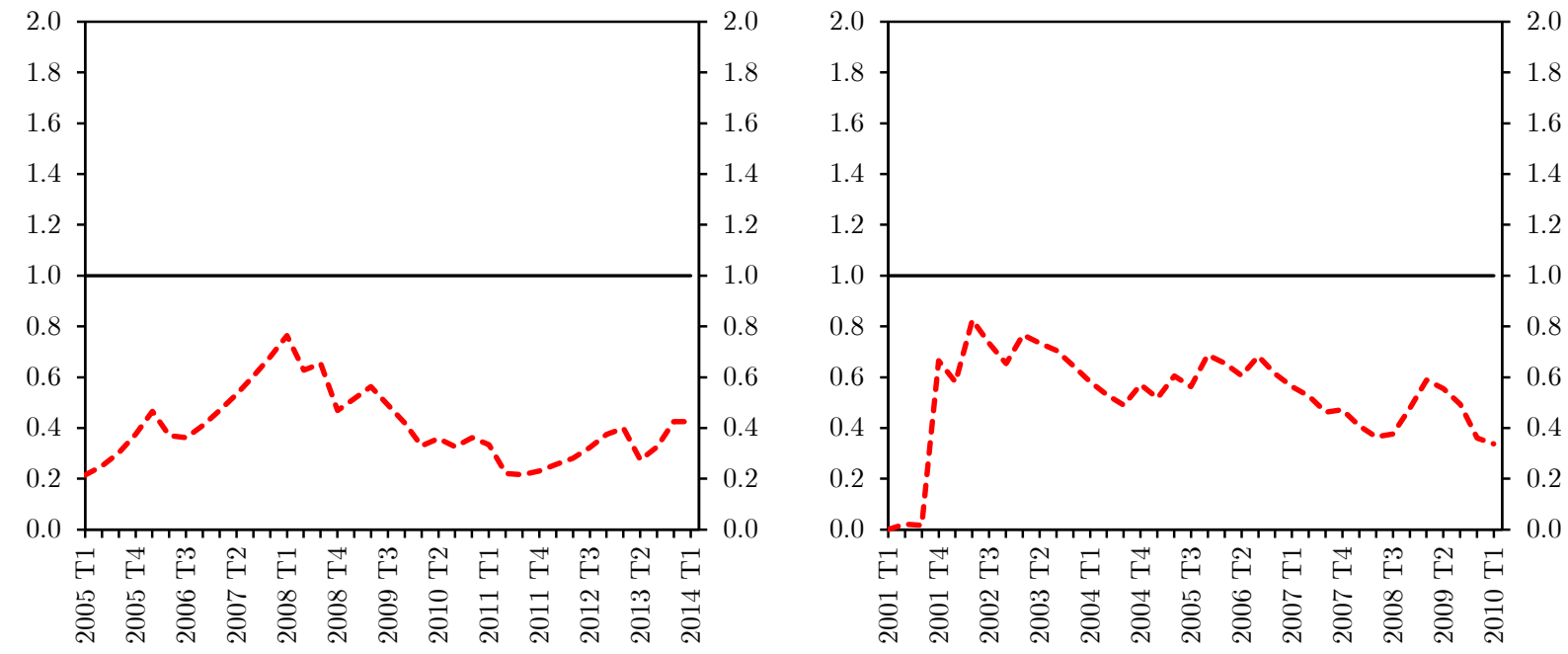

1/ La línea horizontal en el valor de 1 representa el valor crítico al $5 \%$ de la prueba.

Gráfica AIII.4 Prueba de Chow de pronóstico recursivo ${ }^{1 /}$

Hacia adelante (Forward)

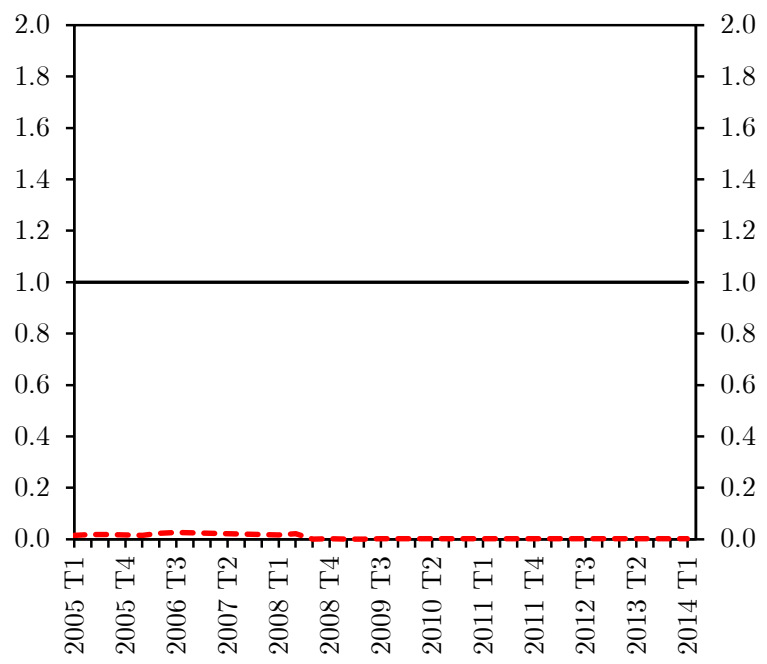

Hacia atrás (Backward)

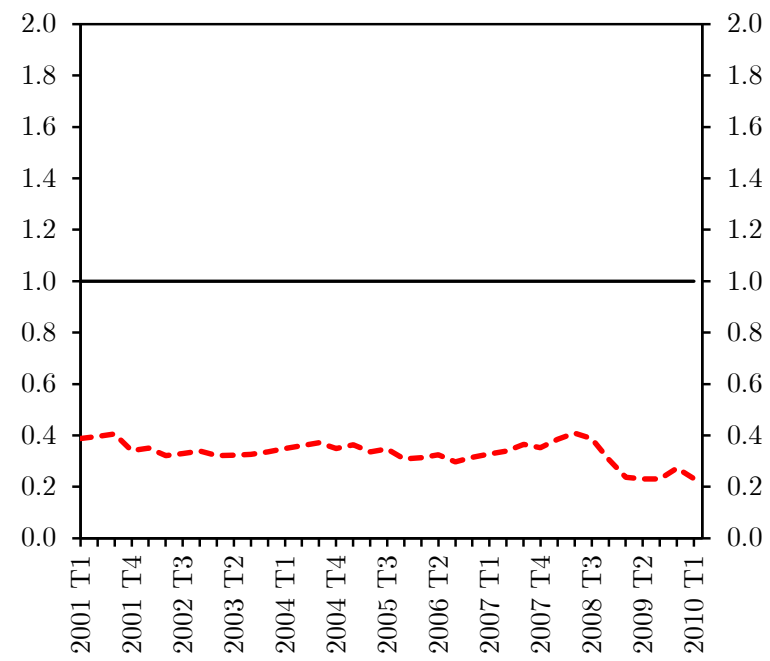

1 / La línea horizontal en el valor de 1 representa el valor crítico al $5 \%$ de la prueba. 


\section{Gráfica AIII.5 Prueba de Chow clásica}

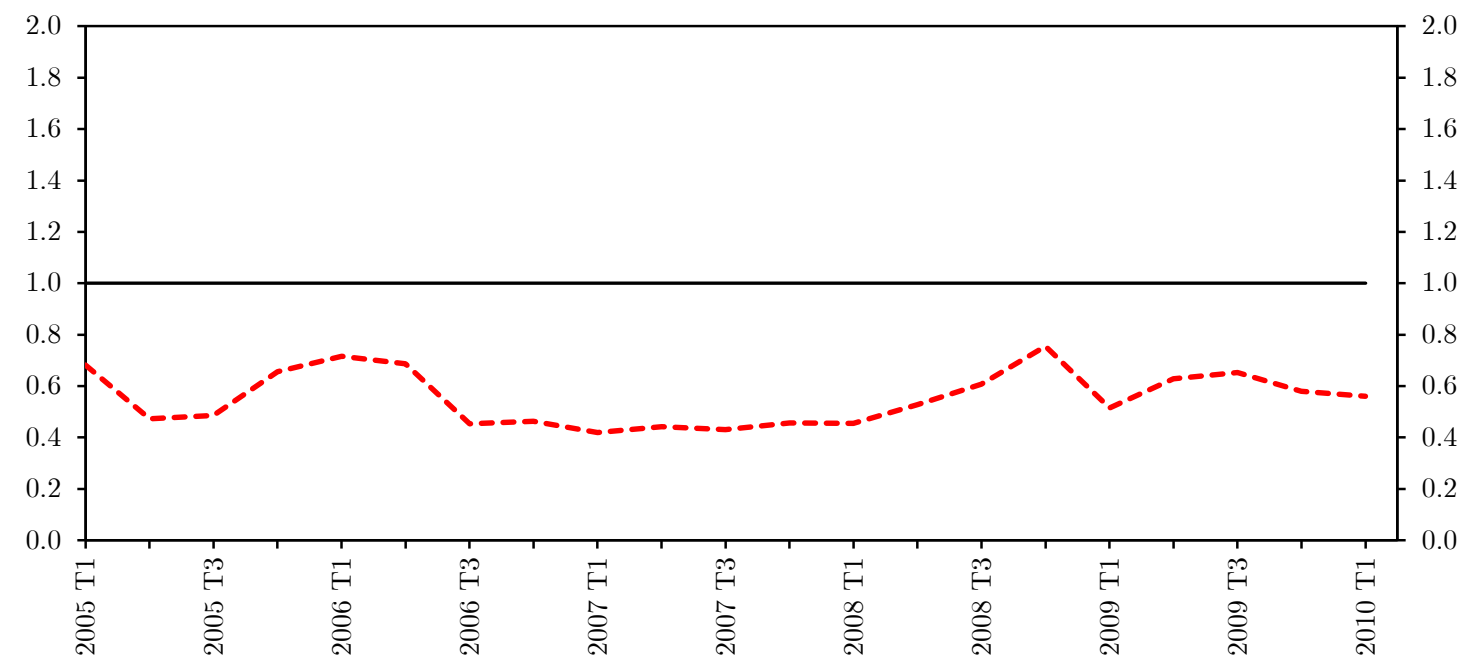

1/ La línea horizontal en el valor de 1 representa el valor crítico al 5\% de la prueba. 
Gráfica AIII.6 Parámetros de largo plazo recursivos: Elasticidad PIB

Hacia adelante (Forward). Forma-X.

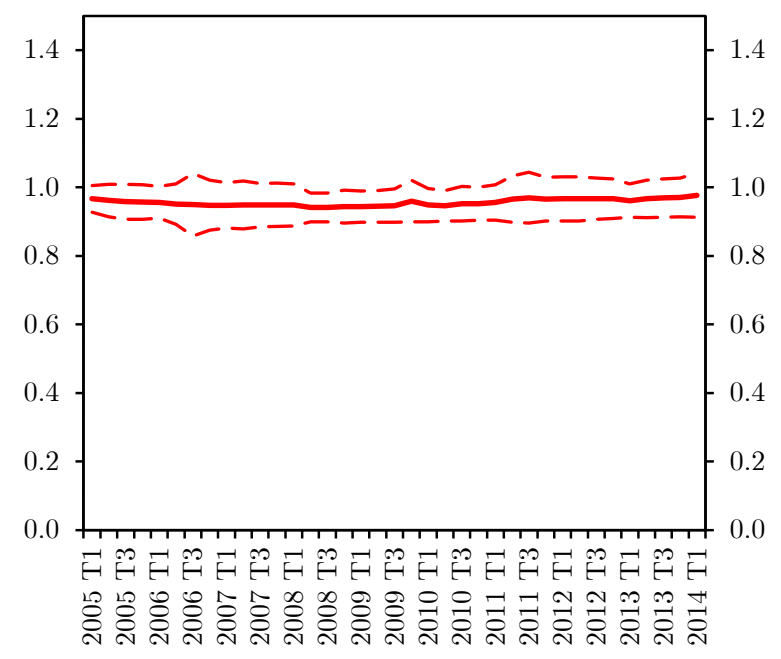

Hacia adelante (Forward). Forma-R.

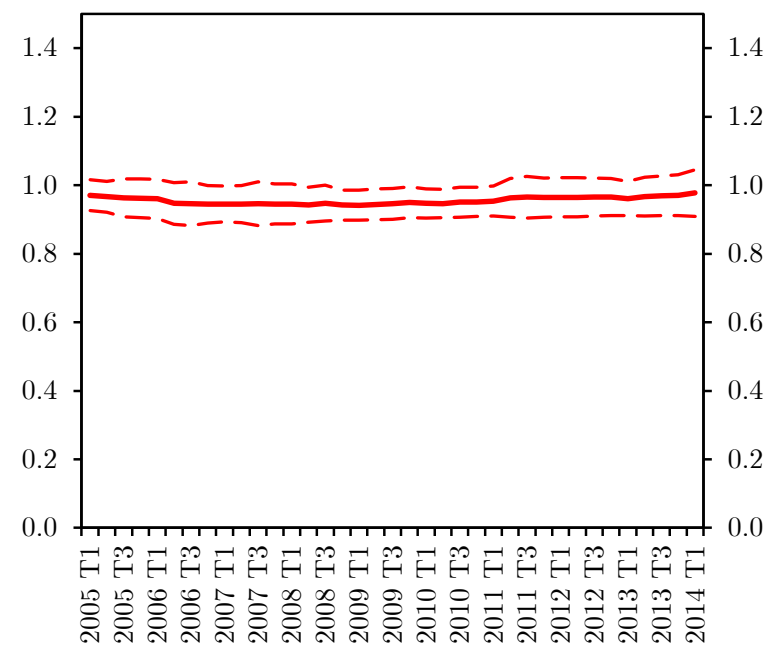

Hacia atrás (Backward). Forma-X.

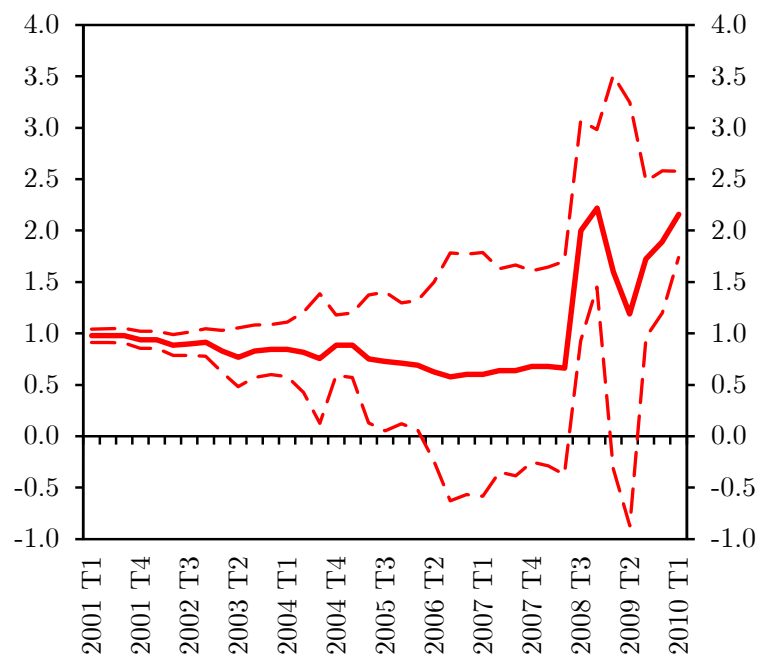

Hacia atrás (Backward). Forma-R.

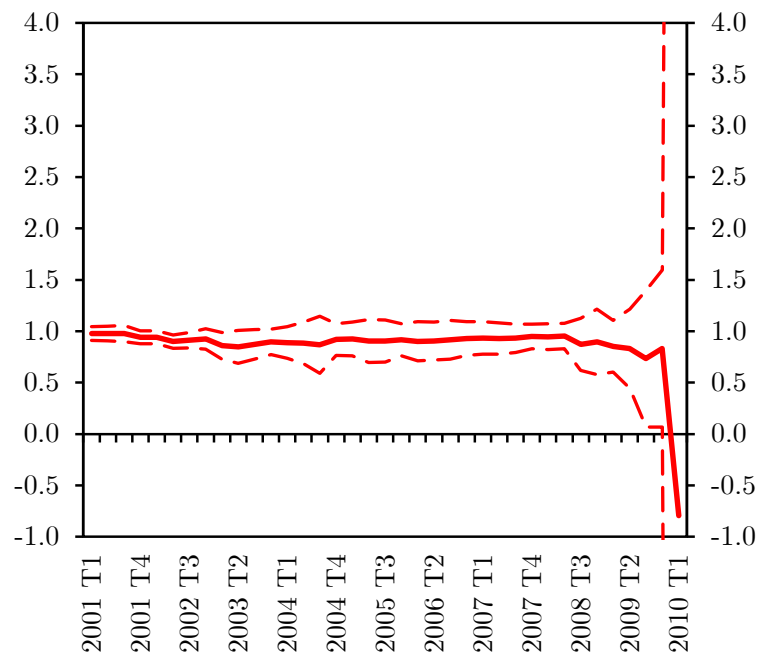

1/ Las líneas discontinuas muestran la banda de confianza al 95 por ciento. 
Gráfica AIII.7 Parámetros de largo plazo recursivos: Elasticidad remesas

Hacia adelante (Forward). Forma-X.

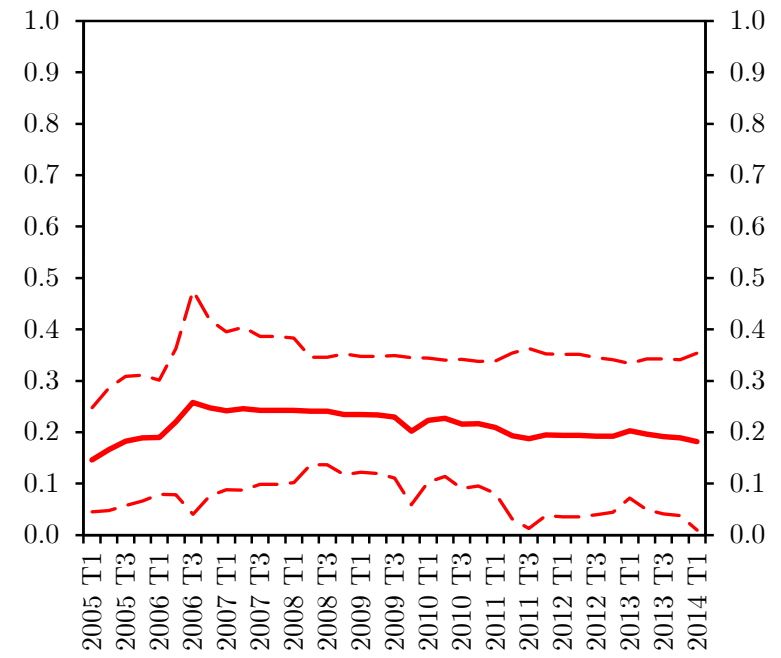

Hacia adelante (Forward). Forma-R.

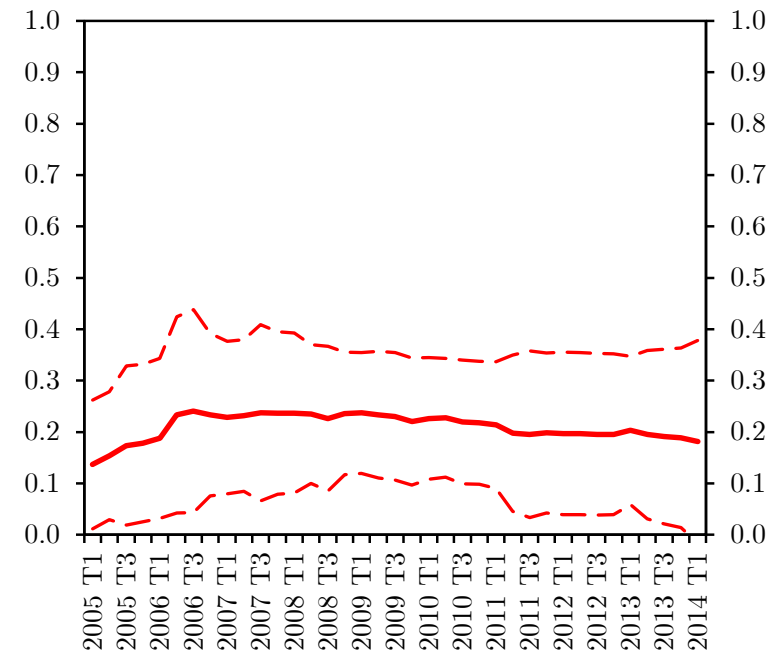

Hacia atrás (Backward). Forma-X.

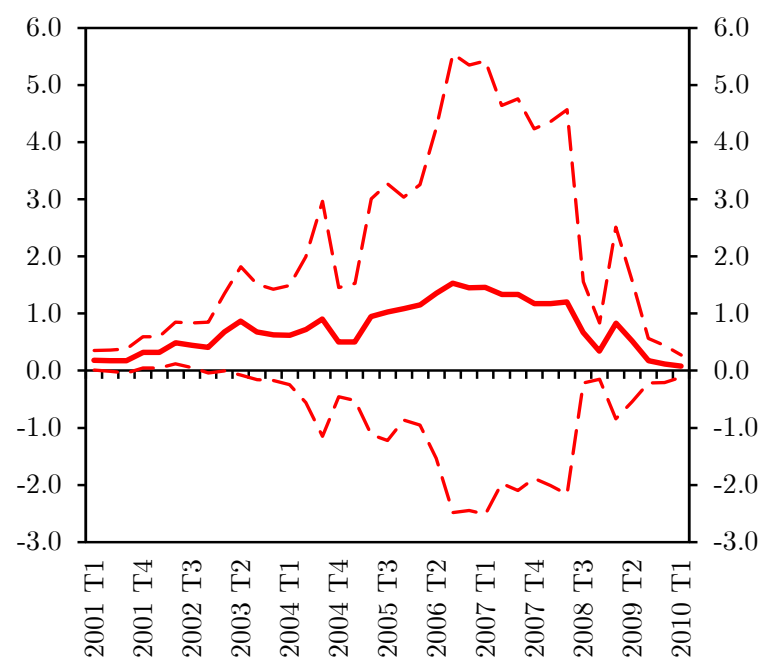

Hacia atrás (Backward) . Forma-R.

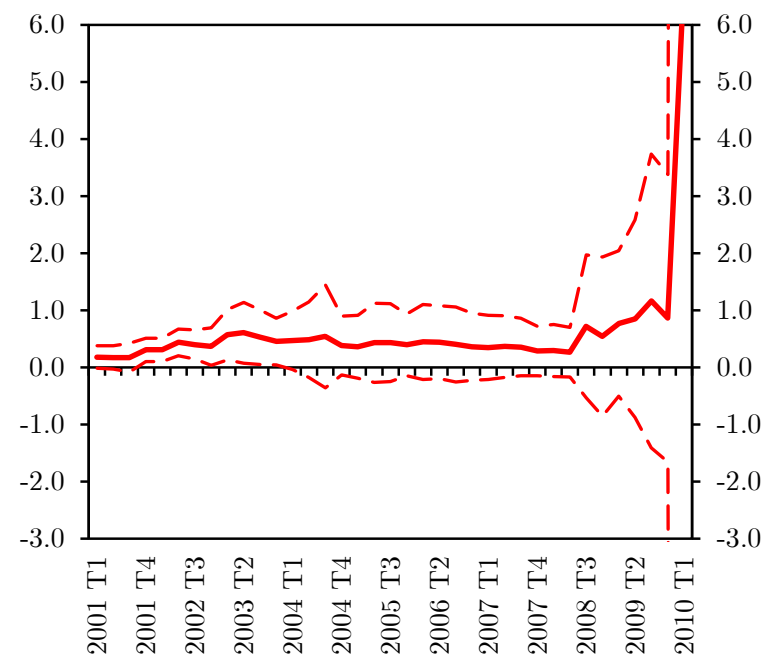

1/ Las líneas discontinuas muestran la banda de confianza al 95 por ciento. 
Gráfica AIII.8 Parámetros de largo plazo recursivos: semi-elasticidad de la tasa de interés Hacia adelante (Forward). Forma-X. Hacia atrás (Backward). Forma-X.
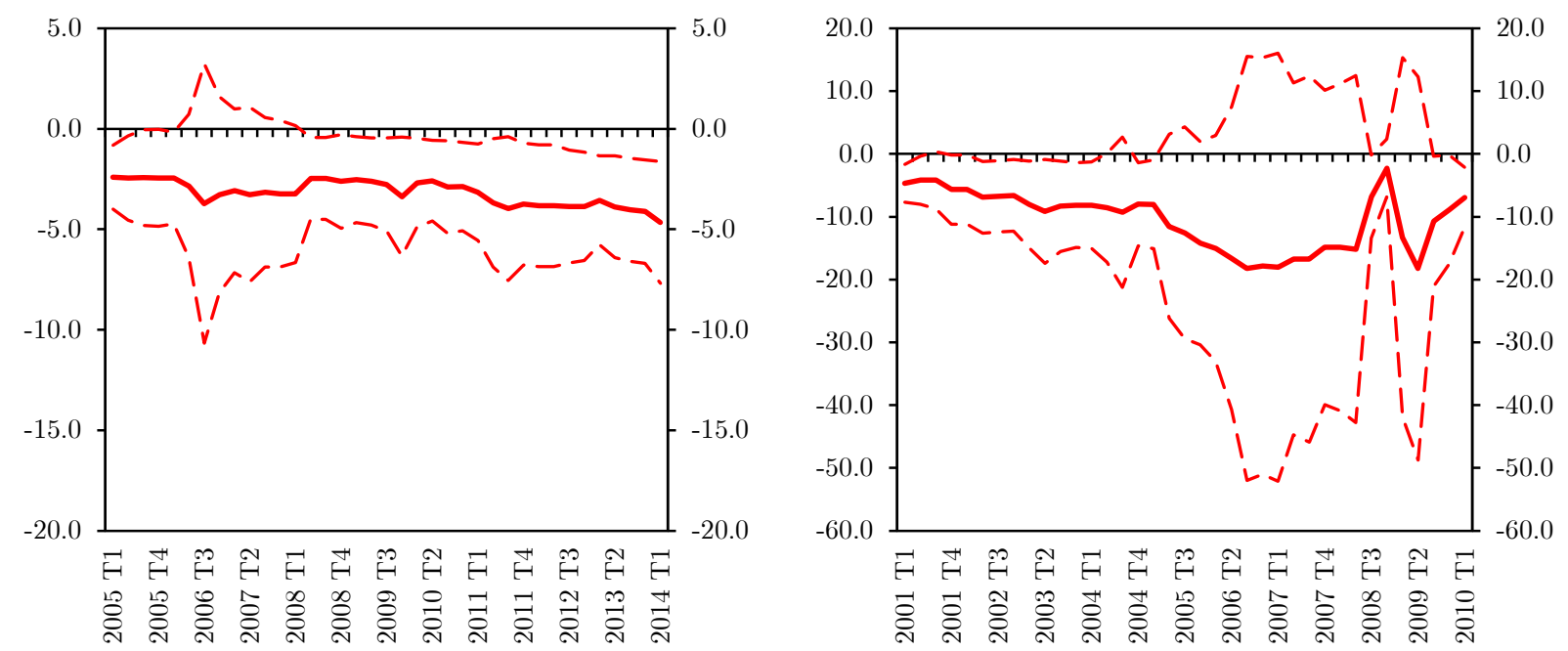

Hacia adelante (Forward). Forma-R.

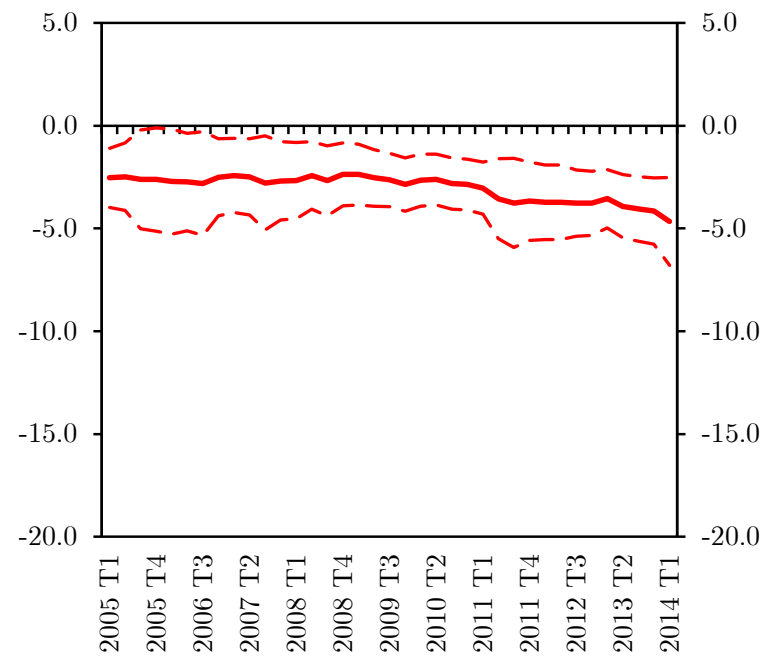

Hacia atrás (Backward). Forma-R.

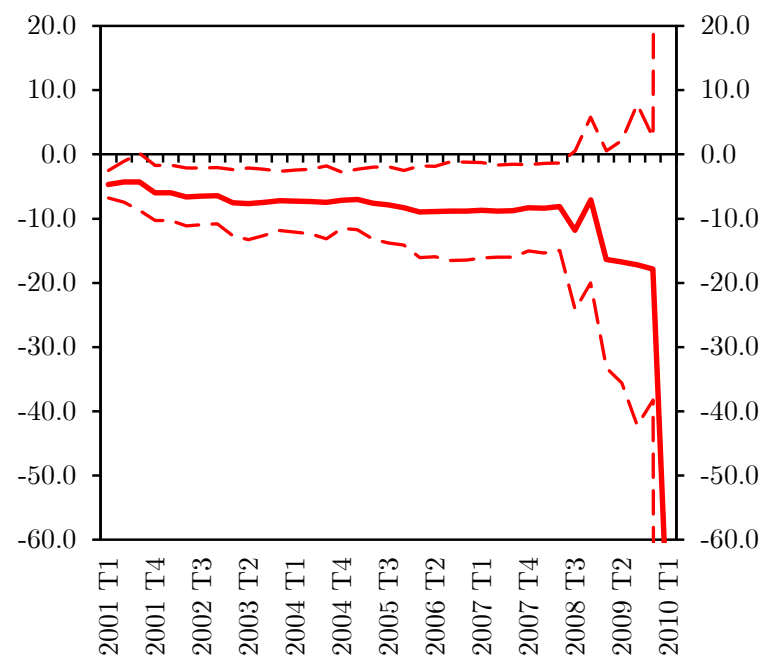

1/ Las líneas discontinuas muestran la banda de confianza al 95 por ciento. 
Gráfica AIII.9 Parámetros de largo plazo recursivos d08T3 Hacia adelante (Forward). Forma-X. Hacia atrás (Backward). Forma-X.
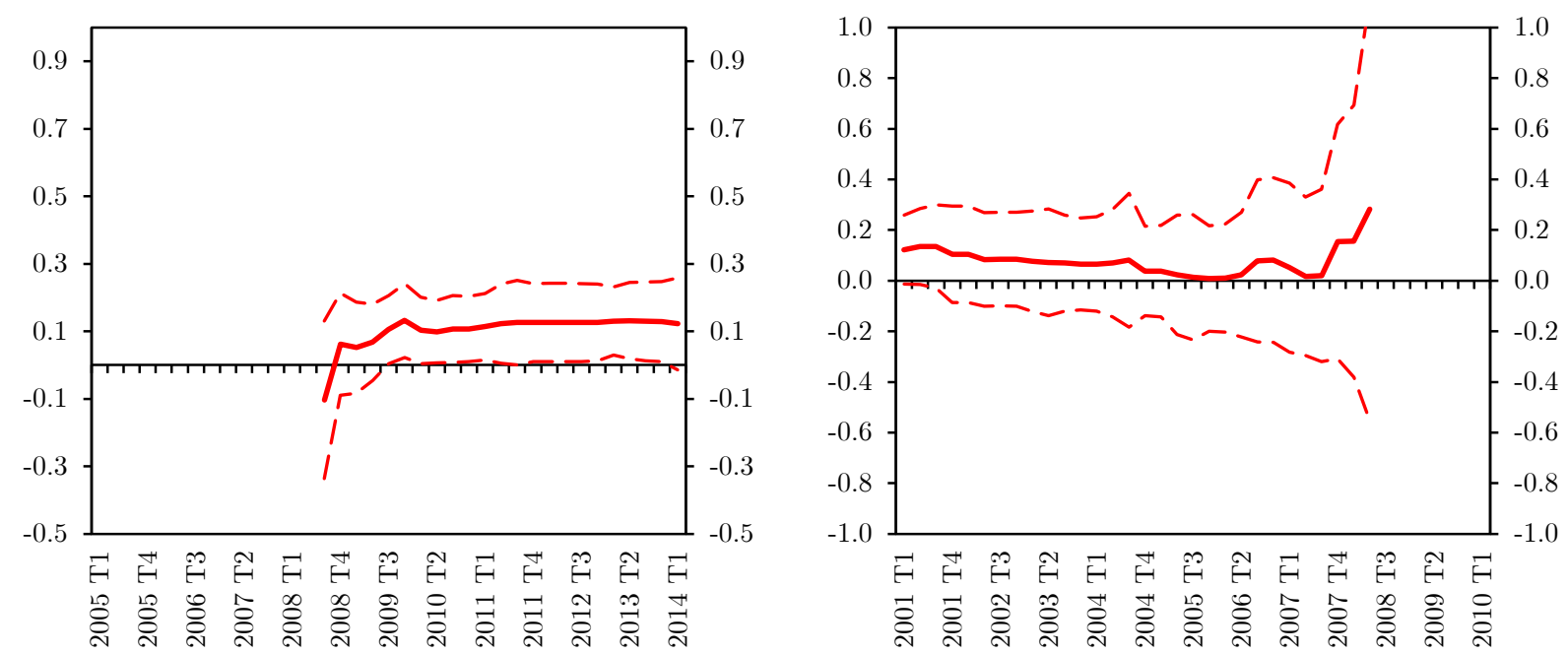

Hacia adelante (Forward). Forma-R.

Hacia atrás (Backward). Forma-R.
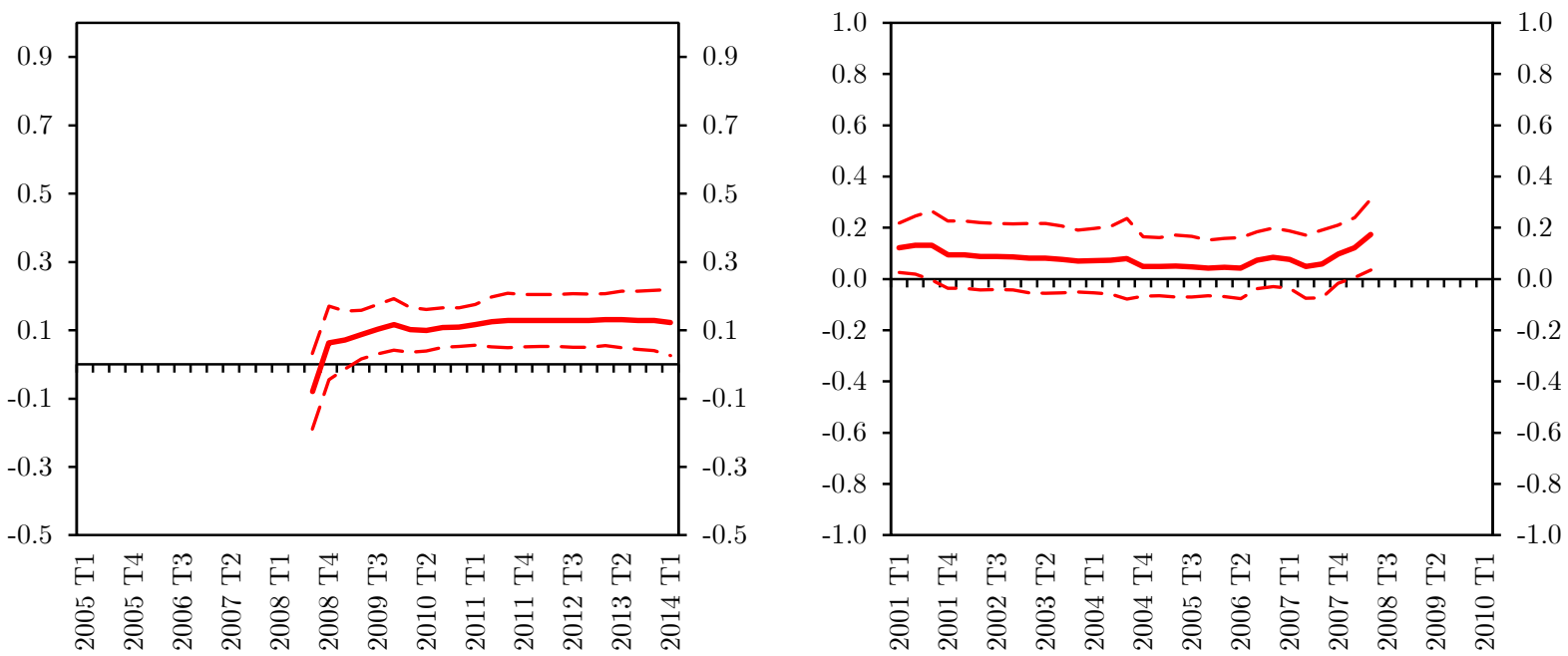

1/ Las líneas discontinuas muestran la banda de confianza al 95 por ciento. 


\section{Apéndice IV. Simulación de la distribución de $\Delta m^{*}$}

Para analizar a detalle la forma en que se distribuye la tasa de crecimiento del indicador $m^{*}$, se realiza un ejercicio de simulación Monte Carlo. Recapitulando, el crecimiento de $m^{*}$ está en función de los parámetros estimados de la demanda por dinero de largo plazo y del valor predeterminado del crecimiento anual de las tendencias de largo plazo de las variables explicativas, como es ilustrado por la ecuación (9) que a continuación se reproduce.

$$
\Delta m^{*}=\Delta m-0.98 \Delta y^{\text {pib_tendencia }}-0.18 \Delta y^{\text {rem_tendencia }}+4.66 \Delta i^{\text {tendencia }}-0.12 \Delta d 08 T 3
$$

Como muestran los Teoremas 2.2 y 3.2 de Pesaran y Shin (1997, pp. 7) los estimadores de los parámetros de largo plazo son superconsistentes y siguen una distribución normal. Dado lo anterior, para realizar la simulación suponemos que los estimadores de los parámetros de largo plazo siguen una distribución normal conjunta, donde la media de cada coeficiente es su valor estimado (estimador puntual) y la matriz de varianzacovarianza de los coeficientes está dada por la matriz estimada por el método delta. De esta manera, este ejercicio refleja la incertidumbre asociada a la estimación de los parámetros de largo plazo. Se realizan 10,000 simulaciones, y en cada simulación un vector de coeficientes de largo plazo es extraído aleatoriamente de una distribución normal conjunta, así con cada vector de coeficientes de largo plazo es posible usar la ecuación (9) para calcular cada uno de los 10,000 valores de $\Delta m^{*}$, y obtener posteriormente su distribución. ${ }^{55}$

Los parámetros utilizados para la simulación son los siguientes:

\begin{tabular}{cc|c|c|c|} 
Vector de Media & \multicolumn{1}{c}{ Y } & Remesas & \multicolumn{1}{c}{ Tasa interés } & D08t3 \\
\cline { 2 - 5 } & 0.977078 & 0.181482 & -4.66422 & 0.122502 \\
\hline
\end{tabular}

\begin{tabular}{c|c|c|c|c|} 
Varianza-Covarianza & \multicolumn{1}{c}{ Y } & \multicolumn{1}{c}{ Remesas } & Tasa interés & D08t3 \\
\cline { 2 - 5 } Y & 0.00107860 & -0.00272580 & -0.02701800 & -0.00069606 \\
\cline { 2 - 5 } Remesas & -0.00272580 & 0.00773660 & 0.03473900 & 0.00033309 \\
\cline { 2 - 5 } Tasa interés & -0.02701800 & 0.03473900 & 2.38880000 & 0.07747500 \\
\cline { 2 - 5 } D08t3 & -0.00069606 & 0.00033309 & 0.07747500 & 0.00484230 \\
\hline
\end{tabular}

Las tasas de crecimiento predeterminadas (promedio en el periodo 2001T1-2014T1) de las tendencias de largo plazo de las variables:

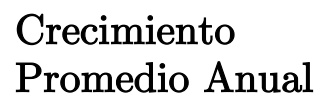

\begin{tabular}{|c|c|r|c|c|}
\multicolumn{1}{c}{ M1 } & \multicolumn{1}{c}{ Y } & \multicolumn{2}{c}{ Remesas } & \multicolumn{1}{c}{ Tasa } \\
interés & \multicolumn{1}{c|}{ D08t3 } \\
\hline 11.831585 & 2.288415 & 5.987608 & -0.962994 & 7.547170 \\
\hline
\end{tabular}

\footnotetext{
${ }^{55} \mathrm{El}$ ejercicio de simulación se realizó para diferente número de repeticiones, y prácticamente desde 5,000 el resultado no se modifica. Se muestra el ejercicio de 10,000 repeticiones por ser representativo. Para obtener los valores aleatorios de la distribución normal conjunta se emplea el comando mvnrnd en MATLAB R2013a.
} 